Keywords: Magnox, Butex, waste loading, glass, properties

Retention: Permanent

\title{
Magnox:Butex Uranium Bearing Glasses: Physical and Chemical Analysis Data Package
}

\author{
D.K. Peeler \\ K.J. Imrich \\ D.R. Click
}

January 2011

Savannah River National Laboratory Savannah River Nuclear Solutions Aiken, SC 29808 
SRNL-STI-2011-00012

Revision 0

\section{DISCLAIMER}

This work was prepared under an agreement with and funded by the U.S. Government. Neither the U.S. Government or its employees, nor any of its contractors, subcontractors or their employees, makes any express or implied:

1. warranty or assumes any legal liability for the accuracy, completeness, or for the use or results of such use of any information, product, or process disclosed; or

2. representation that such use or results of such use would not infringe privately owned rights; or

3. endorsement or recommendation of any specifically identified commercial product, process, or service.

Any views and opinions of authors expressed in this work do not necessarily state or reflect those of the United States Government, or its contractors, or subcontractors.

\section{Printed in the United States of America}

Prepared for U.S. Department of Energy 
SRNL-STI-2011-00012

Revision 0

\section{REVIEWS AND APPROVALS}

AUTHORS:

\begin{tabular}{lc}
\hline D.K. Peeler, Process Technology Programs & Date
\end{tabular}

\begin{tabular}{ll}
\hline K.J. Imrich, Materials Science and Technology Date
\end{tabular}

\begin{tabular}{lc}
\hline D.R. Click, Analytical Development & Date
\end{tabular}

TECHNICAL REVIEW:

$\overline{\text { K.M. Fox, Process Technology Programs }}$ Date

APPROVALS:

C.C. Herman, Manager $\quad$ Date

Process Technology Programs

S.L. Marra, Manager $\quad$ Date

Environmental \& Chemical Process Technology Research Programs

C. Steele, Manager

Date

Technology Division, High Level Waste Plant

Sellafield Ltd 
SRNL-STI-2011-00012

Revision 0

\section{ACKNOWLEDGEMENTS}

This work was funded by Sellafield Ltd in the United Kingdom through a Work for Others (WFO) Agreement (WFO-10-008) to the U. S. Department of Energy (DOE). The authors would like to thank Dr. Carl Steele, Dr. Mike Harrison, Dr. Nick Gribble, Dr. Rick Short, and Dr. Andrew Riley for their technical guidance and insightful technical discussions. The authors would also like to acknowledge the technical support provided by Irene Reamer, Phyllis Workman, David Missimer, Ronnie Rutherford, and Mark Jones for glass fabrication, physical testing and chemical characterization. 
SRNL-STI-2011-00012

Revision 0

\section{EXECUTIVE SUMMARY}

Sellafield Ltd (United Kingdom) requested technical support from the Savannah River National Laboratory (SRNL) to characterize a series of uranium-bearing, mixed alkali borosilicate glasses. The specific glasses to be characterized are based on different blends $(75: 25,60: 40$, and 50:50) of Magnox:Butex waste types as well as different incorporation rates (i.e., waste loadings of 25, 28, and $32 \%$ ) of each blend. Each of the waste blend ratios was mixed with a base glass additive composition targeting the three different waste loadings (WLs) resulting in nine different glasses. These nine glasses (referred to as the UK study glass throughout this report) were fabricated and physically characterized for key processing and product performance properties as defined in the Work for Others (WFO) agreement. Specific characterization techniques for the nine study glasses included: chemical composition analysis, X-ray diffraction (XRD), Scanning Electron Microscopy with Energy Dispersive Spectroscopy (SEM-EDS), durability as defined by the Product Consistency Test (PCT), and high temperature viscosity as a function of temperature. In addition, the corrosion of Nicrofer $6025 \mathrm{HT}$ coupons in each glass system was assessed at a temperature of $1150^{\circ} \mathrm{C}$ for approximately 200 hours. The results of this study are highlighted below:

Visual Observations

Foam formation and crystallization were observed after the initial melts at $1150^{\circ} \mathrm{C}$. Although no formal assessment was performed to isolate the source of foam formation, a review of the glass compositions suggests that thermal reduction of $\mathrm{CeO}_{2}$ is the likely source. The presence of foam was eliminated (or greatly reduced) after a second melt at $1150^{\circ} \mathrm{C}$ although crystallization was still visually apparent.

\section{Compositional Analysis}

Targeted glass compositions were met based on the analytical elemental results.

\section{XRD / SEM-EDS}

Undissolved $\mathrm{RuO}_{2}$ and spinel were identified in all but one of the as-fabricated UK study glasses. The presence of undissolved $\mathrm{RuO}_{2}$ is not surprising given the limited solubility of this oxide in glass. Spinels are common in high level waste (HLW) glasses enriched in $\mathrm{Fe}, \mathrm{Ni}$, and/or $\mathrm{Cr}$ and typically increase in volume or mass percent with increased waste loading. The trend of higher WLs increasing the propensity for spinel formation is consistent with U.S. Defense Waste Processing Facility (DWPF)-type glasses, especially those that have undergone slow cooling to simulate the cooling profile along the centerline of the canister into which the glass is poured. The one UK study glass that did not contain spinel, based on XRD analysis, was the UK-60:40-25 glass (the lowest WL in that series). However, SEM-EDS analysis did identify Cr-rich spinels with the UK60:40-25 glass.

\section{PCT}

Based on the 7-day PCT results, the durability of the UK glasses increased as: (a) WL increased (for each Magnox:Butex blend ratio) and (b) the Magnox:Butex blend ratio decreased. Longer term PCTs were also performed. The boron normalized leachate (NL [B]) release results over the 28 day test period suggest that the corrosion rate is slowing (indicative of the leveling out of the NL [B] values) due to solution saturation. This type of dissolution behavior is consistent with other HLW glasses which generally show corrosion rates increasing while the solution is undersaturated. The corrosion rate typically slows as the solution becomes saturated. If precipitation of secondary phases 
occurs due to solution saturation, then the corrosion rates can return to the forward rate of reaction.

However, tracking the release of $\mathrm{Al}$ shows an opposite trend to that of $\mathrm{B}$ where the elemental release rates slow with time. Although a formal analysis of these results was not performed, these results may be an indication of the precipitation of $\mathrm{Al}(\mathrm{OH})_{3}$ due to complex solution reactions $\left(\mathrm{Al}(\mathrm{OH})_{3}(\mathrm{ppt})\right.$ versus $\mathrm{Al}(\mathrm{OH})_{4}$ (aqueous)) which are also influenced by solution $\mathrm{pH}$. The release rates of $\mathrm{Fe}, \mathrm{Mg}$, and $\mathrm{U}$ follow a similar trend to that of Al.

\section{High Temperature Viscosity}

High temperature viscosity measurements were performed on five of the nine UK study glasses. Based on the series of glasses targeting 28\% WL (UK-50:50-28, UK-60:40-28, and UK-72:25-28), the general trend in viscosity suggests that as the Magnox:Butex blend ratio increases the viscosity slightly decreases. Although these data suggest that there is a slight shift in the viscosity with the Magnox:Butex blend ratio, the shift should have very little, if any, practical impact on melter processing. With respect to the potential impact of $\mathrm{Al}_{2} \mathrm{O}_{3}$ content on the resulting viscosity (a concern mentioned in the WFO), there appears to be very little practical impact.

\section{Corrosion}

There was no significant localized attack of the coupons for any of the nine UK study glasses after $\sim 200$ hours at $1150^{\circ} \mathrm{C}$. The internal attack ranged from 0.068 to $0.284 \mathrm{~mm}$ ( 0.003 to 0.011 inches) with that of UK-60:40-25 being the greatest. Material loss was consistent throughout all the glass formulations and the surface was generally planar with the exceptions of the UK-50:50-32, UK-60:40-32, and UK-75:25-32 coupons.

Corrosion rates for the various waste formulations ranged from 3.044 to $4.139 \mathrm{~mm} / \mathrm{yr}$ ( 0.120 to $0.163 \mathrm{in} / \mathrm{yr})$. These calculated corrosion rates are comparable to corrosion rates measured for components from the Defense Waste Processing Facility (DWPF) Melter.

The objective of this task was to provide Sellafield Ltd. with the technical data to evaluate the impact of various Magnox:Butex blend ratios and WLs on specific glass properties. Without knowing the UK "acceptability" criteria for critical processing or product performance properties, the authors can not provide guidance as to the acceptability of the UK glasses. In fact, some of the properties measured (e.g., PCT) are US HLW glass criteria and may not be applicable to acceptance of UK glasses. 


\section{TABLE OF CONTENTS}

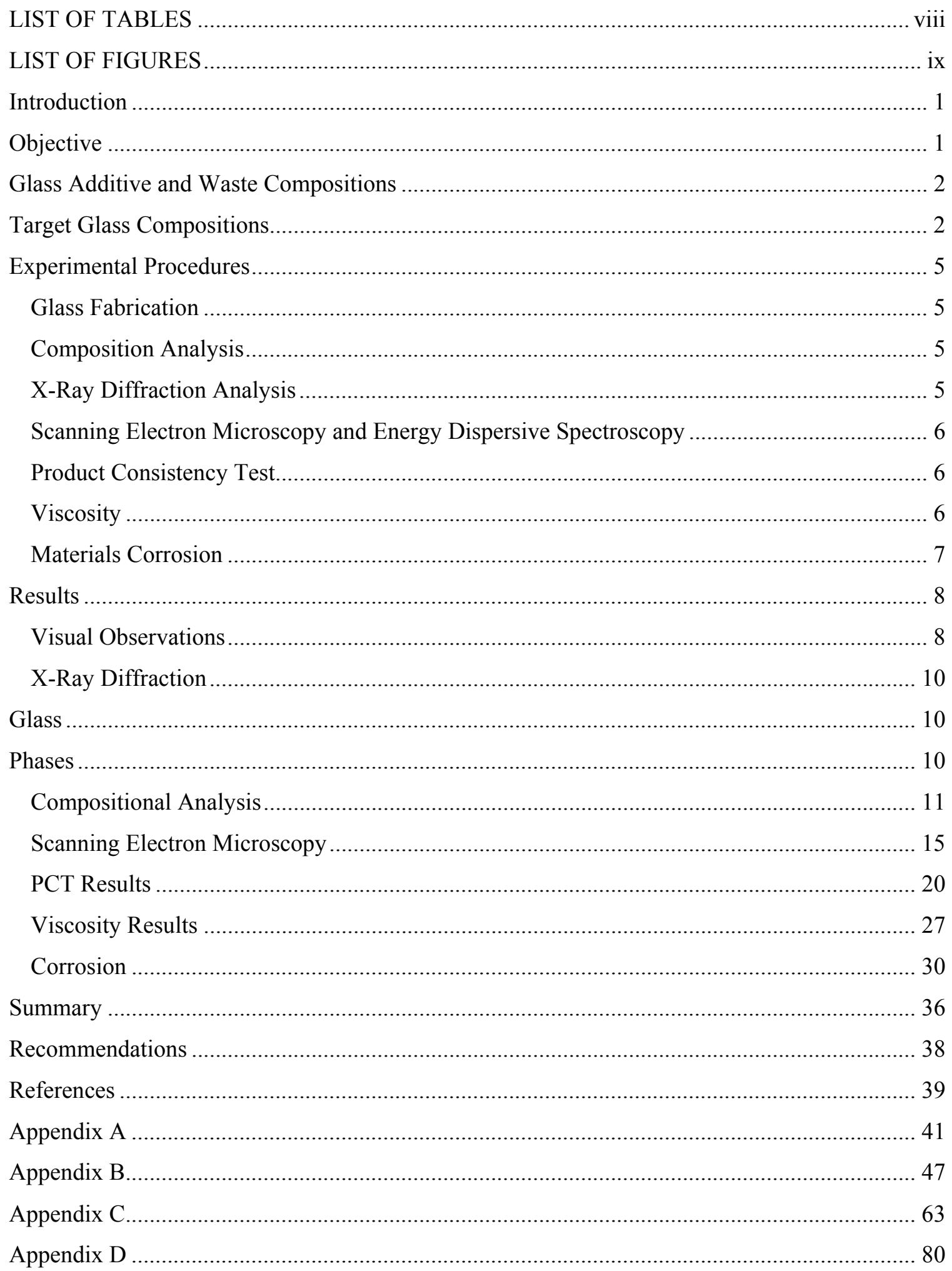




\section{LIST OF TABLES}

Table 1. Nominal Compositions of Magnox:Butex Waste Blends [WFO (2010)] ....................... 3

Table 2. Nominal MW Base Glass Composition [WFO (2010)] .................................................. 3

Table 3. Target Compositions of Nine Magnox:Butex Based Glasses. .......................................... 4

Table 4. Glass Identifiers (IDs) and Their Basis. ....................................................................... 5

Table 5. X-Ray Diffraction Results of As-Fabricated UK Glasses............................................. 10

Table 6. Target Versus Measured Compositions for the UK-75:25 Series................................. 12

Table 7. Target Versus Measured Compositions for the UK-60:40 Series................................ 13

Table 8. Target Versus Measured Compositions for the UK-50:50 Series................................ 14

Table 9. Evaluation of the Measured Versus Targeted Values for the Major Oxides Accounting

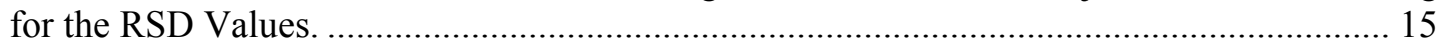

Table 10. Normalized (based on target compositions) PCT Responses for 7, 14, 21, and 28 Day

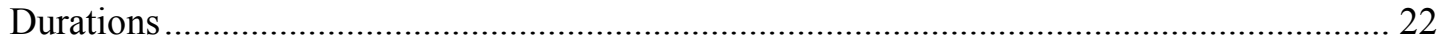

Table 11. Normalized (based on measured compositions) PCT Responses for 7, 14, 21, and 28

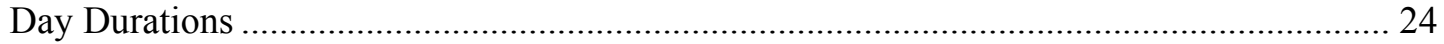

Table 12. Calculated Viscosities at $1150^{\circ} \mathrm{C}$ and $1050^{\circ} \mathrm{C}$ for Select UK Glasses Based on Fulcher

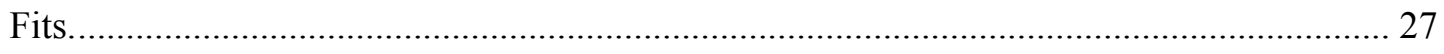

Table 13. Predicted Viscosity at $1150^{\circ} \mathrm{C}$ for the Frit 418 - SB3 System as a Function of WL... 28

Table 14. Measurement of degradation and estimated corrosion rates. 31 


\section{LIST OF FIGURES}

Figure 1. Schematic of coupon showing cross-sectioned surface that was prepared for metallurgical evaluation (blue rectangular area) ................................................................ 7

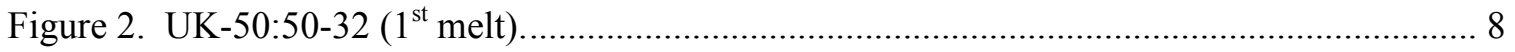



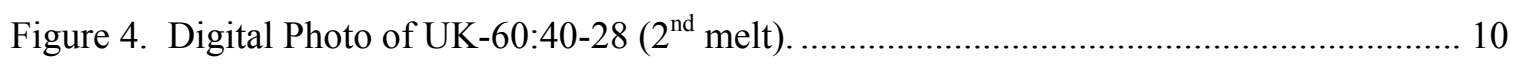



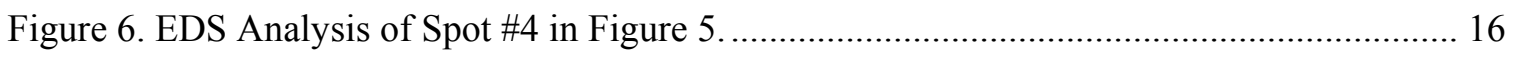

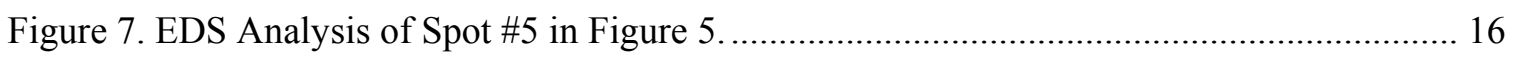

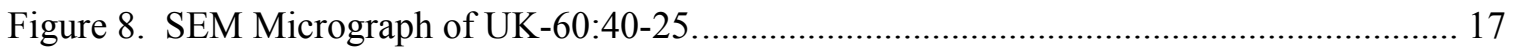

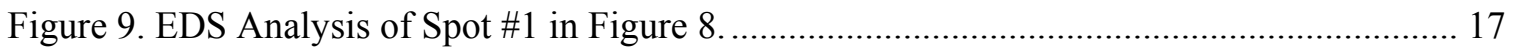



Figure 11. EDS Analysis of Spot \#4 in Figure 8 ................................................................. 18

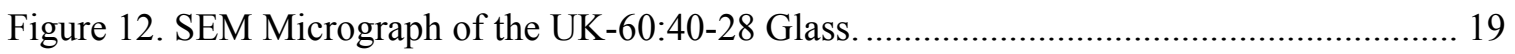

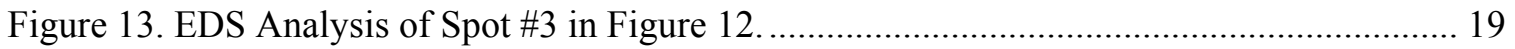

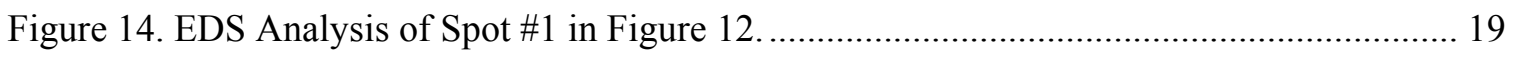

Figure 15. $\log$ NL $[\mathrm{B}](\mathrm{g} / \mathrm{L})$ Values as a Function of Time for Each Magnox:Butex Blend Ratio.

Figure 16. $\log \mathrm{NL}[\mathrm{Al}](\mathrm{g} / \mathrm{L})$ Values as a Function of Time for Each Magnox:Butex Blend Ratio.

Figure 17. Viscosity as a Function of Temperature and WL for the Frit 418 - SB3 System....... 29

Figure 18. Photo micrographs showing as-received material in as-polished condition. (a) entire cross-section at 12.5 times magnification and (b) surface at 200 times magnification. (EDM: electrical discharge machining).

Figure 19. Photo micrographs showing the 50:50 series coupons in as-polished condition. (a) entire cross-section at 12.5 times magnification and (b) maximum depth of internal attack at 200 times magnification.

Figure 20. Photo micrographs showing the 60:40 series coupons in as-polished condition. (a) entire cross-section at 12.5 times magnification and (b) maximum depth of internal attack at 200 times magnification.

Figure 21. Photo micrographs showing the 75:25 series coupons in as-polished condition. (a) entire cross-section at 12.5 times magnification and (b) maximum depth of internal attack at 200 times magnification. 


\section{LIST OF ABBREVIATIONS}

\begin{tabular}{|c|c|}
\hline $\mathrm{AD}$ & Analytical Development \\
\hline AES & Atomic Emission Spectroscopy \\
\hline ARM & Approved Reference Material \\
\hline DOE & Department of Energy \\
\hline DWPF & Defense Waste Processing Facility \\
\hline EA & Environmental Assessment \\
\hline EDS & Energy Dispersive Spectroscopy \\
\hline EDM & Electrical Discharge Machining \\
\hline HLW & High Level Waste \\
\hline $\mathrm{ICP}$ & Inductively coupled Plasma \\
\hline IGA & Intergranular Attack \\
\hline MA & Mixed Acid \\
\hline MS & Mass Spectroscopy \\
\hline PCCS & Product Composition Control System \\
\hline PCT & Product Consistency Test \\
\hline $\mathrm{PF}$ & Peroxide Fusion \\
\hline REDOX & Reduction / Oxidation \\
\hline SB & Sludge Batch \\
\hline SEM & Scanning Electron Microscopy \\
\hline SME & Slurry Mix Evaporator \\
\hline SRNL & Savannah River National Laboratory \\
\hline SRS & Savannah River Site \\
\hline $\mathrm{T}_{\mathrm{L}}$ & Liquidus Temperature \\
\hline UK & United Kingdom \\
\hline$\eta$ & Viscosity \\
\hline WFO & Work for Others \\
\hline WL & Waste Loading \\
\hline XRD & X-Ray Diffraction \\
\hline
\end{tabular}




\section{Introduction}

Sellafield Ltd (United Kingdom) has requested technical support from the Savannah River National Laboratory (SRNL) to characterize a series of uranium-bearing, mixed alkali borosilicate glasses [WFO (2010)]. The specific glasses to be characterized are based on different blends of Magnox (WRW17 simulant) and Butex (or HASTs 1 and 2) waste types as well as different incorporation rates (or waste loadings) of each blend. Specific Magnox:Butex blend ratios of interest include: 75:25, 60:40, and 50:50. Each of these waste blend ratios will be mixed with a base glass additive composition targeting waste loadings (WLs) of 25,28 , and $32 \%$ which will result in nine different glasses. The nine glasses are to be fabricated and physically characterized to provide Sellafield Ltd with the technical data to evaluate the impacts of various Magnox:Butex blend ratios and WLs on key glass properties of interest.

It should be noted that the use of "acceptable" in the Work for Other (WFO) was linked to the results of a durability test (more specifically the Soxhlet leach test). Other processing (e.g., viscosity $(\eta)$, liquidus temperature $\left(T_{L}\right)$ ) or product performance (e.g., Product Consistency Test (PCT) results - in addition to the Soxhlet leach test) property constraints were not identified. For example, a critical hold point in the classification of an "acceptable glass" prior to processing high-level waste (HLW) through the Defense Waste Processing Facility (DWPF) is an evaluation of specific processing and product performance properties against pre-defined constraints. This process is referred to as Slurry Mix Evaporator (SME) acceptability in which predicted glass properties (based on compositional measurements) are compared to predefined constraints to determine whether the glass is acceptable [Brown and Postles (1995)]. As an example, although the nominal melter temperature at $\mathrm{DWPF}$ is $1150^{\circ} \mathrm{C}$, there is a $\mathrm{T}_{\mathrm{L}}$ constraint (without uncertainties applied) of $1050^{\circ} \mathrm{C}$. Any glass which has a $\mathrm{T}_{\mathrm{L}}$ predicted value $>1050^{\circ} \mathrm{C}$ would be classified as unacceptable and the SME product would not be transferred to the melter. As another example, consider durability (as defined by the PCT test) and its related constraints to determine acceptability. If the glass composition yields predicted normalized release values that exceed those associated with the Environmental Assessment (EA) glass (with uncertainties applied) then the glass is deemed unacceptable. The issue of acceptability plays a critical role in high level waste processing but without knowing the pre-defined constraints for the UK HLW system, assessments of acceptability of the glasses to be characterized in this study can not be made. The results of this study will be compared to DWPF constraints to provide a benchmark for determining acceptability.

\section{Objective}

The objective of this task is to provide Sellafield Ltd. with the technical data to evaluate the impacts of various Magnox:Butex blend ratios and WLs on key glass properties of interest. The uranium bearing glasses span a compositional region of interest to Sellafield Ltd. and were physically characterized for key processing and product performance properties as defined in the WFO [WFO (2010)]. One of the specific technical issues (as defined in the WFO) is the potential impact of increasing aluminum concentrations on key properties (in particular viscosity). 
Specific scopes as defined in the WFO included:

Fabrication of nine different glasses varying in the Magnox:Butex ratio and/or waste loading.

$>$ Chemical analysis of the as-fabricated glasses to confirm that target compositions were met.

$>$ Performing product quality tests (on the as-fabricated glasses) by Scanning Electron Microscopy (SEM) with Energy Dispersive Spectroscopy (EDS) and/or X-ray Diffraction (XRD) analysis to identify any crystallization that may have occurred.

$>$ Measurements of molten glass viscosity as a function of temperature.

$>$ Assessments of glass durability as defined by the Product Consistency Test (PCT) on the as-fabricated glasses, and

$>$ Conducting corrosion tests by submerging a Nicrofer 6025HT corrosion coupon in molten glass at a temperature of $1150^{\circ} \mathrm{C}$ for 200 hours.

\section{Glass Additive and Waste Compositions}

The glasses to be fabricated and characterized in this study will be based on specific blends (75:25, 60:40, and 50:50) of Magnox:Butex waste as well as a base glass additive (referred to as the MW Base Glass in the WFO). Table 1 summarizes the nominal Magnox:Butex waste blend compositions. Table 2 summarizes the nominal MW base glass (or additive) composition.

\section{Target Glass Compositions}

Table 3 summarizes the target compositions of the nine glasses to be fabricated and characterized. The glass compositions were calculated based on the different Magnox:Butex blend ratios (Table 1) coupled with the MW base glass additive (Table 2) at WLs of 25,28 , and $32 \%$. It should be noted that the uranium has been converted from $\mathrm{UO}_{2}$ to $\mathrm{U}_{3} \mathrm{O}_{8}$ in Table 3 as the source of uranium to be used at $\mathrm{SRNL}$ is $\mathrm{U}_{3} \mathrm{O}_{8}{ }^{1} \quad$ Table 4 summarizes the Glass identifiers (IDs), Magnox:Butex blend ratios, and targeted WLs. Glass IDs were developed to provide a nomenclature for which each glass could be readily identified. The nomenclatures were based on the fact that these were United Kingdom (UK) based glasses, the blend ratio, and the waste loading. For example, Glass ID "UK-75:25-25" is a UK glass based on the Magnox:Butex blend ratio of 75:25 targeting a WL of $25 \%$. As another example, "UK-50:50-32" is a UK glass targeting a Magnox:Butex blend ratio of $50: 50$ at $32 \% \mathrm{WL}$.

\footnotetext{
${ }^{1}$ Sellafield Ltd. reviewed and approved the calculated glass compositions (including the conversion and use of $\mathrm{U}_{3} \mathrm{O}_{8}$ ). See Page 18 of SRNL-NB-2010-00109.
} 
Table 1. Nominal Compositions of Magnox:Butex Waste Blends [WFO (2010)].

\begin{tabular}{|c|c|c|c|}
\hline & \multicolumn{3}{|c|}{ Calcine Sludges } \\
\hline Sludge & $75: 25$ & $60: 40$ & $50: 50$ \\
\hline $\mathrm{Al}_{2} \mathrm{O}_{3}$ & 22.31 & 24.25 & 25.54 \\
\hline $\mathrm{BaO}$ & 1.75 & 1.56 & 1.43 \\
\hline $\mathrm{CeO}_{2}$ & 3.6 & 3.09 & 2.75 \\
\hline $\mathrm{Cr}_{2} \mathrm{O}_{3}$ & 2.4 & 2.29 & 2.22 \\
\hline $\mathrm{Cs}_{2} \mathrm{O}$ & 3.71 & 3.16 & 2.8 \\
\hline $\mathrm{CuO}$ & 0.13 & 0.21 & 0.26 \\
\hline $\mathrm{Fe}_{2} \mathrm{O}_{3}$ & 13.13 & 13.41 & 13.6 \\
\hline $\mathrm{La}_{2} \mathrm{O}_{3}$ & 2 & 1.71 & 1.51 \\
\hline $\mathrm{MgO}$ & 17.78 & 16.25 & 15.23 \\
\hline $\mathrm{MoO}_{3}$ & 4.05 & 3.56 & 3.23 \\
\hline $\mathrm{Nd}_{2} \mathrm{O}_{3}$ & 6.49 & 5.54 & 4.91 \\
\hline $\mathrm{NiO}$ & 1.47 & 1.39 & 1.34 \\
\hline $\mathrm{PO}_{4}$ & 0.74 & 0.63 & 0.55 \\
\hline $\mathrm{Pr}_{6} \mathrm{O}_{11}$ & 1.92 & 1.63 & 1.44 \\
\hline $\mathrm{RuO}_{2}$ & 2.74 & 2.38 & 2.13 \\
\hline $\mathrm{Sm}_{2} \mathrm{O}_{3}$ & 1.35 & 1.16 & 1.03 \\
\hline $\mathrm{SrO}$ & 0.99 & 0.86 & 0.77 \\
\hline $\mathrm{TeO}_{2}$ & 0.6 & 0.53 & 0.48 \\
\hline $\mathrm{UO}_{2}$ & 7.2 & 11.52 & 14.4 \\
\hline $\mathrm{Y}_{2} \mathrm{O}_{3}$ & 0.62 & 0.54 & 0.48 \\
\hline $\mathrm{ZrO}_{2}$ & 5.01 & 4.34 & 3.9 \\
\hline Sum & 100.0 & 100.0 & 100.0 \\
\hline
\end{tabular}

Table 2. Nominal MW Base Glass Composition [WFO (2010)].

\begin{tabular}{||c|c|}
\hline Oxide & $\mathrm{Wt} \%$ \\
\hline $\mathrm{B}_{2} \mathrm{O}_{3}$ & 21.90 \\
\hline $\mathrm{SiO}_{2}$ & 61.72 \\
\hline $\mathrm{Na}_{2} \mathrm{O}$ & 11.05 \\
\hline $\mathrm{Li}_{2} \mathrm{O}$ & 5.33 \\
\hline
\end{tabular}


Table 3. Target Compositions of Nine Magnox:Butex Based Glasses.

\begin{tabular}{|c|c|c|c|c|c|c|c|c|c|}
\hline Oxide & & $75: 25$ & & & $60: 40$ & & & $50: 50$ & \\
\hline WL & 25 & 28 & 32 & 25 & 28 & 32 & 25 & 28 & 32 \\
\hline $\mathrm{Al}_{2} \mathbf{O}_{3}$ & 5.573 & 6.242 & 7.132 & 6.055 & 6.781 & 7.748 & 6.375 & 7.139 & 8.157 \\
\hline $\mathbf{B}_{2} \mathbf{O}_{3}$ & 16.413 & 15.755 & 14.878 & 16.405 & 15.746 & 14.869 & 16.400 & 15.742 & 14.864 \\
\hline $\mathrm{BaO}$ & 0.437 & 0.490 & 0.559 & 0.390 & 0.436 & 0.498 & 0.357 & 0.400 & 0.457 \\
\hline $\mathrm{CeO}_{2}$ & 0.899 & 1.007 & 1.151 & 0.772 & 0.864 & 0.987 & 0.686 & 0.769 & 0.878 \\
\hline $\mathrm{Cr}_{2} \mathrm{O}_{3}$ & 0.600 & 0.671 & 0.767 & 0.572 & 0.640 & 0.732 & 0.554 & 0.621 & 0.709 \\
\hline $\mathrm{Cs}_{2} \mathrm{O}$ & 0.927 & 1.038 & 1.186 & 0.789 & 0.884 & 1.010 & 0.699 & 0.783 & 0.894 \\
\hline $\mathrm{CuO}$ & 0.032 & 0.036 & 0.042 & 0.052 & 0.059 & 0.067 & 0.065 & 0.073 & 0.083 \\
\hline $\mathrm{Fe}_{2} \mathrm{O}_{3}$ & 3.280 & 3.673 & 4.198 & 3.348 & 3.750 & 4.285 & 3.395 & 3.802 & 4.344 \\
\hline $\mathrm{La}_{2} \mathbf{O}_{3}$ & 0.500 & 0.560 & 0.639 & 0.427 & 0.478 & 0.546 & 0.377 & 0.422 & 0.482 \\
\hline $\mathrm{Li}_{2} \mathrm{O}$ & 3.994 & 3.834 & 3.621 & 3.993 & 3.832 & 3.619 & 3.992 & 3.831 & 3.618 \\
\hline MgO & 4.442 & 4.974 & 5.684 & 4.057 & 4.544 & 5.192 & 3.802 & 4.257 & 4.864 \\
\hline $\mathrm{MoO}_{3}$ & 1.012 & 1.133 & 1.295 & 0.889 & 0.995 & 1.137 & 0.806 & 0.903 & 1.032 \\
\hline $\mathrm{Na}_{2} \mathrm{O}$ & 8.281 & 7.949 & 7.507 & 8.277 & 7.945 & 7.502 & 8.275 & 7.943 & 7.500 \\
\hline $\mathrm{Nd}_{2} \mathrm{O}_{3}$ & 1.621 & 1.816 & 2.075 & 1.383 & 1.549 & 1.770 & 1.226 & 1.373 & 1.568 \\
\hline $\mathrm{NiO}$ & 0.367 & 0.411 & 0.470 & 0.347 & 0.389 & 0.444 & 0.334 & 0.375 & 0.428 \\
\hline $\mathbf{P}_{2} \mathbf{O}_{5}$ & 0.185 & 0.207 & 0.237 & 0.157 & 0.176 & 0.201 & 0.137 & 0.154 & 0.176 \\
\hline $\operatorname{Pr}_{6} \mathbf{O}_{11}$ & 0.480 & 0.537 & 0.614 & 0.407 & 0.456 & 0.521 & 0.359 & 0.403 & 0.460 \\
\hline $\mathrm{RuO}_{2}$ & 0.684 & 0.767 & 0.876 & 0.594 & 0.665 & 0.760 & 0.532 & 0.595 & 0.680 \\
\hline $\mathrm{SiO}_{2}$ & 46.262 & 44.408 & 41.937 & 46.240 & 44.385 & 41.911 & 46.228 & 44.372 & 41.897 \\
\hline $\mathrm{Sm}_{2} \mathrm{O}_{3}$ & 0.337 & 0.378 & 0.432 & 0.290 & 0.324 & 0.371 & 0.257 & 0.288 & 0.329 \\
\hline SrO & 0.247 & 0.277 & 0.317 & 0.215 & 0.240 & 0.275 & 0.192 & 0.215 & 0.246 \\
\hline $\mathrm{TeO}_{2}$ & 0.150 & 0.168 & 0.192 & 0.132 & 0.148 & 0.169 & 0.120 & 0.134 & 0.153 \\
\hline $\mathbf{U}_{3} \mathbf{O}_{8}$ & 1.870 & 2.094 & 2.393 & 2.990 & 3.348 & 3.826 & 3.737 & 4.184 & 4.781 \\
\hline $\mathbf{Y}_{2} \mathbf{O}_{3}$ & 0.155 & 0.173 & 0.198 & 0.135 & 0.151 & 0.173 & 0.120 & 0.134 & 0.153 \\
\hline $\mathrm{ZrO}_{2}$ & 1.252 & 1.402 & 1.602 & 1.084 & 1.214 & 1.387 & 0.974 & 1.090 & 1.246 \\
\hline Totals & 100 & 100 & 100 & 100 & 100 & 100 & 100 & 100 & 100 \\
\hline
\end{tabular}


SRNL-STI-2011-00012

Revision 0

Table 4. Glass Identifiers (IDs) and Their Basis.

\begin{tabular}{||c|c|c||}
\hline Glass ID & $\begin{array}{c}\text { Magnox:Butex } \\
\text { Blend Ratio }\end{array}$ & WL \\
\hline UK-75:25-25 & $75: 25$ & 25 \\
\hline UK-75:25-28 & $75: 25$ & 28 \\
\hline UK-75:25-32 & $75: 25$ & 32 \\
\hline UK-60:40-25 & $60: 40$ & 25 \\
\hline UK-60:40-28 & $60: 40$ & 28 \\
\hline UK-60:40-32 & $60: 40$ & 32 \\
\hline UK-50:50-25 & $50: 50$ & 25 \\
\hline UK-50:50-28 & $50: 50$ & 28 \\
\hline UK-50:50-32 & $50: 50$ & 32 \\
\hline
\end{tabular}

\section{Experimental Procedures}

\section{Glass Fabrication}

Each of the UK study glasses was prepared from the proper proportions of reagent-grade metal oxides, carbonates, boric acid and depleted uranium targeting $175 \mathrm{~g}$ of glass. The raw materials were thoroughly mixed and placed into platinum/gold, $250 \mathrm{~mL}$ crucibles. The batch was placed into a high-temperature furnace at the melt temperature of $1150^{\circ} \mathrm{C}$. The crucible was removed from the furnace after an isothermal hold for 1 hour. The glass was poured onto a clean, stainless steel plate and allowed to air cool (quench). The glass pour patty and residual crucible glass were mixed, ground, and remelted at $1150^{\circ} \mathrm{C}$ for 1 hour to ensure homogeneity of the glass products. The glass was again poured onto a clean, stainless steel plate and allowed to air cool (quench). There was no attempt to control the Reduction / Oxidation (REDOX) state of the glasses through the use of a reductant and/or furnace atmosphere. The glass pour patty from the second melt was used as a sampling stock for the various property measurements described below.

\section{Composition Analysis}

To confirm that the as-fabricated glasses met the target compositions, a representative sample from each quenched glass was submitted to SRNL's Analytical Development (AD) organization for chemical analysis. Two dissolution techniques, sodium peroxide fusion (PF) and mixed acid (MA), were used to prepare the glass samples for analysis. Inductively Coupled Plasma - Atomic Emission Spectroscopy (ICP-AES) and ICP-Mass Spectrometry (ICP-MS) were used to support elemental analysis. ICP-MS was used to measure the following elements: $\mathrm{Cs}, \mathrm{Nd}, \mathrm{Pr}, \mathrm{Ru}, \mathrm{Sm}$, $\mathrm{Te}$, and Y. All other elements (Al, B, Ba, Ce, Cr, Cu, Fe, La, Li, Mg, Mo, Na, Ni, Si, Sr, U, and $\mathrm{Zr}$ ) were measured by ICP-AES.

\section{$X$-Ray Diffraction Analysis}

Representative samples of the as-fabricated glasses were submitted to AD for XRD analysis. Samples were run under conditions providing a detection limit of approximately $0.5 \mathrm{vol} \%$. That is, if crystals (or unincorporated batch material) were present at $0.5 \mathrm{vol} \%$ or greater, the 
diffractometer would not only be capable of detecting the crystals but would also allow a qualitative determination of the type of crystal(s) present. Otherwise, a characteristically high background signal (amorphous hump) devoid of crystalline peaks indicates that the glass is free of crystallization, suggesting either a completely amorphous product or that the degree of crystallization is below the detection limit.

\section{Scanning Electron Microscopy and Energy Dispersive Spectroscopy}

Scanning Electron Microscopy (SEM) and Energy Dispersive Spectroscopy (EDS) were used to provide qualitative information on the types of crystallization present in the as-fabricated glasses. Samples of crushed glass were prepared by adhering particles to carbon tape on aluminum specimen holders.

\section{Product Consistency Test}

The Product Consistency Test (PCT) was performed in duplicate on each as-fabricated UK glass to assess chemical durability [ASTM (2002)]. Also included in the experimental test matrix was the Environmental Assessment (EA) benchmark glass [Jantzen et al. (1993)], the Approved Reference Material (ARM) glass, and blanks from the sample cleaning batch. Samples were ground, washed, and prepared according to the standard procedure. Fifteen milliliters of Type-I ASTM water were added to $1.5 \mathrm{~g}$ of glass in stainless steel vessels. The vessels were closed, sealed, and placed in an oven at $90 \pm 2{ }^{\circ} \mathrm{C}$ where the samples were maintained at temperature for $7,14,21$, and 28 days. Once cooled, the resulting solutions were sampled (filtered and acidified), then labeled and analyzed by AD under the auspices of an analytical plan. ${ }^{2}$ Samples of a multielement, standard solution were also included in the analytical plan as a check on the accuracy of the ICP-AES instrument used for these measurements. The leachates from these tests were diluted by adding $4 \mathrm{~mL}$ of $0.4 \mathrm{M} \mathrm{HNO}_{3}$ to $6 \mathrm{~mL}$ of the leachate (a $6: 10$ volume to volume, $\mathrm{v}: \mathrm{v}$, dilution) before being submitted to AD. The leachates of EA were further diluted (1:10 v:v) with deionized water prior to submission to $A D$ in order to prevent problems with the nebulizer. Normalized release rates were calculated based on the target and measured compositions using the average of the common logarithms of the leachate concentrations.

\section{Viscosity}

The viscosities of the UK glasses were measured following Procedure A of the ASTM C 965 standard [ASTM (2007)]. An Orton high temperature rotating spindle viscometer was used with platinum crucibles and spindles. The crucible and spindle were specially designed to operate with small quantities of glass to support measurements of radioactive glasses [Schumacher and Peeler (1998)]. A well characterized standard glass was used to determine the appropriate spindle constants [Schumacher et al. (2001) and Crum et al. (unpublished)].

Measurements were taken over a range of temperatures from 1050 to $1200^{\circ} \mathrm{C}$ in $50^{\circ} \mathrm{C}$ intervals. Measurements at $1150^{\circ} \mathrm{C}$ were taken at three different times during the procedure to provide an opportunity to identify the effects of any crystallization or volatilization that may have occurred during the test. The data were fit to a Fulcher equation [Fulcher (1925)] to provide a measured viscosity value at the nominal melt temperature of $1150^{\circ} \mathrm{C}$ as well as $1050^{\circ} \mathrm{C}$.

\footnotetext{
${ }^{2}$ TB Edwards, “Analytical Plan for Measuring The PCT Solution of Glasses From The Study of the Impact of Aluminum on Glass Properties for the UK", SRNL-L5200-2010-0035, Savannah River National Laboratory, InterOffice Memorandum, September 7, 2010.
} 


\section{Materials Corrosion}

Nine pre-cut Nicrofer coupons were provided by Sellafield Ltd to support the corrosion tests. One coupon was suspended in each of the nine different glass compositions. The coupons were suspended on an $\mathrm{Al}_{2} \mathrm{O}_{3}$ rod which spanned the diameter of the $\mathrm{Al}_{2} \mathrm{O}_{3}$-crucible being used for this test. Approximately $1 / 2$ of each coupon was immersed in the molten glass while the other half was exposed to the vapor space or furnace atmosphere. The coupons were isothermally held at $1150^{\circ} \mathrm{C}$ for 196 hours after which the crucibles were removed from the furnace. Prior to glass solidification, the coupons were removed from the molten glass and allowed to cool to room temperature. After cooling, there was a thin layer of residual glass covering most of the coupon surface (for each of the nine coupons).

The nine coupons that were exposed to molten glass were submitted for metallurgical evaluation. The lower portion of the sample, the bottom $1 / 4$ " that was fully immersed in the molten glass, was sectioned using a low speed diamond saw. The samples were aligned in the saw to ensure the cut was made orthogonally with respect to all axes (see Figure 1). The sample was encapsulated in a cold mount and the cut surface was ground and polished starting at 240 grit and ending at 0.1 micron. The samples were left in the as-polished condition (samples were not etched) to evaluate the depth of internal attack, e.g. intergranular attack (IGA) and internal void formation. Small scratches may be visible on some of the photomicrographs. These scratches resulted from small particles of glass that are dislodged from the mount during polishing and trapped in the polishing cloth. The entire perimeter of each sample was visually observed using a Zeiss Axiovert ${ }^{\mathrm{TM}} 200$ optical microscope. Photo micrographs were taken at 12.5 times magnification to show the entire cross-section and at 200 times magnification to reveal a region with the greatest depth of internal attack. Measurements taken on the mounted samples were made using the microscope with the AxioVision ${ }^{\mathrm{TM}}$ Software package.

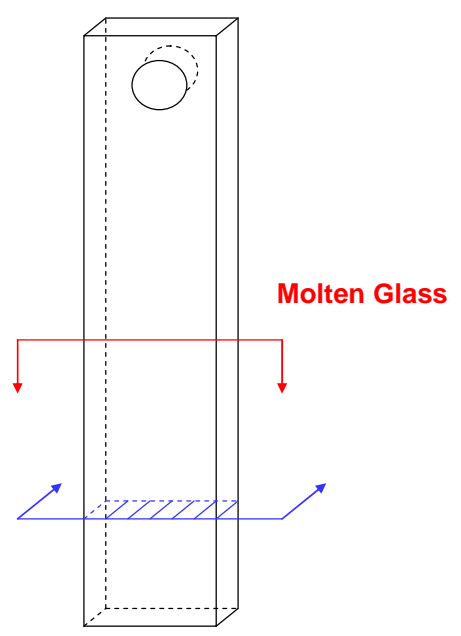

Figure 1. Schematic of coupon showing cross-sectioned surface that was prepared for metallurgical evaluation (blue rectangular area). 


\section{Results}

\section{Visual Observations}

Visual observations were recorded for the resulting pour patties and residual crucible glass after the initial melt at $1150^{\circ} \mathrm{C}$. All nine pour patties were described as having "grey foam swirls on the surface and crystals within the bulk". ${ }^{3}$ Figure 2 is an example of the grey foam that was visually observed on the surface of the UK-50:50-32 glass pour patty - again characteristic of all nine glasses. Crystallization within the bulk (or cross section) is not apparent in Figure 2. Visual observations of the residual crucible glass (i.e., glass remaining in the crucible after the initial pour) indicated air bubbles or foam was present. In addition, a foam layer was observed around the melt line attached to the Pt crucible.

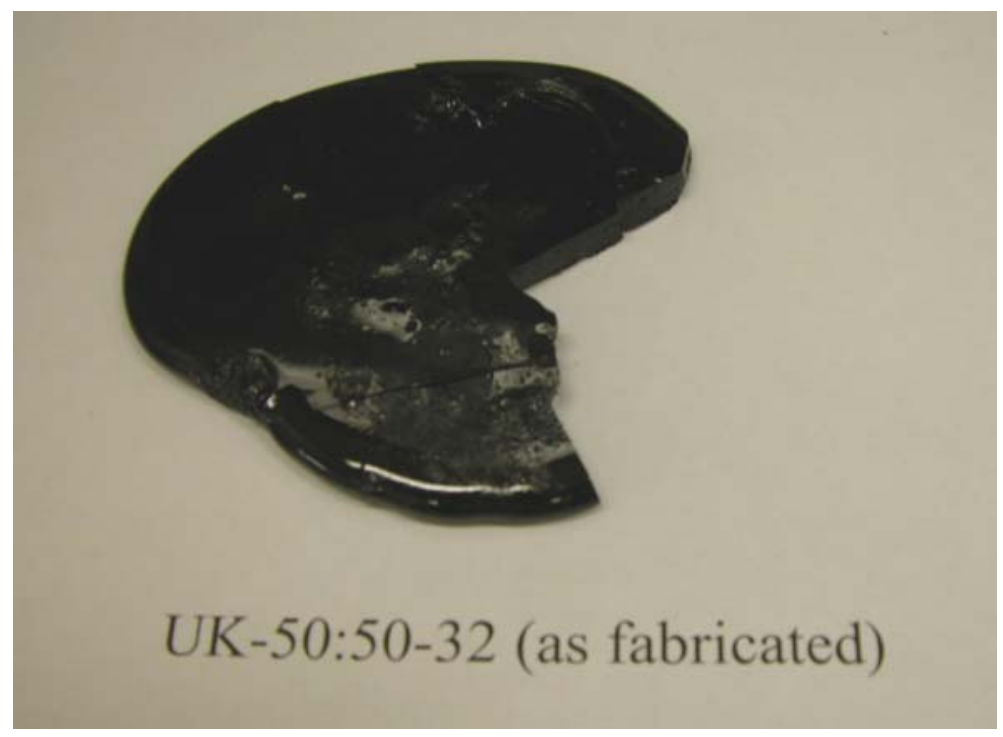

Figure 2. UK-50:50-32 (1 ${ }^{\text {st }}$ melt $)$.

The presence of foam on the surface of the UK melts is inconsistent with the general observations when typical DWPF glasses are fabricated under similar conditions. More specifically, after an isothermal hold at $1150^{\circ} \mathrm{C}$ for a typical DWPF glass, the glasses are generally characterized as "black and shiny" (with no foam visually apparent). In DWPF glasses that target higher WLs and/or are subjected to a simulated slow cooling profile, crystallization (spinel formation) is sometimes observed on the surface and within the bulk glass. A review of the targeted UK compositions (Table 3) identifies several oxides that are present in the UK glasses that are not included in typical DWPF melts. These include: $\mathrm{CeO}_{2}, \operatorname{Pr}_{6} \mathrm{O}_{11}, \mathrm{Sm}_{2} \mathrm{O}_{3}$, and $\mathrm{Y}_{2} \mathrm{O}_{3}$. During the development of a vitrification flowsheet for an $\mathrm{Am} / \mathrm{Cm}$ based stream at the Savannah River Site (SRS), thermal reduction of $\mathrm{CeO}_{2}$ was identified as the primary source for batch expansion and high temperature bubble formation in high lanthanide borosilicate glasses [Vienna et al. (1999), Peeler et al. (2000) and Peeler and Reamer (2001)]. Although the $\mathrm{CeO}_{2}$ concentrations in the

\footnotetext{
${ }^{3}$ See pages $38-40$ of SRNL-NB-2010-00109 for more details regarding the visual observations of the initial and second melts of the nine UK glasses.
} 
lanthanide borosilicate glasses studied by Peeler and Reamer (2001) were on the order of $3-4$ wt $\%$ (in glass), volume expansion and high temperature bubble formation in the melts were noticed at temperatures of $\sim 1100^{\circ} \mathrm{C}$ and above. ${ }^{4}$ Although no formal evaluation was made to isolate the potential cause of the foam in the UK initial melts, thermal reduction of $\mathrm{CeO}_{2}$ is a likely candidate.

To ensure the UK glasses were homogeneous prior to subsequent physical characterization, a second isothermal hold at $1150^{\circ} \mathrm{C}$ was performed. In general, the resulting pour patties were black and shiny with very little, if any, foam observed on the surface of the melts. Figure 3 and Figure 4 show the resulting glass pour patties after the $2^{\text {nd }}$ melt for the UK-50:50-32 and UK60:40-28 glasses, respectively. Although the surfaces of the nine UK glasses appear homogeneous, crystallization within the bulk glass was still visually apparent.

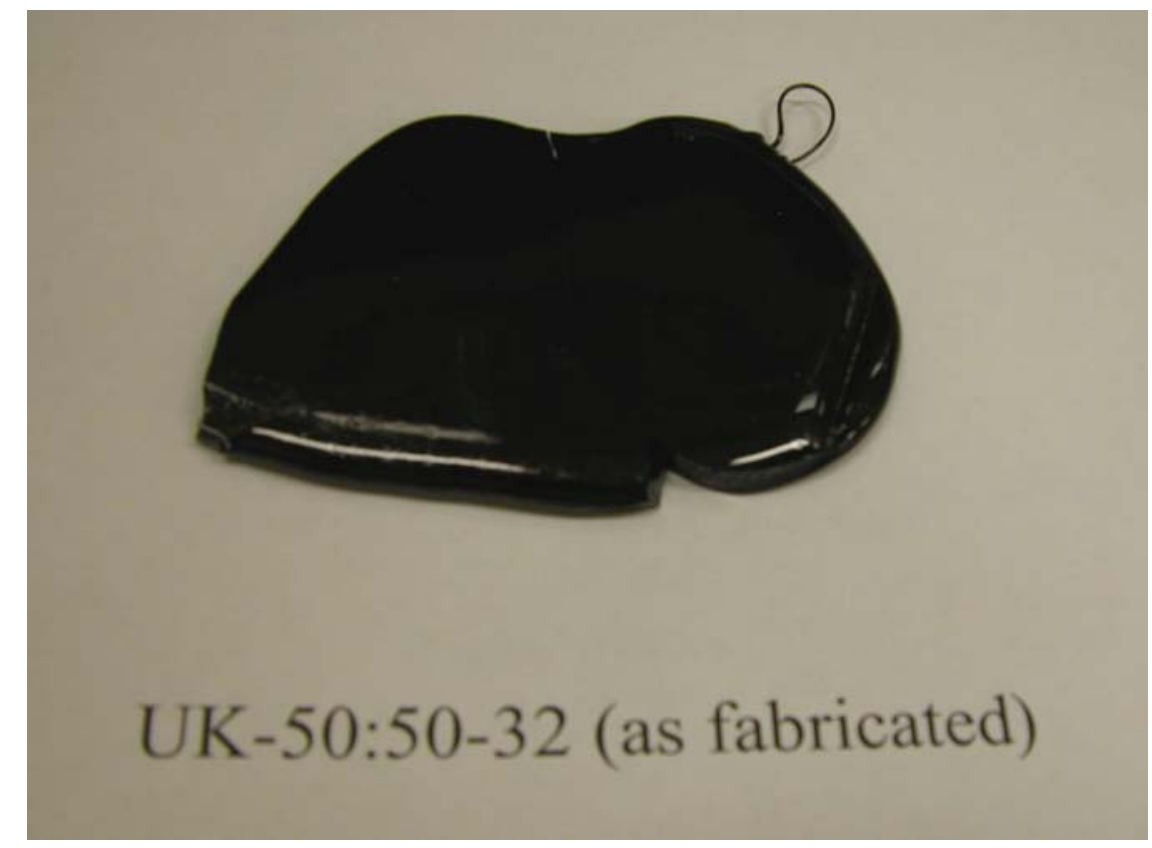

Figure 3. Digital Photo of UK-50:50-32 ( $2^{\text {nd }}$ melt $)$.

\footnotetext{
${ }^{4} \mathrm{H}$. Schreiber (personal communication during the $\mathrm{Am} / \mathrm{Cm}$ flowsheet development task) indicated that cerium will establish a +4 to +3 equilibrium at $1150^{\circ} \mathrm{C}$ in borosilicate glass and therefore it is subject to temperature induced reduction from its usual +4 state.
} 


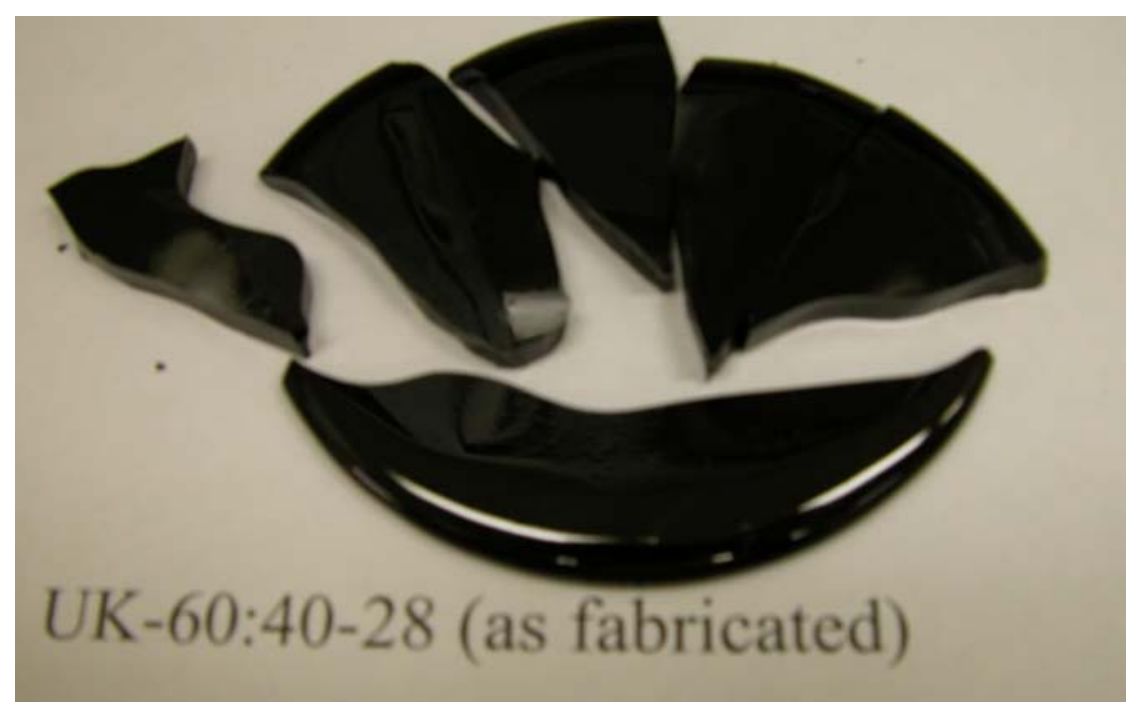

Figure 4. Digital Photo of UK-60:40-28 ( $2^{\text {nd }}$ melt $)$.

\section{$X$-Ray Diffraction}

Table 5 summarizes the XRD results of the nine UK "as fabricated" glasses. Representative samples from the glass pour patty were obtained and submitted to AD for XRD analysis. $\mathrm{RuO}_{2}$ was detected in all of the UK glasses. This is not surprising since the solubility of $\mathrm{RuO}_{2}$ in borosilicate glasses is very limited. Trevorite $\left(\mathrm{NiFe}_{2} \mathrm{O}_{4}\right)$ was also detected in all UK glasses with the exception of the UK-60:40-25 glass. Spinels are common in high level waste glasses enriched in $\mathrm{Fe}, \mathrm{Ni}$, and/or $\mathrm{Cr}$ and typically increase (volume or mass percent) with increased waste loading. The one sample in which trevorite was not detected (UK-60:40-25) was the lowest waste loading in the UK-60:40 series of glasses. The XRD results confirm visual observations of crystallization within the bulk glasses after the $2^{\text {nd }}$ melt as discussed in the previous section. Appendix A provides the XRD patterns for all nine UK glasses (see Figures A-1 through A-9).

Table 5. X-Ray Diffraction Results of As-Fabricated UK Glasses.

\begin{tabular}{||c|c|}
\hline \hline Glass & Phases \\
\hline UK-75:25-25 & $\mathrm{RuO}_{2}$, Trevorite $\left(\mathrm{NiFe}_{2} \mathrm{O}_{4}\right)$ \\
\hline UK-75:25-28 & $\mathrm{RuO}_{2}$, Trevorite $\left(\mathrm{NiFe}_{2} \mathrm{O}_{4}\right)$ \\
\hline UK-75:25-32 & $\mathrm{RuO}_{2}$, Trevorite $\left(\mathrm{NiFe}_{2} \mathrm{O}_{4}\right)$ \\
\hline UK-60:40-25 & RuO \\
\hline UK-60:40:28 & $\mathrm{RuO}_{2}$, Trevorite $\left(\mathrm{NiFe}_{2} \mathrm{O}_{4}\right)$ \\
\hline UK-60:40:32 & $\mathrm{RuO}_{2}$, Trevorite $\left(\mathrm{NiFe}_{2} \mathrm{O}_{4}\right)$ \\
\hline UK-50:50-25 & $\mathrm{RuO}_{2}$, Trevorite $\left(\mathrm{NiFe}_{2} \mathrm{O}_{4}\right)$ \\
\hline UK-50:50-28 & $\mathrm{RuO}_{2}$, Trevorite $\left(\mathrm{NiFe}_{2} \mathrm{O}_{4}\right)$ \\
\hline UK-50:50-32 & $\mathrm{RuO}_{2}$, Trevorite $\left(\mathrm{NiFe}_{2} \mathrm{O}_{4}\right)$ \\
\hline
\end{tabular}


SRNL-STI-2011-00012

Revision 0

\section{Compositional Analysis}

Tables 6 through 8 compare the targeted and measured compositions of the nine UK glasses. The relative standard deviations (RSDs) of the oxide measurements are also provided in these tables. A general comparison of the target versus measured concentrations indicates no significant issues with the batching and fabrication of the nine UK glasses. A more detailed assessment was performed to identify those oxides whose measured values were outside the targeted value accounting for the relative standard deviations reported.

Table 9 summarizes the results of this assessment for the major oxides (i.e., major being defined as $>1 \mathrm{wt} \%$ in glass (targeted value) for at least one of the nine UK glasses). As noted in Table 9, all of the measured values for $\mathrm{B}_{2} \mathrm{O}_{3}, \mathrm{Fe}_{2} \mathrm{O}_{3}$, and $\mathrm{Li}_{2} \mathrm{O}$ were within the targeted values once the RSDs were accounted for. In fact, there were only 8 cases in which the measured values of the major oxides fall outside of the targeted values once RSDs are accounted for (refer to Table 9). However, a review of the target versus measured values for these 8 cases suggests no significant issues with respect to batching. For example, for the UK-75:25-25 glass, both the $\mathrm{Al}_{2} \mathrm{O}_{3}$ and $\mathrm{MgO}$ measured values are outside the targeted values with the RSDs applied. The targeted $\mathrm{Al}_{2} \mathrm{O}_{3}$ value for this glass was $5.57 \mathrm{wt} \%$ with a measured value of $6.59 \mathrm{wt} \%$ (a difference of $\sim 1 \mathrm{wt} \%$ ). The MgO targeted value for UK-75:25-25 was $4.44 \mathrm{wt} \%$ with a measured value of $5.04 \mathrm{wt} \%$ (a difference of $0.6 \mathrm{wt} \%$ ). With the exception of the $\mathrm{SiO}_{2}$ values, the $\mathrm{Na}_{2} \mathrm{O}$ value for UK-60:40-32 shows the largest difference between the targeted and measured values of the major oxides. The targeted value was $7.50 \mathrm{wt} \%$ while the measured value was $8.79 \mathrm{wt} \%$ - a $1.29 \mathrm{wt} \%$ difference. Although the differences highlighted above may be of statistical significance they should not have a practical impact on the objectives of this study. 
Table 6. Target Versus Measured Compositions for the UK-75:25 Series.

\begin{tabular}{|c|c|c|c|c|c|c|c|c|c|c|c|}
\hline \multirow[t]{2}{*}{ Method } & \multirow[t]{2}{*}{ Digestion } & \multirow[t]{2}{*}{ Oxide } & \multicolumn{3}{|c|}{25} & \multicolumn{3}{|c|}{28} & \multicolumn{3}{|c|}{32} \\
\hline & & & Target & Measured & \%RSD & Target & Measured & \%RSD & Target & Measured & \%RSD \\
\hline ES & $\mathrm{PF}$ & $\mathrm{Al}_{2} \mathrm{O}_{3}$ & 5.57 & 6.59 & 10.0 & 6.24 & 5.91 & 10.0 & 7.13 & 7.44 & 10.0 \\
\hline ES & $\mathrm{PF}$ & $\mathrm{B}_{2} \mathrm{O}_{3}$ & 16.41 & 15.68 & 10.0 & 15.75 & 16.23 & 10.0 & 14.88 & 14.68 & 10.0 \\
\hline ES & $\mathrm{PF}$ & $\mathrm{BaO}$ & 0.44 & 0.51 & 10.0 & 0.49 & 0.45 & 10.0 & 0.56 & 0.58 & 10.0 \\
\hline ES & $\mathrm{PF}$ & $\mathrm{CeO}_{2}$ & 0.90 & 1.00 & 10.1 & 1.01 & 0.87 & 10.0 & 1.15 & 1.16 & 10.1 \\
\hline $\mathrm{ES}$ & $\mathrm{PF}$ & $\mathrm{Cr}_{2} \mathrm{O}_{3}$ & 0.60 & 0.66 & 10.1 & 0.67 & 0.62 & 10.0 & 0.77 & 0.84 & 10.0 \\
\hline MS & $\mathrm{PF}$ & $\mathrm{Cs}_{2} \mathrm{O}$ & 0.93 & 0.98 & 20.0 & 1.04 & 0.85 & 20.0 & 1.19 & 1.10 & 20.0 \\
\hline ES & PF & $\mathrm{CuO}$ & 0.03 & 0.03 & 11.6 & 0.04 & 0.03 & 11.9 & 0.04 & 0.04 & 10.6 \\
\hline ES & $\mathrm{PF}$ & $\mathrm{Fe}_{2} \mathrm{O}_{3}$ & 3.28 & 3.86 & 10.0 & 3.67 & 3.40 & 10.0 & 4.20 & 4.40 & 10.0 \\
\hline ES & $\mathrm{PF}$ & $\mathrm{La}_{2} \mathrm{O}_{3}$ & 0.50 & 0.44 & 10.0 & 0.56 & 0.39 & 10.0 & 0.64 & 0.52 & 10.0 \\
\hline ES & $\mathrm{PF}$ & $\mathrm{Li}_{2} \mathrm{O}$ & 3.99 & 3.70 & 10.0 & 3.83 & 3.83 & 10.0 & 3.62 & 3.49 & 10.0 \\
\hline $\mathrm{ES}$ & $\mathrm{PF}$ & $\mathrm{MgO}$ & 4.44 & 5.04 & 10.0 & 4.97 & 4.44 & 10.0 & 5.68 & 5.74 & 10.0 \\
\hline ES & MA & $\mathrm{MoO}_{3}$ & 1.01 & 1.07 & 10.0 & 1.13 & 1.10 & 10.0 & 1.29 & 1.41 & 10.0 \\
\hline $\mathrm{ES}$ & MA & $\mathrm{Na}_{2} \mathrm{O}$ & 8.28 & 8.68 & 10.0 & 7.95 & 7.70 & 10.0 & 7.51 & 8.14 & 10.0 \\
\hline MS & $\mathrm{PF}$ & $\mathrm{Nd}_{2} \mathrm{O}_{3}$ & 1.62 & 1.66 & 20.0 & 1.82 & 1.36 & 20.0 & 2.07 & 1.93 & 20.0 \\
\hline ES & MA & $\mathrm{NiO}$ & 0.37 & 0.41 & 10.0 & 0.41 & 0.41 & 10.0 & 0.47 & 0.49 & 10.0 \\
\hline ES & MA & $\mathrm{PO}_{4}$ & 0.18 & NA & - & 0.21 & NA & - & 0.24 & NA & - \\
\hline MS & $\mathrm{PF}$ & $\operatorname{Pr}_{6} \mathrm{O}_{11}$ & 0.48 & 0.44 & 20.0 & 0.54 & 0.38 & 20.0 & 0.61 & 0.51 & 20.0 \\
\hline MS & $\mathrm{PF}$ & $\mathrm{RuO}_{2}$ & 0.68 & 0.55 & 20.0 & 0.77 & 0.52 & 20.0 & 0.88 & 0.75 & 20.0 \\
\hline ES & $\mathrm{PF}$ & $\mathrm{SiO}_{2}$ & 46.26 & 48.56 & 10.0 & 44.41 & 49.85 & 10.0 & 41.94 & 45.14 & 10.0 \\
\hline MS & $\mathrm{PF}$ & $\mathrm{Sm}_{2} \mathrm{O}_{3}$ & 0.34 & 0.35 & 20.0 & 0.38 & 0.27 & 20.0 & 0.43 & 0.37 & 20.0 \\
\hline $\mathrm{ES}$ & $\mathrm{PF}$ & $\mathrm{SrO}$ & 0.25 & 0.27 & 10.0 & 0.28 & 0.24 & 10.0 & 0.32 & 0.33 & 10.0 \\
\hline MS & $\mathrm{PF}$ & $\mathrm{TeO}_{2}$ & 0.15 & 0.15 & 20.0 & 0.17 & 0.12 & 20.0 & 0.19 & 0.19 & 20.0 \\
\hline ES & MA & $\mathrm{U}_{3} \mathrm{O}_{8}$ & 1.87 & 1.93 & 10.1 & 2.09 & 1.99 & 10.0 & 2.39 & 2.56 & 10.0 \\
\hline MS & $\mathrm{PF}$ & $\mathrm{Y}_{2} \mathrm{O}_{3}$ & 0.15 & 0.15 & 20.0 & 0.17 & 0.13 & 20.0 & 0.20 & 0.17 & 20.0 \\
\hline $\mathrm{ES}$ & MA & $\mathrm{ZrO}_{2}$ & 1.25 & 1.09 & 10.0 & 1.40 & 1.12 & 10.0 & 1.60 & 1.40 & 10.0 \\
\hline & & Total & & 103.8 & & & 102.2 & & & 103.4 & \\
\hline
\end{tabular}


Table 7. Target Versus Measured Compositions for the UK-60:40 Series.

\begin{tabular}{|c|c|c|c|c|c|c|c|c|c|c|c|}
\hline \multirow{2}{*}{ Method } & \multirow{2}{*}{ Digestion } & \multirow{2}{*}{ " Oxide } & \multicolumn{3}{|c|}{25} & \multicolumn{3}{|c|}{28} & \multicolumn{3}{|c|}{32} \\
\hline & & & Target & Measured & \%RSD & Target & Measured & \%RSD & Target & Measured & \%RSD \\
\hline ES & $\mathrm{PF}$ & $\mathrm{Al}_{2} \mathrm{O}_{3}$ & 6.06 & 6.44 & 10.0 & 6.78 & 7.22 & 10.1 & 7.75 & 8.16 & 10.1 \\
\hline ES & $\mathrm{PF}$ & $\mathrm{B}_{2} \mathrm{O}_{3}$ & 16.40 & 16.13 & 10.0 & 15.75 & 15.52 & 10.0 & 14.87 & 14.62 & 10.0 \\
\hline ES & $\mathrm{PF}$ & $\mathrm{BaO}$ & 0.39 & 0.40 & 10.0 & 0.44 & 0.46 & 10.0 & 0.50 & 0.52 & 10.0 \\
\hline $\mathrm{ES}$ & $\mathrm{PF}$ & $\mathrm{CeO}_{2}$ & 0.77 & 0.74 & 10.1 & 0.86 & 0.89 & 10.1 & 0.99 & 0.96 & 10.0 \\
\hline ES & $\mathrm{PF}$ & $\mathrm{Cr}_{2} \mathrm{O}_{3}$ & 0.57 & 0.58 & 10.1 & 0.64 & 0.63 & 10.0 & 0.73 & 0.61 & 10.0 \\
\hline MS & $\mathrm{PF}$ & $\mathrm{Cs}_{2} \mathrm{O}$ & 0.79 & 0.72 & 20.0 & 0.88 & 0.80 & 20.0 & 1.01 & 0.93 & 20.0 \\
\hline ES & $\mathrm{PF}$ & $\mathrm{CuO}$ & 0.05 & 0.04 & 10.5 & 0.06 & 0.05 & 10.2 & 0.07 & 0.05 & 10.1 \\
\hline ES & $\mathrm{PF}$ & $\mathrm{Fe}_{2} \mathrm{O}_{3}$ & 3.35 & 3.50 & 10.0 & 3.75 & 3.96 & 10.0 & 4.28 & 4.45 & 10.0 \\
\hline ES & $\mathrm{PF}$ & $\mathrm{La}_{2} \mathrm{O}_{3}$ & 0.43 & 0.33 & 10.1 & 0.48 & 0.39 & 10.0 & 0.55 & 0.43 & 10.0 \\
\hline ES & $\mathrm{PF}$ & $\mathrm{Li}_{2} \mathrm{O}$ & 3.99 & 3.83 & 10.0 & 3.83 & 3.72 & 10.0 & 3.62 & 3.49 & 10.0 \\
\hline ES & $\mathrm{PF}$ & $\mathrm{MgO}$ & 4.06 & 4.08 & 10.0 & 4.54 & 4.59 & 10.0 & 5.19 & 5.21 & 10.0 \\
\hline ES & MA & $\mathrm{MoO}_{3}$ & 0.89 & 0.89 & 10.0 & 1.00 & 0.96 & 10.0 & 1.14 & 1.34 & 10.0 \\
\hline ES & MA & $\mathrm{Na}_{2} \mathrm{O}$ & 8.28 & 8.14 & 10.0 & 7.95 & 7.59 & 10.0 & 7.50 & 8.79 & 10.0 \\
\hline MS & $\mathrm{PF}$ & $\mathrm{Nd}_{2} \mathrm{O}_{3}$ & 1.38 & 1.20 & 20.0 & 1.55 & 1.38 & 20.0 & 1.77 & 1.50 & 20.0 \\
\hline $\mathrm{ES}$ & MA & $\mathrm{NiO}$ & 0.35 & 0.36 & 10.0 & 0.39 & 0.38 & 10.0 & 0.44 & 0.50 & 10.0 \\
\hline ES & MA & $\mathrm{PO}_{4}$ & 0.16 & NA & - & 0.18 & NA & - & 0.20 & NA & - \\
\hline MS & $\mathrm{PF}$ & $\operatorname{Pr}_{6} \mathrm{O}_{11}$ & 0.41 & 0.32 & 20.0 & 0.46 & 0.38 & 20.0 & 0.52 & 0.41 & 20.0 \\
\hline MS & $\mathrm{PF}$ & $\mathrm{RuO}_{2}$ & 0.59 & 0.42 & 20.0 & 0.67 & 0.46 & 20.0 & 0.76 & 0.44 & 20.0 \\
\hline ES & $\mathrm{PF}$ & $\mathrm{SiO}_{2}$ & 46.24 & 49.85 & 10.0 & 44.38 & 48.35 & 10.0 & 41.91 & 45.57 & 10.0 \\
\hline $\mathrm{MS}$ & $\mathrm{PF}$ & $\mathrm{Sm}_{2} \mathrm{O}_{3}$ & 0.29 & 0.25 & 20.0 & 0.32 & 0.28 & 20.0 & 0.37 & 0.35 & 20.0 \\
\hline ES & $\mathrm{PF}$ & $\mathrm{SrO}$ & 0.21 & 0.21 & 10.0 & 0.24 & 0.25 & 10.0 & 0.27 & 0.27 & 10.0 \\
\hline $\mathrm{MS}$ & PF & $\mathrm{TeO}_{2}$ & 0.13 & 0.13 & 20.0 & 0.15 & 0.15 & 20.0 & 0.17 & 0.18 & 20.0 \\
\hline ES & $\mathrm{MA}$ & $\mathrm{U}_{3} \mathrm{O}_{8}$ & 2.99 & 2.92 & 10.0 & 3.35 & 3.16 & 10.0 & 3.83 & 4.43 & 10.0 \\
\hline MS & $\mathrm{PF}$ & $\mathrm{Y}_{2} \mathrm{O}_{3}$ & 0.13 & 0.11 & 20.0 & 0.15 & 0.13 & 20.0 & 0.17 & 0.15 & 20.0 \\
\hline ES & MA & $\mathrm{ZrO}_{2}$ & 1.08 & 0.90 & 10.0 & 1.21 & 0.98 & 10.0 & 1.39 & 1.35 & 10.0 \\
\hline & & Total & & 102.5 & & & 102.7 & & & 104.7 & \\
\hline
\end{tabular}


Table 8. Target Versus Measured Compositions for the UK-50:50 Series.

\begin{tabular}{|c|c|c|c|c|c|c|c|c|c|c|c|}
\hline \multirow[t]{2}{*}{ Method } & \multirow[t]{2}{*}{ Digestion } & \multirow[t]{2}{*}{ Oxide } & \multicolumn{3}{|c|}{25} & \multicolumn{3}{|c|}{28} & \multicolumn{3}{|c|}{32} \\
\hline & & & Target & Measured & \%RSD & Target & Measured & \%RSD & Target & Measured & \%RSD \\
\hline ES & $\mathrm{PF}$ & $\mathrm{Al}_{2} \mathrm{O}_{3}$ & 6.38 & 6.75 & 10.0 & 7.14 & 7.46 & 10.0 & 8.16 & 8.65 & 10.0 \\
\hline ES & $\mathrm{PF}$ & $\mathrm{B}_{2} \mathrm{O}_{3}$ & 16.40 & 15.94 & 10.0 & 15.74 & 15.26 & 10.0 & 14.86 & 14.59 & 10.0 \\
\hline ES & $\mathrm{PF}$ & $\mathrm{BaO}$ & 0.36 & 0.37 & 10.1 & 0.40 & 0.41 & 10.1 & 0.46 & 0.47 & 10.0 \\
\hline ES & $\mathrm{PF}$ & $\mathrm{CeO}_{2}$ & 0.69 & 0.69 & 10.3 & 0.77 & 0.74 & 10.0 & 0.88 & 0.89 & 10.0 \\
\hline ES & $\mathrm{PF}$ & $\mathrm{Cr}_{2} \mathrm{O}_{3}$ & 0.55 & 0.54 & 10.1 & 0.62 & 0.59 & 10.0 & 0.71 & 0.63 & 10.1 \\
\hline $\mathrm{MS}$ & $\mathrm{PF}$ & $\mathrm{Cs}_{2} \mathrm{O}$ & 0.70 & 0.66 & 20.0 & 0.78 & 0.71 & 20.0 & 0.89 & 0.86 & 20.0 \\
\hline ES & $\mathrm{PF}$ & $\mathrm{CuO}$ & 0.06 & 0.06 & 10.3 & 0.07 & 0.06 & 10.0 & 0.08 & 0.07 & 10.2 \\
\hline $\mathrm{ES}$ & $\mathrm{PF}$ & $\mathrm{Fe}_{2} \mathrm{O}_{3}$ & 3.39 & 3.55 & 10.0 & 3.80 & 3.96 & 10.0 & 4.34 & 4.50 & 10.0 \\
\hline ES & $\mathrm{PF}$ & $\mathrm{La}_{2} \mathrm{O}_{3}$ & 0.38 & 0.31 & 10.0 & 0.42 & 0.33 & 10.1 & 0.48 & 0.40 & 10.0 \\
\hline ES & $\mathrm{PF}$ & $\mathrm{Li}_{2} \mathrm{O}$ & 3.99 & 3.87 & 10.0 & 3.83 & 3.70 & 10.0 & 3.62 & 3.49 & 10.0 \\
\hline ES & $\mathrm{PF}$ & $\mathrm{MgO}$ & 3.80 & 3.80 & 10.0 & 4.26 & 4.26 & 10.0 & 4.86 & 4.88 & 10.0 \\
\hline ES & MA & $\mathrm{MoO}_{3}$ & 0.81 & 0.76 & 10.0 & 0.90 & 0.95 & 10.0 & 1.03 & 1.02 & 10.0 \\
\hline ES & MA & $\mathrm{Na}_{2} \mathrm{O}$ & 8.28 & 7.59 & 10.0 & 7.94 & 8.18 & 10.0 & 7.50 & 6.94 & 10.0 \\
\hline MS & PF & $\mathrm{Nd}_{2} \mathrm{O}_{3}$ & 1.23 & 1.12 & 20.0 & 1.37 & 1.21 & 20.0 & 1.57 & 1.46 & 20.0 \\
\hline ES & $\mathrm{MA}$ & $\mathrm{NiO}$ & 0.33 & 0.33 & 10.0 & 0.37 & 0.40 & 10.0 & 0.43 & 0.39 & 10.0 \\
\hline ES & MA & $\mathrm{PO}_{4}$ & 0.14 & NA & - & 0.15 & NA & - & 0.18 & NA & - \\
\hline MS & $\mathrm{PF}$ & $\operatorname{Pr}_{6} \mathrm{O}_{11}$ & 0.36 & 0.30 & 20.0 & 0.40 & 0.31 & 20.0 & 0.46 & 0.39 & 20.0 \\
\hline MS & $\mathrm{PF}$ & $\mathrm{RuO}_{2}$ & 0.53 & 0.39 & 20.0 & 0.60 & 0.42 & 20.0 & 0.68 & 0.45 & 20.0 \\
\hline ES & $\mathrm{PF}$ & $\mathrm{SiO}_{2}$ & 46.23 & 49.85 & 10.0 & 44.37 & 47.92 & 10.0 & 41.90 & 45.57 & 10.0 \\
\hline MS & PF & $\mathrm{Sm}_{2} \mathrm{O}_{3}$ & 0.26 & 0.22 & 20.0 & 0.29 & 0.23 & 20.0 & 0.33 & 0.29 & 20.0 \\
\hline ES & PF & $\mathrm{SrO}$ & 0.19 & 0.20 & 10.0 & 0.22 & 0.22 & 10.0 & 0.25 & 0.25 & 10.0 \\
\hline MS & PF & $\mathrm{TeO}_{2}$ & 0.12 & 0.11 & 20.0 & 0.13 & 0.11 & 20.0 & 0.15 & 0.13 & 20.0 \\
\hline $\mathrm{ES}$ & MA & $\mathrm{U}_{3} \mathrm{O}_{8}$ & 3.74 & 3.43 & 10.0 & 4.18 & 4.15 & 10.0 & 4.78 & 4.55 & 10.0 \\
\hline MS & $\mathrm{PF}$ & $\mathrm{Y}_{2} \mathrm{O}_{3}$ & 0.12 & 0.11 & 20.0 & 0.13 & 0.11 & 20.0 & 0.15 & 0.14 & 20.0 \\
\hline ES & MA & $\mathrm{ZrO}_{2}$ & 0.97 & 0.77 & 10.0 & 1.09 & 1.08 & 10.0 & 1.25 & 1.03 & 10.0 \\
\hline & & Total & & 101.7 & & & 102.8 & & & 102.1 & \\
\hline
\end{tabular}


SRNL-STI-2011-00012

Revision 0

Table 9. Evaluation of the Measured Versus Targeted Values for the Major Oxides Accounting for the RSD Values.

\begin{tabular}{||c|c|c|c||}
\hline \hline Oxide & Glass ID & Target wt $\%$ & Measured wt $\%$ \\
\hline $\mathrm{Al}_{2} \mathrm{O}_{3}$ & UK-75:25-25 & 5.57 & 6.59 \\
\hline $\mathrm{B}_{2} \mathrm{O}_{3}$ & \multicolumn{3}{|c||}{ All measured values within target \pm RSD } \\
\hline $\mathrm{CeO}_{2}$ & UK-75:25-28 & 1.01 & 0.87 \\
\hline $\mathrm{Fe}_{2} \mathrm{O}_{3}$ & \multicolumn{2}{|c||}{ All measured values within target \pm RSD } \\
\hline $\mathrm{Li}_{2} \mathrm{O}$ & \multicolumn{2}{|c||}{ All measured values within target \pm RSD } \\
\hline \multirow{2}{*}{$\mathrm{MgO}$} & UK-75:25-25 & 4.44 & 5.04 \\
\cline { 2 - 4 } & UK-75:25-28 & 4.97 & 4.44 \\
\hline $\mathrm{Na}_{2} \mathrm{O}$ & UK-60:40-32 & 7.50 & 8.79 \\
\hline $\mathrm{Nd}_{2} \mathrm{O}_{3}$ & UK-75:25-28 & 1.82 & 1.36 \\
\hline $\mathrm{SiO}_{2}$ & UK-75:25-28 & 44.41 & 49.85 \\
\hline $\mathrm{U}_{3} \mathrm{O}_{8}$ & UK-60:40-32 & 3.83 & 4.43 \\
\hline
\end{tabular}

\section{Scanning Electron Microscopy}

$\mathrm{SEM} / \mathrm{EDS}$ analysis was performed to further characterize the as-fabricated UK glasses. Based on the visual and XRD analysis (Table 5), it was anticipated that the results of the SEM/EDS analysis would indicate the presence of spinels and undissolved $\mathrm{RuO}_{2}$ and indeed that was the case. Appendix B provides representative SEM/EDS data for all nine UK glasses. A general discussion is provided below for a couple of specific glasses (UK-50:50-25 and UK-60:40-25) to provide guidance on the interpretation of the SEM/EDS data.

Figure 5 shows a SEM micrograph for the UK-50:50-25 glass with isolated crystallization within the bulk of the glass. ${ }^{5}$ Based on the EDS spectra, Spots \#4 and \#5 are enriched in $\mathrm{Fe}, \mathrm{Cr}$, and $\mathrm{Ni}$ and are somewhat cubic in nature which is consistent with the morphology of spinels (and is consistent with the XRD results provided in Table 5). Although spinels are present in this area of the glass their overall concentration is relatively low. However, given the detection of spinel (Trevorite) in the XRD spectrum, its concentration must be on the order of $0.5 \mathrm{wt} \%$ or greater (i.e., the approximate XRD detection limit based on the run conditions used for that assessment).

\footnotetext{
${ }^{5}$ It should be noted that the SEM micrographs are focused on areas where crystallization was found and may not be representative of the entire sample.
} 


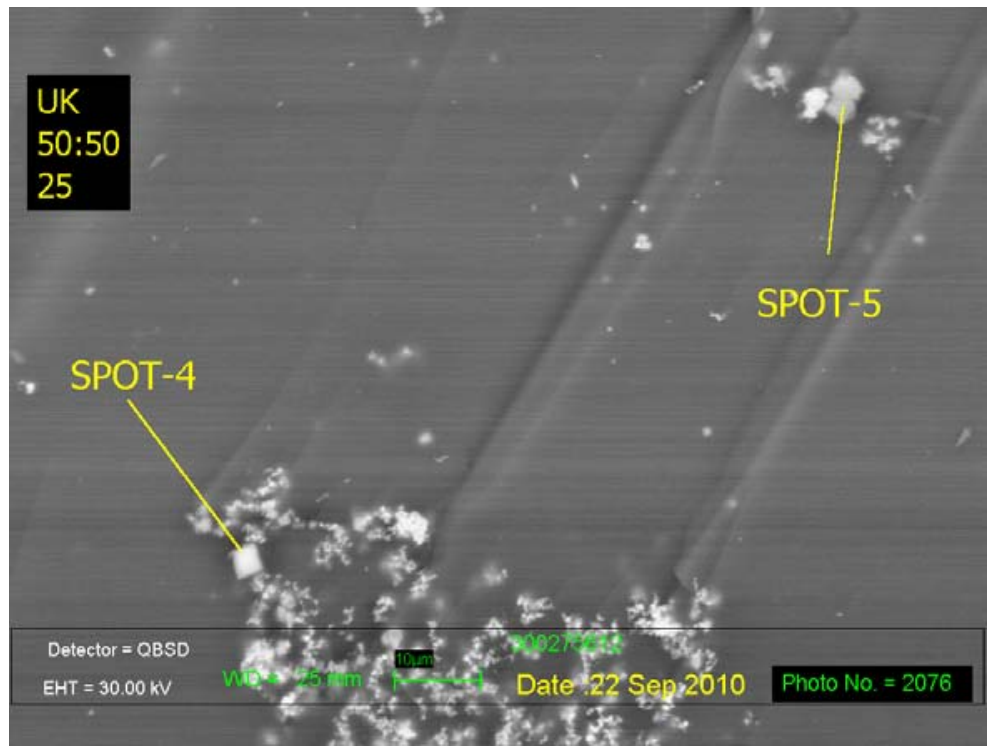

Figure 5. SEM Micrograph of UK-50:50-25.

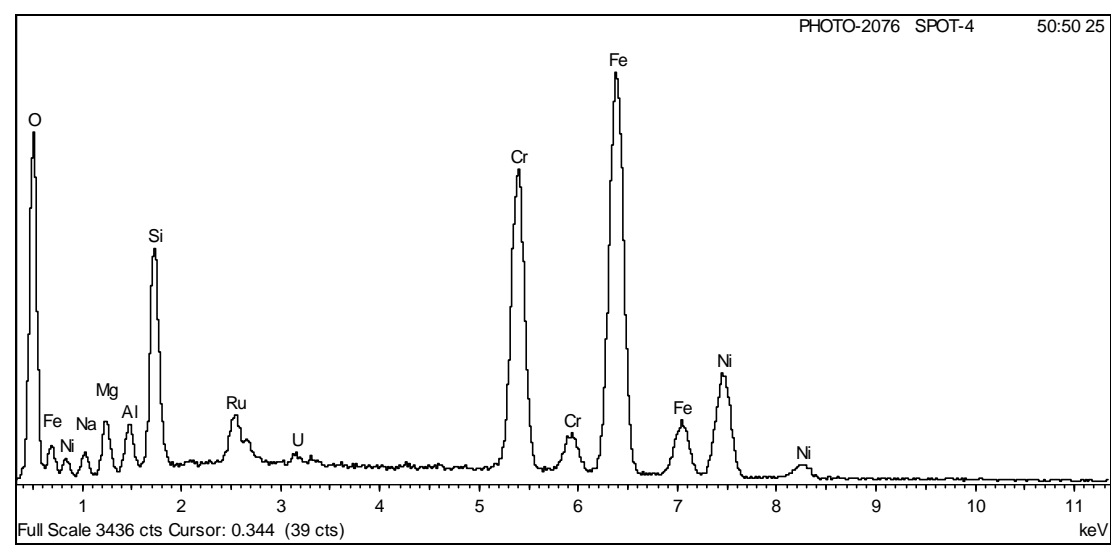

Figure 6. EDS Analysis of Spot \#4 in Figure 5.

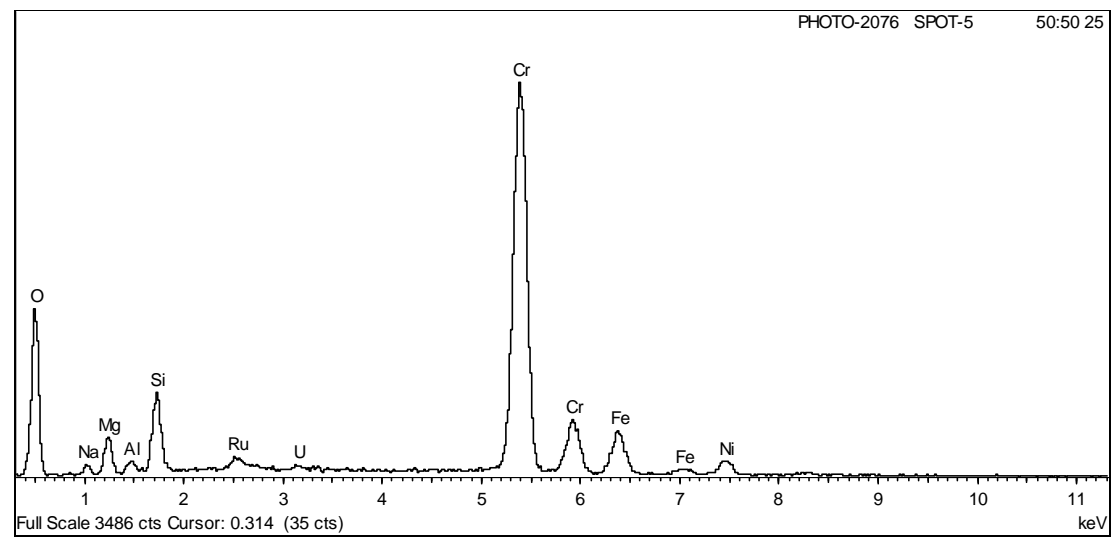

Figure 7. EDS Analysis of Spot \#5 in Figure 5. 
Figure 8 is a micrograph of a specific area within the UK-60:40-25 glass. EDS analysis of Spot \#1 (see Figure 9) and the relatively sharp edges (or morphology) of the crystal suggest the presence of a Cr-enriched spinel. EDS results of Spots \#2 and \#4 (see Figures 10 and 11, respectively) indicate that the cluster of crystals in the center of the area under analysis in Figure 8 is enriched in $\mathrm{Ru}$. XRD analysis indicates the presence of undissolved $\mathrm{RuO}_{2}$ (consistent with the EDS spectrum of Spots \#2 and \#4) but did not detect the presence of spinels in the UK-60:4025 glass. Although the results of the Spot \#1 analysis suggest the presence of a Cr-rich spinel, the volume percent of spinels present in this sample must be below the XRD detection limit. However, as WL increases within the UK-60:40 series (i.e., the -28 and -32 glasses), spinel formation is detected by XRD (refer to Table 5) which was confirmed through SEM/EDS analysis as shown in Figure 12 and Figure 13.

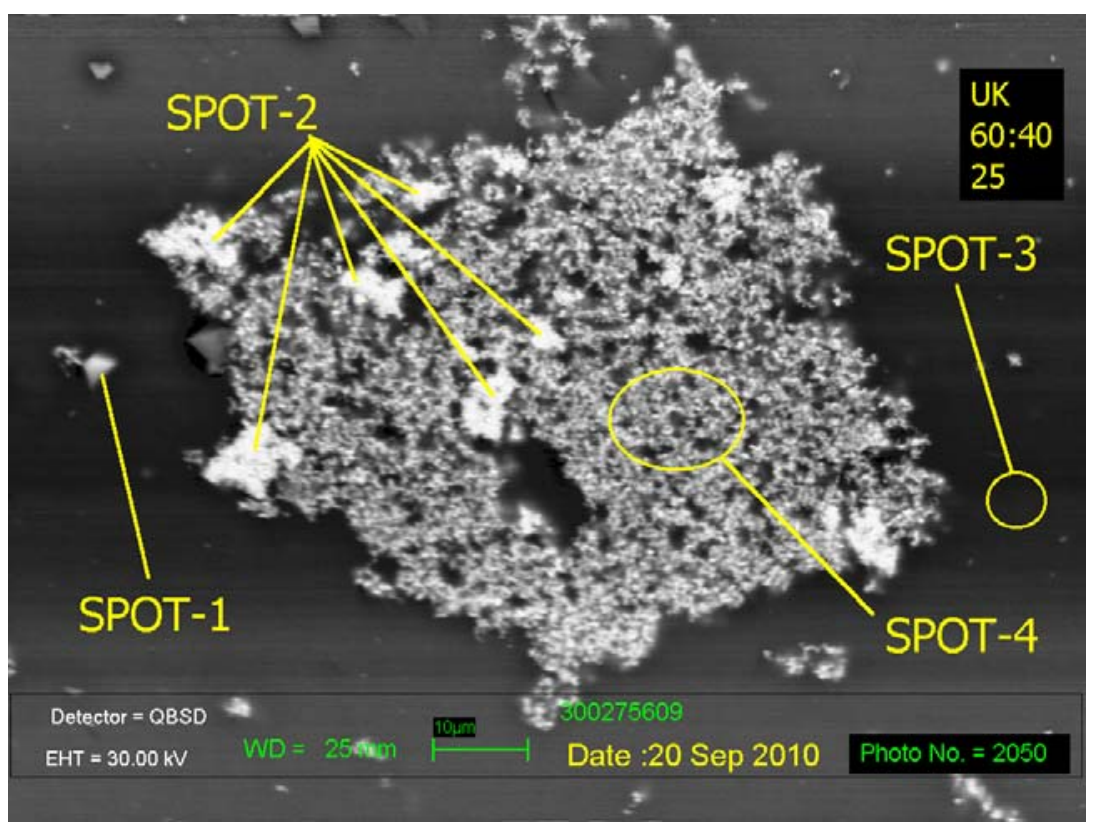

Figure 8. SEM Micrograph of UK-60:40-25.



Figure 9. EDS Analysis of Spot \#1 in Figure 8. 




Figure 10. EDS Analysis of Spot \#2 in Figure 8.

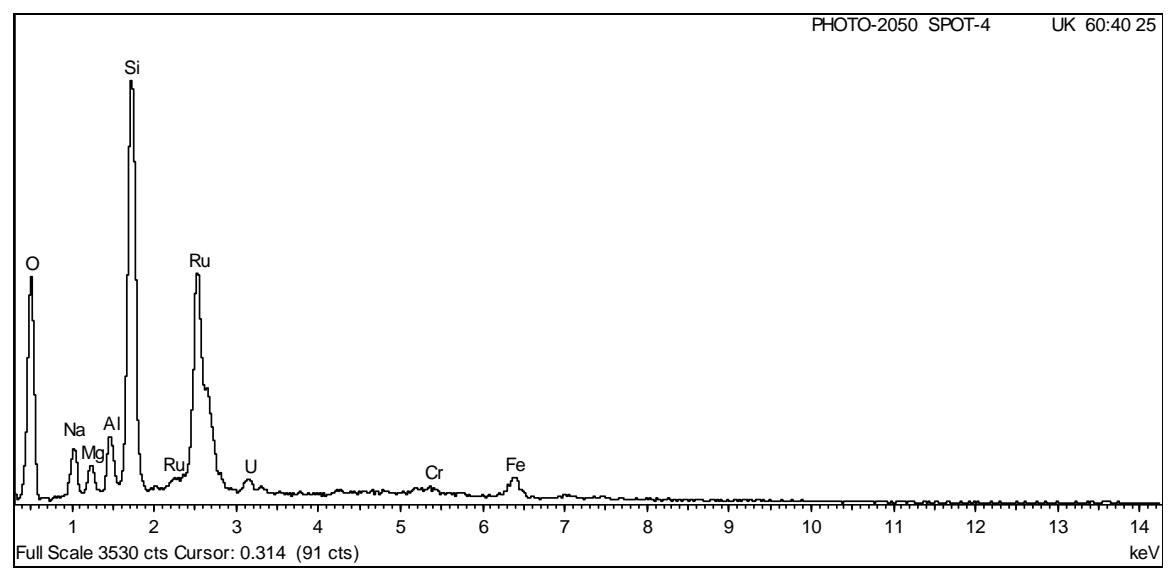

Figure 11. EDS Analysis of Spot \#4 in Figure 8.

Figure 12 shows a SEM micrograph of the UK-60:40-28 glass which shows a cluster of undissolved $\mathrm{RuO}_{2}$ on the right (see Figure 13 for EDS analysis of Spot \#3) and a cluster of Crrich crystals on the left (see Figure 14 for EDS analysis of Spot \#1). Combining the XRD and SEM/EDS results for the UK-60:40 series of glasses suggests that the volume percent of spinels at the lower WLs is below the XRD detection limit and increases as WL increases. The trend of higher WLs increasing the propensity for spinel formation is consistent with DWPF-type glasses, especially those that have undergone slow cooling to simulate the cooling profile along the centerline of the canister into which the glass is poured.

Appendix B provides additional SEM and EDS analyses of the UK glass series. The information from these analyses is consistent with the visual and XRD analyses (more specifically the presence of undissolved $\mathrm{RuO}_{2}$ and spinels). 


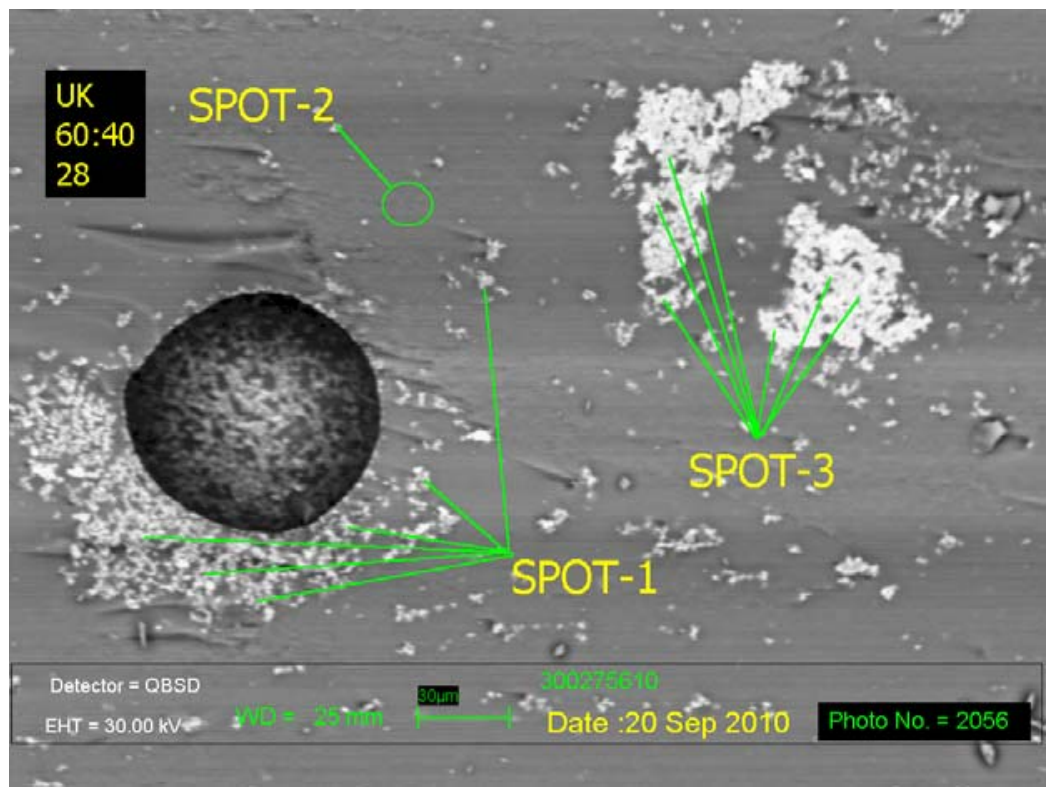

Figure 12. SEM Micrograph of the UK-60:40-28 Glass.



Figure 13. EDS Analysis of Spot \#3 in Figure 12.

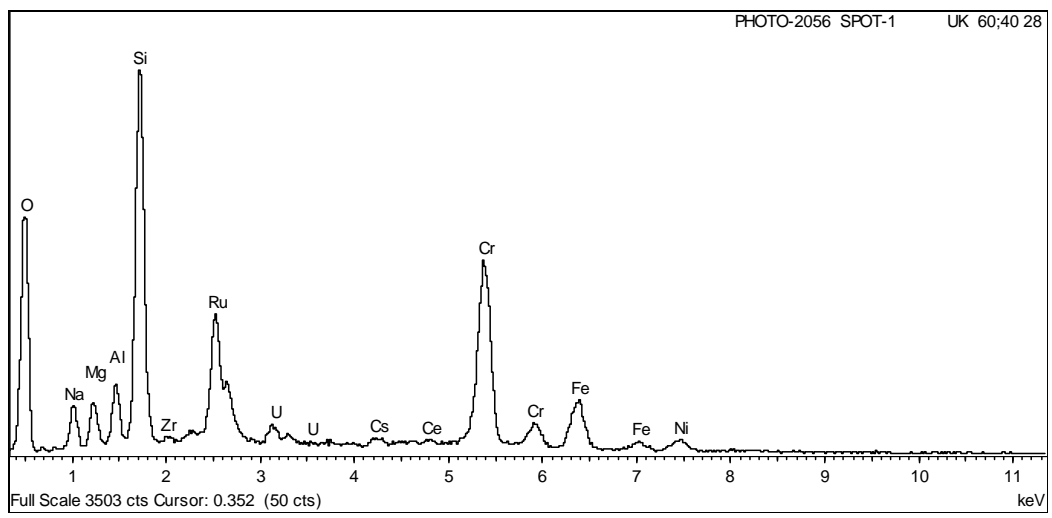

Figure 14. EDS Analysis of Spot \#1 in Figure 12. 


\section{PCT Results}

Table $\mathrm{C} 1$ in Appendix C provides the PCT elemental leachate concentration measurements (ppm values) determined by $\mathrm{AD}$ for each of the duplicate solution samples. The data in Table $\mathrm{C} 1$ show the reproducibility of the duplicate measurements for each of the UK glasses as a function of time. Table $\mathrm{C} 2$ in Appendix $\mathrm{C}$ provides the same information but the ppm values of the EA glass (and other reference glasses) have been removed to expand the y-axis (elemental ppm values) for a more detailed assessment. The ppm values were adjusted for sample dilution factors (e.g., dilution by adding $4 \mathrm{~mL}$ of $0.4 \mathrm{M} \mathrm{HNO}_{3}$ to $6 \mathrm{~mL}$ of the leachate (a $6: 10$ volume to volume, v: $\mathrm{v}$, dilution) before being submitted to $\mathrm{AD}$ ). More specifically, the values for the study glasses, the blanks, and the ARM glass were multiplied by 1.6667 to determine the values in parts per million (ppm) and the values for EA were multiplied by 16.6667 .

One of the quality control checkpoints for the PCT procedure is solution weight-loss over the course of the test. Based on a comparison of the weights before and after the tests, there were no issues with solution weight-loss - all test vessels met the acceptance criterion. In addition, the ppm results for the multi-element solution standard and ARM results (for the 7-day test) indicate the test was performed under control and there were consistent and accurate ICP-AES measurements throughout the leachate analysis process.

PCT leachate concentrations were normalized using cation concentrations in the glass. The normalization of the PCTs is typically conducted using the measured compositions of the glasses. This is the preferred normalization process for the PCTs. For completeness, the targeted cation compositions were also used to normalize the PCT responses.

As is the usual convention, the common logarithm of the normalized PCT (normalized leachate, NL) for each element of interest was determined and used for comparison. To accomplish this computation, one must

1.Determine the common logarithm of the elemental parts per million (ppm) leachate concentration for each of the duplicates and each of the elements of interest,

2.Average the common logarithms over the duplicates for each element of interest, and then

Normalizing Using Measured Composition (preferred method)

3. Subtract a quantity equal to 1 plus the common logarithm of the average cation measured concentration (expressed as a weight percent of the glass) from the average computed in step 2.

Or Normalizing Using Target Composition

3. Subtract a quantity equal to 1 plus the common logarithm of the target cation concentration (expressed as a weight percent of the glass) from the average computed in step 2 .

Table 10 and Table 11 summarize the normalized PCTs (based on target and measured compositions, respectively) for the UK study glasses. The discussion below uses normalized boron release values (NL [B]) as the metric to compare the durability responses of the UK glasses. Numerous specific comparisons can be made based on the measured PCT data but in this report general comparisons are made to provide insight into the following: 
$>$ durability of the UK glasses as compared to US HLW glasses as defined by the 7-day PCT results,

$>$ durability as a function of time within a specific Magnox:Butex waste blend ratio,

$>$ durability as a function of Magnox:Butex waste blend ratios (as a function of time or at a fixed time), and

$>$ durability as a function of WL within a specific Magnox:Butex blend ratio.

With respect to the durability of the UK glasses as compared to typical DWPF HLW glasses, it must be recognized that the metric for acceptability for the US HLW glasses is based on a comparison to the EA glass [Jantzen et al. (1993)] after a 7-day PCT (Method A). More specifically, the DWPF criterion for product acceptability (durability) is that the normalized B, $\mathrm{Li}$, and $\mathrm{Na}$ values must be at least 2 sigma better than the corresponding elemental release values from EA glass after being subjected to the 7-day PCT (Method A). The NL [B] for EA is 16.695 $\mathrm{g} / \mathrm{L}$ [Jantzen et al. (1993)]. To provide some additional perspective, glass samples from the DWPF radioactive melter have been characterized representing each sludge batch (or waste type) processed. The NL [B] values (as measured by the PCT 7-day test) for these samples were on the order of $0.5-1.5 \mathrm{~g} / \mathrm{L}$. These results suggest that the durability of the glasses being processed through the DWPF melter are an order of magnitude better than that of the EA benchmark glass. Although use of the EA glass benchmark for acceptability may be inappropriate as a metric to assess the acceptability of the UK glasses, it is all the authors have to provide some general feedback on the measured durability data. In addition, the vast majority of the DWPF data which could be used to compare to the UK glass responses are based on the 7-day test duration (PCT Method A) which limits any detailed discussion of the acceptability of the UK glasses for the longer test periods (i.e., 14, 21, and 28 days). That is, although these data can be reported and general comments made, there is no metric from which to make decisions regarding acceptability statements for the longer duration tests. With that being said, the following discussion will be based on general trends in the data and when possible comparisons to typical DWPF HLW glasses and/or the EA benchmark glass will be made (although the latter may not be applicable to disposal of HLW glasses in the UK).

A review of the 7-day NL [B] data in Table 10 and Table 11 indicates that the NL [B] values range from approximately $0.72 \mathrm{~g} / \mathrm{L}$ (for UK-50:50-32 based on the target composition) to approximately $3.7 \mathrm{~g} / \mathrm{L}$ (for UK-75:25-25 based on the measured composition). Based on the US Department of Energy (DOE) HLW metric (i.e., EA glass), these glasses would be defined as acceptable. Prior to evaluating the longer time period $(14,21$, and 28 day) results, a few more general comments about the 7-day responses are warranted. Consider the UK-50:50 series of glasses (i.e., 25, 28, and 32\% WL series). As WL increases for this series, the durability (as defined by the 7-day response) increases or the NL [B] values decrease. The trend of increasing durability with increasing WL is consistent for all three Magnox:Butex blend ratios. When evaluating the impact of the Magnox:Butex ratio on durability, the 7-day PCT results suggest that as the Magnox:Butex ratio increases $(50: 50$ to $75: 25)$ the durability of the glasses decreases at a fixed WL. For example, consider the 7-day PCT responses for UK-50:50-25, UK-60:40-25, and UK-75:25-25. The NL [B] values (based on target compositions) for these glasses are $1.294 \mathrm{~g} / \mathrm{L}$, $1.552 \mathrm{~g} / \mathrm{L}$, and $3.546 \mathrm{~g} / \mathrm{L}$, respectively. Therefore, the 7-day PCT results suggest that durability of the UK glasses increases with a lower Magnox:Butex blend ratio and higher WL. 
Table 10. Normalized (based on target compositions) PCT Responses for 7, 14, 21, and 28 Day Durations

\begin{tabular}{|c|c|c|c|c|c|c|c|c|c|c|c|}
\hline $\begin{array}{c}\text { Duration } \\
\text { Days }\end{array}$ & Glass ID & $\begin{array}{c}\text { Comp } \\
\text { View }\end{array}$ & $\begin{array}{c}\mathrm{NL} \\
\mathrm{Al}(\mathrm{g} / \mathrm{L})\end{array}$ & $\begin{array}{c}\mathrm{NL} \\
\mathrm{B}(\mathrm{g} / \mathrm{L})\end{array}$ & $\begin{array}{c}\mathrm{NL} \\
\mathrm{Fe}(\mathrm{g} / \mathrm{L})\end{array}$ & $\begin{array}{c}\mathrm{NL} \\
\mathrm{Li}(\mathrm{g} / \mathrm{L})\end{array}$ & $\begin{array}{c}\mathrm{NL} \\
\operatorname{Mg}(\mathrm{g} / \mathrm{L})\end{array}$ & $\begin{array}{c}\text { NL } \\
\text { Mo }(g / L)\end{array}$ & $\begin{array}{c}\text { NL } \\
\mathrm{Na}(\mathrm{g} / \mathrm{L})\end{array}$ & $\begin{array}{c}\text { NL } \\
\text { Si (g/L) }\end{array}$ & $\begin{array}{c}\text { NL } \\
\mathrm{U}(\mathrm{g} / \mathrm{L})\end{array}$ \\
\hline \multicolumn{12}{|c|}{ Reference Glasses (Normalized based on Reference Compositions) } \\
\hline 7 & ARM & ref & 0.176 & 0.574 & & 0.644 & & & 0.576 & 0.317 & \\
\hline 7 & EA & ref & 0.080 & 17.932 & 0.003 & 9.545 & 0.166 & 0.117 & 13.771 & 4.212 & . \\
\hline 14 & ARM & ref & 0.186 & 0.725 & & 0.800 & & & 0.702 & 0.369 & $\cdot$ \\
\hline 14 & EA & ref & 0.080 & 19.851 & 0.004 & 9.348 & 0.166 & 0.117 & 15.511 & 4.475 & . \\
\hline 21 & ARM & ref & 0.199 & 0.636 & & 0.765 & & & 0.654 & 0.355 & . \\
\hline 21 & EA & ref & 0.080 & 11.616 & 0.004 & 6.372 & 0.004 & 0.117 & 9.595 & 3.251 &. \\
\hline 28 & ARM & ref & 0.208 & 0.644 & & 0.793 & . & & 0.669 & 0.363 & . \\
\hline 28 & EA & ref & 0.080 & 6.876 & 0.004 & 2.947 & 0.004 & 0.117 & 5.544 & 1.519 &. \\
\hline \multicolumn{12}{|c|}{ Normalized Based on Target Compositions } \\
\hline 7 & $50-50-25$ & targeted & 0.156 & 1.294 & 0.018 & 1.272 & 0.035 & 0.580 & 0.929 & 0.326 & 0.079 \\
\hline 7 & $50-50-28$ & targeted & 0.173 & 0.926 & 0.012 & 0.974 & 0.020 & 0.548 & 0.667 & 0.304 & 0.059 \\
\hline 7 & $50-50-32$ & targeted & 0.183 & 0.722 & 0.004 & 0.814 & 0.006 & 0.566 & 0.527 & 0.293 & 0.048 \\
\hline 7 & $60-40-25$ & targeted & 0.128 & 1.552 & 0.014 & 1.478 & 0.027 & 0.693 & 1.121 & 0.341 & 0.112 \\
\hline 7 & $60-40-28$ & targeted & 0.140 & 1.053 & 0.006 & 1.063 & 0.006 & 0.604 & 0.779 & 0.308 & 0.085 \\
\hline 7 & $60-40-32$ & targeted & 0.159 & 0.774 & 0.003 & 0.837 & 0.006 & 0.597 & 0.590 & 0.288 & 0.072 \\
\hline 7 & $75-25-25$ & targeted & 0.068 & 3.546 & 0.009 & 3.126 & 0.027 & 2.408 & 2.421 & 0.498 & 0.123 \\
\hline 7 & $75-25-28$ & targeted & 0.112 & 1.325 & 0.007 & 1.263 & 0.008 & 0.728 & 1.002 & 0.316 & 0.120 \\
\hline 7 & $75-25-32$ & targeted & 0.127 & 0.927 & 0.003 & 0.938 & 0.005 & 0.682 & 0.738 & 0.291 & 0.090 \\
\hline 14 & $50-50-25$ & targeted & 0.112 & 2.744 & 0.018 & 2.490 & 0.033 & 0.915 & 1.773 & 0.391 & 0.074 \\
\hline 14 & $50-50-28$ & targeted & 0.145 & 1.657 & 0.012 & 1.611 & 0.020 & 0.749 & 1.093 & 0.350 & 0.060 \\
\hline 14 & $50-50-32$ & targeted & 0.185 & 1.018 & 0.008 & 1.096 & 0.013 & 0.682 & 0.689 & 0.327 & 0.045 \\
\hline 14 & $60-40-25$ & targeted & 0.091 & 3.227 & 0.014 & 2.871 & 0.022 & 1.169 & 2.105 & 0.409 & 0.093 \\
\hline 14 & $60-40-28$ & targeted & 0.116 & 1.881 & 0.008 & 1.788 & 0.010 & 0.842 & 1.275 & 0.355 & 0.075 \\
\hline 14 & $60-40-32$ & targeted & 0.153 & 1.159 & 0.005 & 1.190 & 0.008 & 0.750 & 0.812 & 0.327 & 0.060 \\
\hline 14 & $75-25-25$ & targeted & 0.081 & 6.180 & 0.014 & 5.260 & 0.061 & 3.805 & 3.934 & 0.550 & 0.126 \\
\hline 14 & $75-25-28$ & targeted & 0.085 & 2.384 & 0.005 & 2.162 & 0.006 & 1.052 & 1.659 & 0.363 & 0.142 \\
\hline
\end{tabular}




\begin{tabular}{||c|c|c|c|c|c|c|c|c|c|c|c||}
\hline $\begin{array}{c}\text { Duration } \\
\text { Days }\end{array}$ & Glass ID & $\begin{array}{c}\text { Comp } \\
\text { View }\end{array}$ & $\begin{array}{c}\mathbf{N L} \\
\mathbf{A l}(\mathbf{g} / \mathbf{L})\end{array}$ & $\begin{array}{c}\mathbf{N L} \\
\mathbf{B}(\mathbf{g} / \mathbf{L})\end{array}$ & $\begin{array}{c}\mathbf{N L} \\
\mathbf{F e}(\mathbf{g} / \mathbf{L})\end{array}$ & $\begin{array}{c}\mathbf{N L} \\
\mathbf{L i}(\mathbf{g} / \mathbf{L})\end{array}$ & $\begin{array}{c}\mathbf{N L} \\
\mathbf{M g} \mathbf{( g / L} \mathbf{L})\end{array}$ & $\begin{array}{c}\mathbf{N L} \\
\mathbf{M o}(\mathbf{g} / \mathbf{L})\end{array}$ & $\begin{array}{c}\mathbf{N L} \\
\mathbf{N a}(\mathbf{g} / \mathbf{L})\end{array}$ & $\begin{array}{c}\mathbf{N L} \\
\mathbf{S i} \mathbf{( g / L )}\end{array}$ & $\begin{array}{c}\mathbf{N L} \\
\mathbf{U}(\mathbf{g} / \mathbf{L})\end{array}$ \\
\hline 14 & $75-25-32$ & targeted & 0.110 & 1.428 & 0.002 & 1.372 & 0.005 & 0.882 & 1.053 & 0.329 & 0.113 \\
\hline 21 & $50-50-25$ & targeted & 0.090 & 3.992 & 0.020 & 3.496 & 0.046 & 1.252 & 2.418 & 0.418 & 0.059 \\
\hline 21 & $50-50-28$ & targeted & 0.108 & 2.500 & 0.012 & 2.290 & 0.023 & 0.997 & 1.533 & 0.371 & 0.043 \\
\hline 21 & $50-50-32$ & targeted & 0.155 & 1.408 & 0.008 & 1.433 & 0.015 & 0.823 & 0.884 & 0.344 & 0.028 \\
\hline 21 & $60-40-25$ & targeted & 0.065 & 4.940 & 0.009 & 4.215 & 0.020 & 1.883 & 3.040 & 0.464 & 0.068 \\
\hline 21 & $60-40-28$ & targeted & 0.085 & 3.089 & 0.008 & 2.762 & 0.016 & 1.228 & 1.933 & 0.381 & 0.039 \\
\hline 21 & $60-40-32$ & targeted & 0.123 & 1.626 & 0.006 & 1.586 & 0.009 & 0.934 & 1.062 & 0.340 & 0.033 \\
\hline 21 & $75-25-25$ & targeted & 0.071 & 7.404 & 0.004 & 6.149 & 0.015 & 4.371 & 4.598 & 0.550 & 0.136 \\
\hline 21 & $75-25-28$ & targeted & 0.069 & 3.679 & 0.005 & 3.177 & 0.007 & 1.557 & 2.412 & 0.396 & 0.087 \\
\hline 21 & $75-25-32$ & targeted & 0.084 & 2.195 & 0.002 & 1.997 & 0.003 & 1.193 & 1.496 & 0.347 & 0.055 \\
\hline 28 & $50-50-25$ & targeted & 0.086 & 4.712 & 0.022 & 4.081 & 0.040 & 1.421 & 2.878 & 0.437 & 0.067 \\
\hline 28 & $50-50-28$ & targeted & 0.102 & 2.956 & 0.016 & 2.676 & 0.031 & 1.121 & 1.815 & 0.388 & 0.052 \\
\hline 28 & $50-50-32$ & targeted & 0.160 & 1.493 & 0.014 & 1.532 & 0.026 & 0.854 & 0.954 & 0.359 & 0.040 \\
\hline 28 & $60-40-25$ & targeted & 0.067 & 5.300 & 0.012 & 4.556 & 0.026 & 2.041 & 3.339 & 0.477 & 0.066 \\
\hline 28 & $60-40-28$ & targeted & 0.079 & 3.388 & 0.008 & 3.001 & 0.014 & 1.311 & 2.129 & 0.386 & 0.037 \\
\hline 28 & $60-40-32$ & targeted & 0.119 & 1.801 & 0.007 & 1.750 & 0.014 & 0.996 & 1.183 & 0.354 & 0.047 \\
\hline 28 & $75-25-25$ & targeted & 0.074 & 7.684 & 0.005 & 6.419 & 0.021 & 4.447 & 4.856 & 0.549 & 0.126 \\
\hline 28 & $75-25-28$ & targeted & 0.066 & 3.866 & 0.005 & 3.383 & 0.005 & 1.652 & 2.582 & 0.405 & 0.042 \\
\hline 28 & $75-25-32$ & targeted & 0.080 & 2.323 & 0.002 & 2.116 & 0.002 & 1.248 & 1.595 & 0.355 & 0.037 \\
\hline
\end{tabular}


Table 11. Normalized (based on measured compositions) PCT Responses for 7, 14, 21, and 28 Day Durations

\begin{tabular}{|c|c|c|c|c|c|c|c|c|c|c|c|}
\hline $\begin{array}{c}\text { Duration } \\
\text { Days }\end{array}$ & Glass ID & $\begin{array}{l}\text { Comp } \\
\text { View }\end{array}$ & $\begin{array}{c}\mathrm{NL} \\
\mathrm{Al}(\mathrm{g} / \mathrm{L})\end{array}$ & $\begin{array}{c}\text { NL } \\
\text { B(g/L) }\end{array}$ & $\begin{array}{c}\mathrm{NL} \\
\mathrm{Fe}(\mathrm{g} / \mathrm{L})\end{array}$ & $\begin{array}{c}\mathrm{NL} \\
\mathrm{Li}(\mathrm{g} / \mathrm{L})\end{array}$ & $\begin{array}{c}\mathrm{NL} \\
\mathrm{Mg}(\mathrm{g} / \mathrm{L})\end{array}$ & $\begin{array}{c}\text { NL } \\
\text { Mo }(g / L)\end{array}$ & $\begin{array}{c}\mathrm{NL} \\
\mathrm{Na}(\mathrm{g} / \mathrm{L})\end{array}$ & $\begin{array}{c}\mathrm{NL} \\
\mathrm{Si}(\mathrm{g} / \mathrm{L})\end{array}$ & $\begin{array}{c}\mathrm{NL} \\
\mathrm{U}(\mathrm{g} / \mathrm{L})\end{array}$ \\
\hline \multicolumn{12}{|c|}{ Reference Glasses (Normalized based on Reference Compositions) } \\
\hline 7 & ARM & ref & 0.176 & 0.574 & & 0.644 & & & 0.576 & 0.317 & \\
\hline 7 & EA & ref & 0.080 & 17.932 & 0.003 & 9.545 & 0.166 & 0.117 & 13.771 & 4.212 & . \\
\hline 14 & ARM & ref & 0.186 & 0.725 & & 0.800 & & & 0.702 & 0.369 & . \\
\hline 14 & EA & ref & 0.080 & 19.851 & 0.004 & 9.348 & 0.166 & 0.117 & 15.511 & 4.475 & 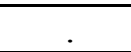 \\
\hline 21 & ARM & ref & 0.199 & 0.636 & & 0.765 & & & 0.654 & 0.355 & - \\
\hline 21 & EA & ref & 0.080 & 11.616 & 0.004 & 6.372 & 0.004 & 0.117 & 9.595 & 3.251 & . \\
\hline 28 & ARM & ref & 0.208 & 0.644 & & 0.793 & & & 0.669 & 0.363 & . \\
\hline 28 & EA & ref & 0.080 & 6.876 & 0.004 & 2.947 & 0.004 & 0.117 & 5.544 & 1.519 &  \\
\hline \multicolumn{12}{|c|}{ Normalized Based on Measured Compositions } \\
\hline 7 & $50-50-25$ & measured & 0.147 & 1.332 & 0.018 & 1.312 & 0.035 & 0.615 & 1.012 & 0.303 & 0.086 \\
\hline 7 & $50-50-28$ & measured & 0.165 & 0.955 & 0.012 & 1.008 & 0.020 & 0.521 & 0.648 & 0.282 & 0.059 \\
\hline 7 & $50-50-32$ & measured & 0.172 & 0.735 & 0.004 & 0.843 & 0.006 & 0.572 & 0.570 & 0.269 & 0.051 \\
\hline 7 & $60-40-25$ & measured & 0.121 & 1.579 & 0.013 & 1.541 & 0.027 & 0.693 & 1.140 & 0.317 & 0.115 \\
\hline 7 & $60-40-28$ & measured & 0.132 & 1.068 & 0.005 & 1.095 & 0.006 & 0.626 & 0.816 & 0.283 & 0.090 \\
\hline 7 & $60-40-32$ & measured & 0.151 & 0.787 & 0.003 & 0.868 & 0.005 & 0.507 & 0.504 & 0.265 & 0.062 \\
\hline 7 & $75-25-25$ & measured & 0.057 & 3.712 & 0.008 & 3.374 & 0.024 & 2.278 & 2.309 & 0.475 & 0.119 \\
\hline 7 & $75-25-28$ & measured & 0.119 & 1.286 & 0.007 & 1.265 & 0.009 & 0.750 & 1.034 & 0.281 & 0.126 \\
\hline 7 & $75-25-32$ & measured & 0.121 & 0.939 & 0.003 & 0.973 & 0.005 & 0.626 & 0.680 & 0.270 & 0.084 \\
\hline 14 & $50-50-25$ & measured & 0.106 & 2.823 & 0.017 & 2.568 & 0.033 & 0.971 & 1.933 & 0.363 & 0.081 \\
\hline 14 & $50-50-28$ & measured & 0.139 & 1.709 & 0.012 & 1.668 & 0.020 & 0.712 & 1.062 & 0.324 & 0.060 \\
\hline 14 & $50-50-32$ & measured & 0.174 & 1.037 & 0.008 & 1.136 & 0.013 & 0.690 & 0.745 & 0.301 & 0.047 \\
\hline 14 & $60-40-25$ & measured & 0.086 & 3.282 & 0.013 & 2.993 & 0.022 & 1.167 & 2.140 & 0.379 & 0.095 \\
\hline 14 & $60-40-28$ & measured & 0.109 & 1.909 & 0.008 & 1.842 & 0.010 & 0.873 & 1.335 & 0.326 & 0.079 \\
\hline 14 & $60-40-32$ & measured & 0.145 & 1.178 & 0.005 & 1.234 & 0.008 & 0.636 & 0.693 & 0.300 & 0.052 \\
\hline 14 & $75-25-25$ & measured & 0.068 & 6.469 & 0.012 & 5.678 & 0.054 & 3.599 & 3.753 & 0.524 & 0.122 \\
\hline 14 & $75-25-28$ & measured & 0.090 & 2.315 & 0.006 & 2.164 & 0.006 & 1.083 & 1.713 & 0.323 & 0.149 \\
\hline
\end{tabular}




\begin{tabular}{||c|c|c|c|c|c|c|c|c|c|c|c||}
\hline $\begin{array}{c}\text { Duration } \\
\text { Days }\end{array}$ & Glass ID & $\begin{array}{c}\text { Comp } \\
\text { View }\end{array}$ & $\begin{array}{c}\mathbf{N L} \\
\mathbf{A l}(\mathbf{g} / \mathbf{L})\end{array}$ & $\begin{array}{c}\mathbf{N L} \\
\mathbf{B}(\mathbf{g} / \mathbf{L})\end{array}$ & $\begin{array}{c}\mathbf{N L} \\
\mathbf{F e}(\mathbf{g} / \mathbf{L})\end{array}$ & $\begin{array}{c}\mathbf{N L} \\
\mathbf{L i}(\mathbf{g} / \mathbf{L})\end{array}$ & $\begin{array}{c}\mathbf{N L} \\
\mathbf{M g} \mathbf{( g / L})\end{array}$ & $\begin{array}{c}\mathbf{N L} \\
\mathbf{M o}(\mathbf{g} / \mathbf{L})\end{array}$ & $\begin{array}{c}\mathbf{N L} \\
\mathbf{N a}(\mathbf{g} / \mathbf{L})\end{array}$ & $\begin{array}{c}\mathbf{N L} \\
\mathbf{S i} \mathbf{( g / L )}\end{array}$ & $\begin{array}{c}\mathbf{N L} \\
\mathbf{U}(\mathbf{g} / \mathbf{L})\end{array}$ \\
\hline 14 & $75-25-32$ & measured & 0.105 & 1.448 & 0.002 & 1.424 & 0.005 & 0.810 & 0.971 & 0.306 & 0.106 \\
\hline 21 & $50-50-25$ & measured & 0.085 & 4.107 & 0.019 & 3.607 & 0.046 & 1.328 & 2.636 & 0.388 & 0.064 \\
\hline 21 & $50-50-28$ & measured & 0.103 & 2.578 & 0.011 & 2.371 & 0.023 & 0.947 & 1.488 & 0.343 & 0.044 \\
\hline 21 & $50-50-32$ & measured & 0.146 & 1.434 & 0.008 & 1.486 & 0.015 & 0.832 & 0.955 & 0.316 & 0.029 \\
\hline 21 & $60-40-25$ & measured & 0.061 & 5.024 & 0.009 & 4.394 & 0.020 & 1.881 & 3.091 & 0.430 & 0.070 \\
\hline 21 & $60-40-28$ & measured & 0.080 & 3.134 & 0.008 & 2.845 & 0.016 & 1.272 & 2.023 & 0.350 & 0.042 \\
\hline 21 & $60-40-32$ & measured & 0.116 & 1.653 & 0.006 & 1.645 & 0.009 & 0.792 & 0.906 & 0.313 & 0.028 \\
\hline 21 & $75-25-25$ & measured & 0.060 & 7.751 & 0.003 & 6.637 & 0.013 & 4.134 & 4.387 & 0.524 & 0.132 \\
\hline 21 & $75-25-28$ & measured & 0.072 & 3.571 & 0.005 & 3.181 & 0.007 & 1.604 & 2.490 & 0.353 & 0.091 \\
\hline 21 & $75-25-32$ & measured & 0.081 & 2.224 & 0.002 & 2.072 & 0.003 & 1.096 & 1.380 & 0.322 & 0.051 \\
\hline 28 & $50-50-25$ & measured & 0.081 & 4.848 & 0.021 & 4.209 & 0.040 & 1.507 & 3.138 & 0.405 & 0.073 \\
\hline 28 & $50-50-28$ & measured & 0.098 & 3.049 & 0.015 & 2.771 & 0.031 & 1.065 & 1.762 & 0.359 & 0.053 \\
\hline 28 & $50-50-32$ & measured & 0.151 & 1.521 & 0.013 & 1.588 & 0.026 & 0.864 & 1.031 & 0.330 & 0.042 \\
\hline 28 & $60-40-25$ & measured & 0.063 & 5.390 & 0.011 & 4.750 & 0.025 & 2.038 & 3.395 & 0.442 & 0.068 \\
\hline 28 & $60-40-28$ & measured & 0.074 & 3.437 & 0.007 & 3.091 & 0.014 & 1.358 & 2.229 & 0.354 & 0.040 \\
\hline 28 & $60-40-32$ & measured & 0.113 & 1.832 & 0.007 & 1.815 & 0.013 & 0.845 & 1.010 & 0.325 & 0.041 \\
\hline 28 & $75-25-25$ & measured & 0.063 & 8.043 & 0.004 & 6.929 & 0.018 & 4.206 & 4.633 & 0.523 & 0.122 \\
\hline 28 & $75-25-28$ & measured & 0.070 & 3.753 & 0.005 & 3.387 & 0.005 & 1.702 & 2.665 & 0.360 & 0.044 \\
\hline 28 & $75-25-32$ & measured & 0.077 & 2.354 & 0.002 & 2.195 & 0.002 & 1.147 & 1.471 & 0.329 & 0.034 \\
\hline
\end{tabular}


Figure 15 shows the log NL [B] release values as a function of time (7 to 28 days) for each of the UK glasses. The results suggest that the corrosion rate slows over the 28-day test period (indicative of the plateau or leveling out of the NL [B] values) indicative of solution saturation. That is, the difference in the NL [B] values between sequential test durations becomes smaller with increased time for all UK glasses (note the NL [B] values shown in Figure 15 are on a log basis). This type of dissolution behavior is consistent with other HLW glasses which generally show dissolution rates increasing while the solution is undersaturated. The dissolution rate typically slows as the solution becomes saturated. If precipitation of secondary phases occurs due to solution saturation, then the corrosion rates can return to the forward rate of reaction.

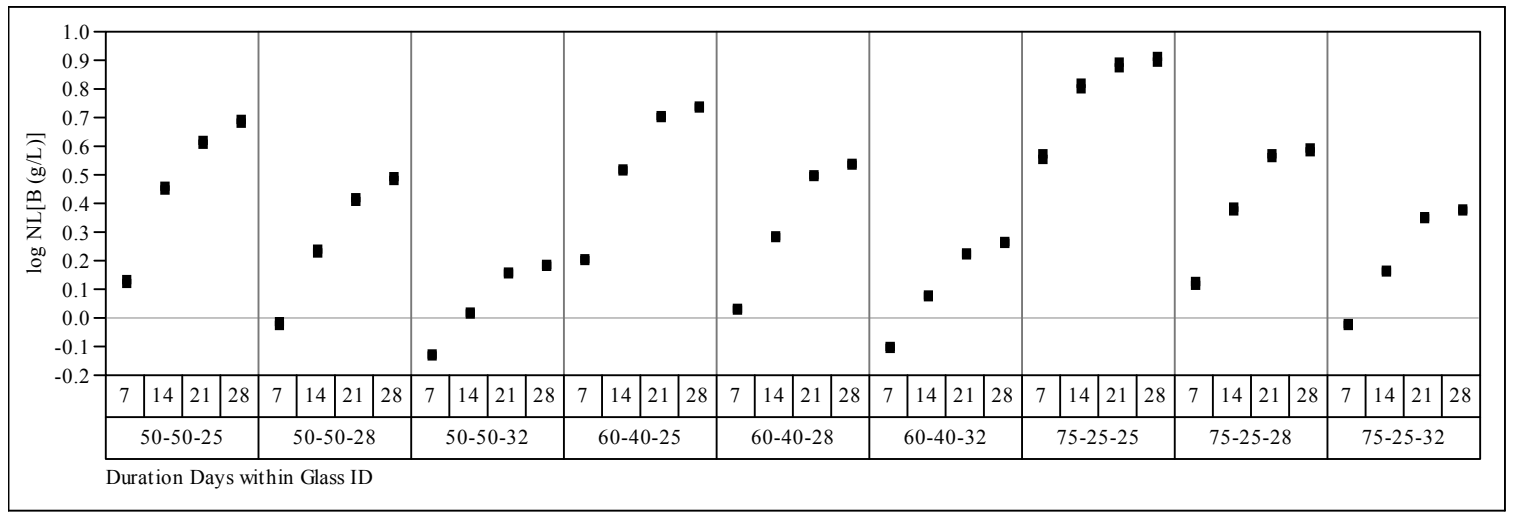

Figure 15. $\log$ NL [B] (g/L) Values as a Function of Time for Each Magnox:Butex Blend Ratio.

Table C3 in Appendix C contains similar views of the normalized elemental responses (for the major elements) as a function of time for each Magnox:Butex blend ratio. A review of these data indicates that the elemental releases for $\mathrm{Li}, \mathrm{Mo}, \mathrm{Na}$, and $\mathrm{Si}$ show similar behavior as that for $\mathrm{B}$. Of particular interest is the release of other key (major) elements ( $\mathrm{Al}, \mathrm{Fe}, \mathrm{Mg}$, and $\mathrm{U}$ ) as a function of time for these same glasses. Figure 16 summarizes the general trends on the Al release values for each Magnox:Butex blend ratio as a function of time. In general, the release of Al shows an opposite trend to that of B (as shown in Figure 15). Although a formal analysis of these results was not performed, these results may be an indication of the precipitation of $\mathrm{Al}(\mathrm{OH})_{3}$ due to complex solution reactions $\left(\mathrm{Al}(\mathrm{OH})_{3}\right.$ (ppt) versus $\mathrm{Al}(\mathrm{OH})_{4}$ (aqueous)) which are also influenced by solution $\mathrm{pH}$. Similar precipitation reactions could also explain the elemental releases for $\mathrm{Fe}, \mathrm{Mg}$, and $\mathrm{U}$. 


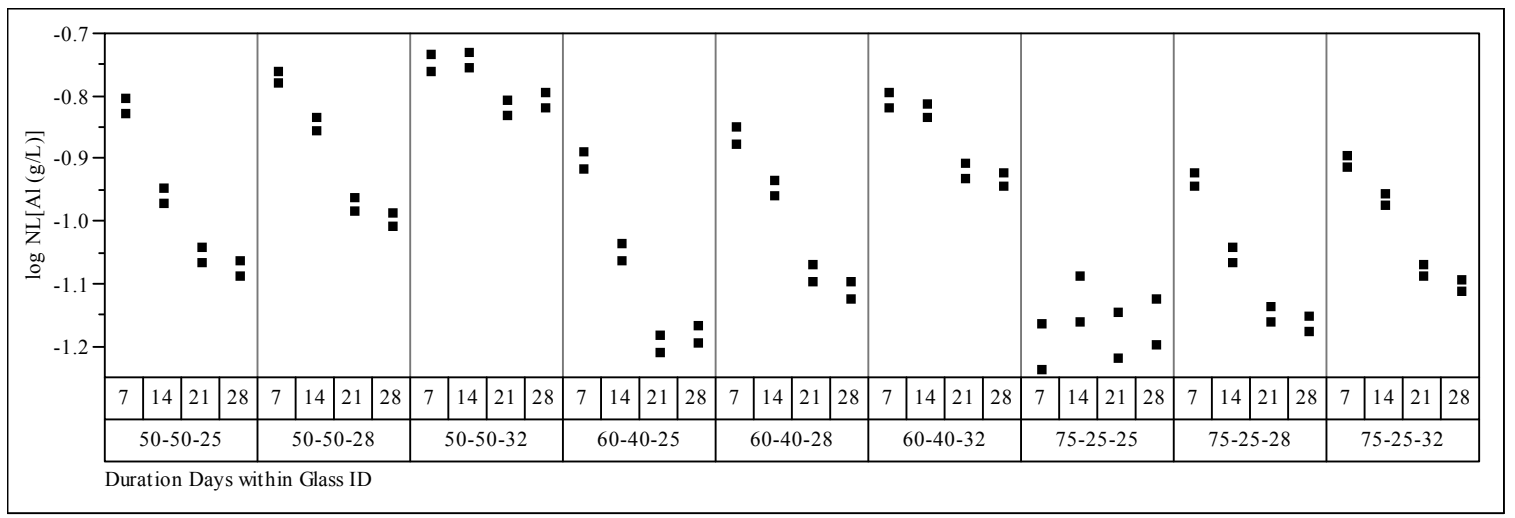

Figure 16. $\log \mathrm{NL}[\mathrm{Al}](\mathrm{g} / \mathrm{L})$ Values as a Function of Time for Each Magnox:Butex Blend Ratio.

\section{Viscosity Results}

High temperature viscosity data as a function of temperature were measured for five of the nine UK glasses. Appendix D provides all of the raw (temperature versus viscosity) data for these five glasses. The measured viscosity at $1150^{\circ} \mathrm{C}$ was determined by fitting the raw data for each glass to the Fulcher equation [Fulcher (1925)]. The results of the Fulcher fits were then used to calculate a measured viscosity value for each glass at $1150{ }^{\circ} \mathrm{C}$ and $1050^{\circ} \mathrm{C}$. These calculated values are given in Table 12.

Table 12. Calculated Viscosities at $1150^{\circ} \mathrm{C}$ and $1050^{\circ} \mathrm{C}$ for Select UK Glasses Based on Fulcher Fits.

\begin{tabular}{||c|c|c||}
\hline \hline Glass ID & $\begin{array}{c}\text { Viscosity (Poise) } \\
\left.\text { from Fit (1150 }{ }^{\circ} \mathbf{C}\right)\end{array}$ & $\begin{array}{c}\text { Viscosity (Poise) } \\
\text { from Fit (1050 }\end{array}$ C) \\
\hline UK 50-50-25 & 54.7 & 142.5 \\
\hline UK 50-50-28 & 52.5 & 139.3 \\
\hline UK 50-50-32 & 58.4 & 157.0 \\
\hline UK 60-40-28 & 50.3 & 132.1 \\
\hline UK 75-25-28 & 48.7 & 127.5 \\
\hline
\end{tabular}

Based on the series of glasses targeting 28\% WL (UK-50:50-28, UK-60:40-28, and UK-75:2528 ), the general trend in viscosity suggests that as the Magnox:Butex blend ratio increases the viscosity decreases. More specifically, the viscosity $\left(\right.$ at $\left.1150^{\circ} \mathrm{C}\right)$ of the UK-50:50-28, UK-60:4028, and UK-75:25-28 glasses drops from 52.5 to 50.3 to 48.7 Poise, respectively. Although these data suggest that there is a slight shift in the viscosity with the Magnox:Butex blend ratio, the shift should have no practical impact on melter processing. With respect to the potential impacts of $\mathrm{Al}_{2} \mathrm{O}_{3}$ content on the resulting viscosities (a concern mentioned in the WFO), there appears to be very little practical impact. The $\mathrm{Al}_{2} \mathrm{O}_{3}$ concentrations for these three glasses range from 6.2 $\mathrm{wt} \%$ (in UK-75:25-28) to 7.1 wt\% (in UK-50:50-28) with very little change (on the order of 4 to 5 Poise) in the $1150^{\circ} \mathrm{C}$ measured viscosities. It should be noted the impact of an increasing $\mathrm{Al}_{2} \mathrm{O}_{3}$ 
content on viscosity may be countered by a decreasing $\mathrm{SiO}_{2}$ content. Therefore a direct relationship between the impact of $\mathrm{Al}_{2} \mathrm{O}_{3}$ content and viscosity may not be feasible due to confounded compositional effects.

The viscosity data for the UK-50:50 waste loading series is also of interest. The predicted $1150^{\circ} \mathrm{C}$ viscosities are $54.7,52.5$, and 58.4 Poise as WL increases from 25 to $32 \%$. These data suggest a non-linear behavior in viscosity with WL which is inconsistent with the general trends that SRNL typically observes with DWPF type glasses. For example, Peeler et al. (2004) assessed the impact of WL (ranging from $30 \%$ to $45 \%$ ) on the viscosity within the Frit 418 Sludge Batch 3 (SB3) system. The results of that study (see Figure 17) indicated that as WL increased, the viscosity of the glass system decreased at a fixed temperature. Table 13 provides the calculated viscosities at $1150^{\circ} \mathrm{C}$ based on data fit to the Fulcher equation. The results indicate a gradual decrease in viscosity as WL increases - which is consistent with most of the DWPFtype glass systems processed. It is noted that the impact of transitioning from $30 \% \mathrm{WL}$ to $37 \%$ WL (a 7 point WL interval) translates into about a 10 Poise reduction in viscosity. Again, although a measurable impact, the difference is of very little, if any, practical concern.

Table 13. Predicted Viscosity at $1150^{\circ} \mathrm{C}$ for the Frit 418 - SB3 System as a Function of WL.

\begin{tabular}{||c|c|c||}
\hline Glass & WL (\%) & $\eta_{1150}(\mathrm{P})$ \\
\hline VIS-01 & 30 & 42.33 \\
\hline VIS-02 & 33 & 39.11 \\
\hline VIS-03 & 35 & 36.54 \\
\hline VIS-04 & 37 & 32.66 \\
\hline VIS-05 & 40 & 31.27 \\
\hline VIS-06 & 45 & 24.77 \\
\hline
\end{tabular}


SRNL-STI-2011-00012

Revision 0

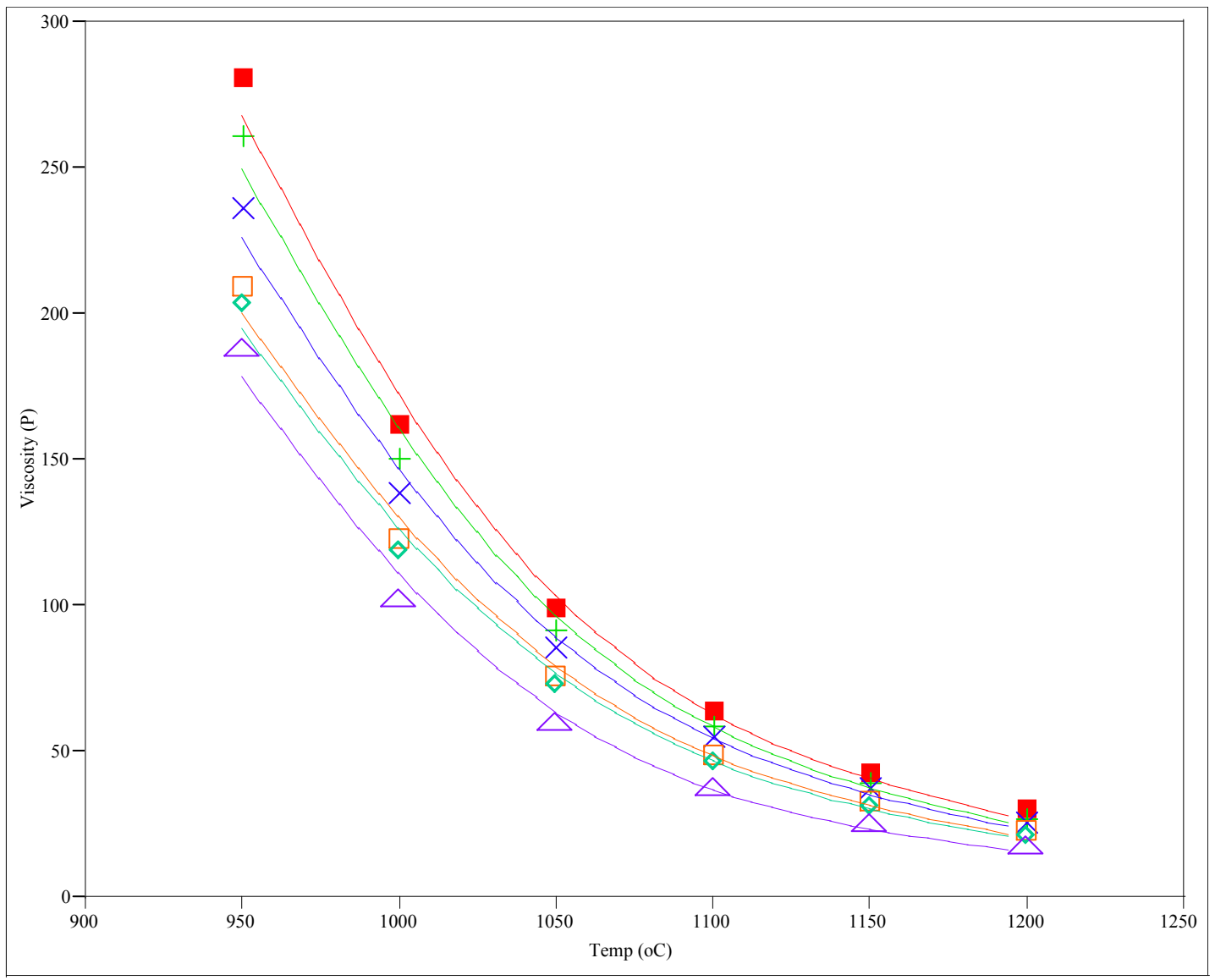

Smoothing Spline Fit, lambda $=100000 \mathrm{WL}==30$

Smoothing Spline Fit, lambda $=100000 \mathrm{WL}==33$

Smoothing Spline Fit, lambda $=100000 \mathrm{WL}==35$

Smoothing Spline Fit, lambda $=100000 \mathrm{WL}==37$

Smoothing Spline Fit, lambda $=100000 \mathrm{WL}==40$

Smoothing Spline Fit, lambda $=100000 \mathrm{WL}==45$

Figure 17. Viscosity as a Function of Temperature and WL for the Frit 418 - SB3 System. 


\section{Corrosion}

Photo micrographs of the as-polished coupons are shown in Figure 18 and Figures 19(a), 20(a), and 21(a). Final thicknesses and the depth of internal attack are summarized in Table 14. The initial thickness of the as-received material was $5.029 \mathrm{~mm}(0.198 \mathrm{in})$. With the exception of the UK-50:50-32 sample (Figure 19a), all coupons exhibited similar total material thickness loss, which ranged from 0.139 to $0.189 \mathrm{~mm}(0.005$ to $0.007 \mathrm{in})$. The surface morphology and internal depths of attack are shown in Figures 19(b) through 21(b). Depths of internal attack are summarized in Table 14. Generally, all coupon surfaces were planar although several exhibited some degree of non-uniform corrosion, broad pitting. The UK-50:50-32, UK-60:40-32, and UK75:25-32 coupons contained the deepest (approximately 50 microns $(0.002$ in)) and broadest pits that appeared to be filled with an oxide. SEM analyses were not performed, so the presence and elemental composition of the oxide were not determined. Attack in these three samples appeared to have occurred throughout the entire matrix. The UK-50:50-25 and UK-60:40-28 samples appeared to have the most planar surface with only a few very small pits $(<10$ microns deep) visible. Depths of internal attack, IGA and internal void formation ranged from 0.068 to 0.284 $\mathrm{mm}(0.003$ to $0.011 \mathrm{in})$. The UK-60:40-25 sample exhibited the deepest internal attack, while the shallowest attack was observed on the UK-60:40-28 coupon. ${ }^{6}$

Except for the UK-75:25-25 coupon, none of the samples contained a continuous oxide layer on the surface. The surface oxide on the UK-75:25-25 coupon was continuous but varied in thickness (Figure 21(b)). Evidence of a very thin, non-continuous surface oxide layer was observed on the other coupons. All samples appeared to have oxide deposits in the internally attacked regions, i.e., along the affected grain boundaries or in the voids. SEM analyses were not performed so the elemental composition of the oxide was not determined.

Material loss from general corrosion appeared to be similar for all samples. The one exception was the UK-50:50-32 sample, which is shown in Figure 19(a). Measurement of the mating surface on the un-mounted portion of the coupon with a vernier caliper did not reveal any appreciable material loss. Due to the glass deposits on this surface this measurement would also be in error resulting in a smaller total material loss. The actual material loss is expected to be between these two numbers and would most likely be in agreement with the corrosion rates of the other samples. The calculated corrosion rate determined using material loss data only (no internal attack) from one side of the coupon ranged from 3.044 to $4.139 \mathrm{~mm} / \mathrm{yr}(0.120$ to $0.163 \mathrm{in} / \mathrm{yr})$. Corrosion rates up to $4.78 \mathrm{~mm} / \mathrm{yr}(0.188 \mathrm{in} / \mathrm{yr})$ have been observed on components removed from the DWPF Melter. The highest corrosion rate was observed on the melter pour spout insert, which is in contact with flowing glass. This would be considered a dynamic, more aggressive condition than the static immersion tests reported in this document.

\footnotetext{
${ }^{6}$ General corrosion is uniform and is manifested by a planar attack of the metal surface. However, in the case of a localized form of corrosion such as pitting the attack rate can accelerate (pit forms, pit is not flushed by the bulk glass chemistry, chemistry in the pit becomes more aggressive, pitting rate accelerates). It is impossible to predict a corrosion rate when pitting is observed. The UK-50:50-32, UK-60:40-32, and UK-75:25-32 did exhibit evidence of a non-planar attack, which may indicate the onset of pitting. Longer term testing would be required to confirm the presence of pitting attack. More than likely corrosion would become more uniform in the pitted (non-planar) regions as the oxide layer thickens and becomes more protective. This results because diffusion in these areas is more difficult and corrosive species in the molten glass can not enter the pit. Assuming the protective oxide is stable (does not spall) and is not porous, the anode, the site where corrosion takes place, would move to a more favorable location. Hence the corrosion front would become more planar.
} 
The morphology of the surface and internal attack was consistent with other molten glass tests performed in support of the DWPF. Initially attack is generally observed along grain boundaries where diffusion is favorable. However, as the attack progresses or the test temperature is increased, the attack can occur throughout the matrix. The corrosion process is associated with chromium diffusion to the surface to form a $\mathrm{Cr}_{2} \mathrm{O}_{3}$ layer. Oxygen from the environment diffuses inwardly. There may be some nickel and iron oxide formation but these are less favorable than the chromium oxide. The oxide layer may spall off by internal stresses or erosion or may be fluxed away by chloride or sulfate salts if present. The solubility of chromium (chromium oxide) in the glass may also affect the stability of the oxide layer. Ultimately the oxide will reform and the cycle will repeat.

Table 14. Measurement of degradation and estimated corrosion rates.

(Corrosion rate is based on material loss only (no internal attack).

Original coupon thickness was $5.029 \mathrm{~mm}(0.198 \mathrm{in})$ ).

\begin{tabular}{|c|c|c|c|c|c|c|c|c|c|c|}
\hline \multirow[t]{2}{*}{ ID } & \multicolumn{2}{|c|}{ Final Thickness } & \multicolumn{2}{|c|}{ Total Thickness Change } & \multicolumn{2}{|c|}{ Internal Attack Depth } & \multicolumn{2}{|c|}{ 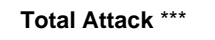 } & \multicolumn{2}{|c|}{ Corrosion Rate } \\
\hline & $\mathrm{mm}$ & in & mm & in & $\mathrm{mm}$ & in & mm & in & $\mathrm{mm} / \mathrm{yr}$ & in/yr \\
\hline $5050-25$ & 4.89 & 0.193 & 0.139 & 0.005 & 0.156 & 0.006 & 0.226 & 0.009 & 3.044 & 0.120 \\
\hline $5050-28$ & 4.89 & 0.193 & 0.139 & 0.005 & 0.110 & 0.004 & 0.180 & 0.007 & 3.044 & 0.120 \\
\hline $5050-32^{*}$ & 3.76 & 0.148 & 1.269 & 0.050 & 0.155 & 0.006 & 0.790 & 0.031 & 27.791 & 1.094 \\
\hline $5050 \_32^{* *}$ & 4.99 & 0.196 & 0.039 & 0.002 & 0.155 & 0.006 & 0.175 & 0.007 & 0.854 & 0.034 \\
\hline $6040-25$ & 4.88 & 0.192 & 0.149 & 0.006 & 0.284 & 0.011 & 0.359 & 0.014 & 3.263 & 0.129 \\
\hline $6040-28$ & 4.86 & 0.191 & 0.169 & 0.007 & 0.068 & 0.003 & 0.153 & 0.006 & 3.701 & 0.146 \\
\hline $6040-32$ & 4.86 & 0.191 & 0.169 & 0.007 & 0.113 & 0.004 & 0.198 & 0.008 & 3.701 & 0.146 \\
\hline $7525-25$ & 4.84 & 0.191 & 0.189 & 0.007 & 0.201 & 0.008 & 0.296 & 0.012 & 4.139 & 0.163 \\
\hline $7525-28$ & 4.87 & 0.192 & 0.159 & 0.006 & 0.140 & 0.006 & 0.220 & 0.009 & 3.482 & 0.137 \\
\hline 7525-32 & 4.89 & 0.193 & 0.139 & 0.005 & 0.089 & 0.004 & 0.159 & 0.006 & 3.044 & 0.120 \\
\hline
\end{tabular}

* Measurement error possibly due to metallurgical preparation

** Measured unmounted portion of the coupon with a vernier caliper

*** Total Attack (one side) $=$ Total Thickness Change/2 + Internal Attack 




(a)

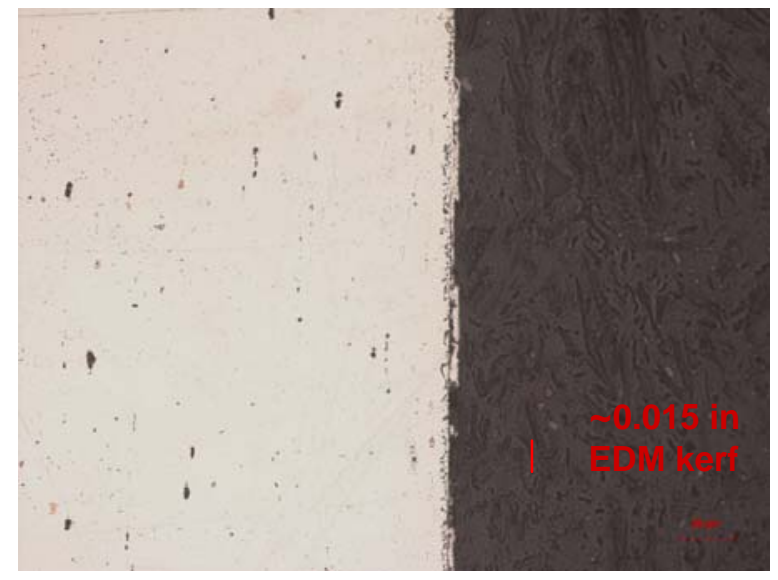

(b)

Figure 18. Photo micrographs showing as-received material in as-polished condition. (a) entire cross-section at $\mathbf{1 2 . 5}$ times magnification and (b) surface at 200 times magnification. (EDM: electrical discharge machining) 

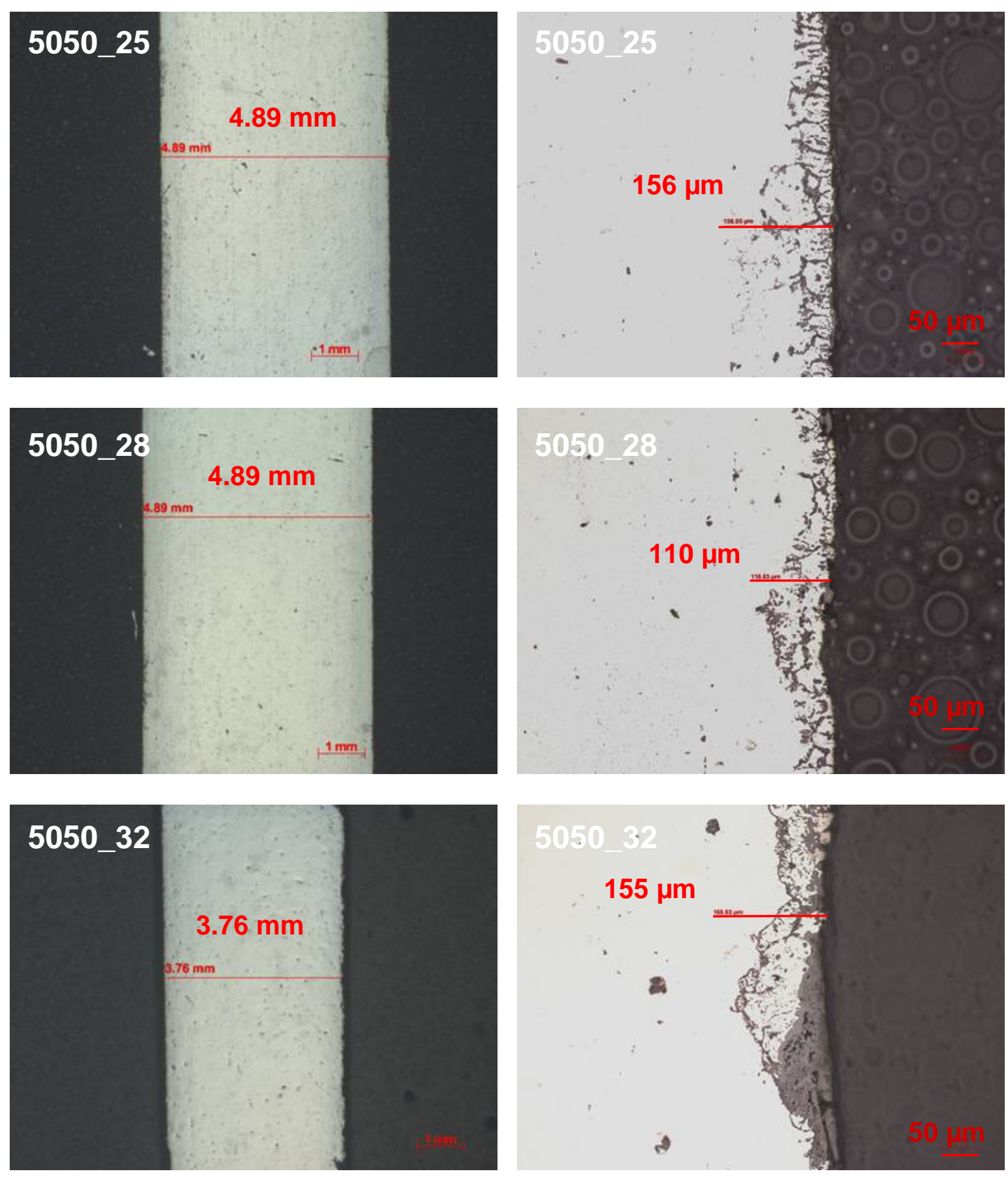

(a)

(b)

Figure 19. Photo micrographs showing the 50:50 series coupons in as-polished condition. (a) entire cross-section at 12.5 times magnification and (b) maximum depth of internal attack at 200 times magnification. 

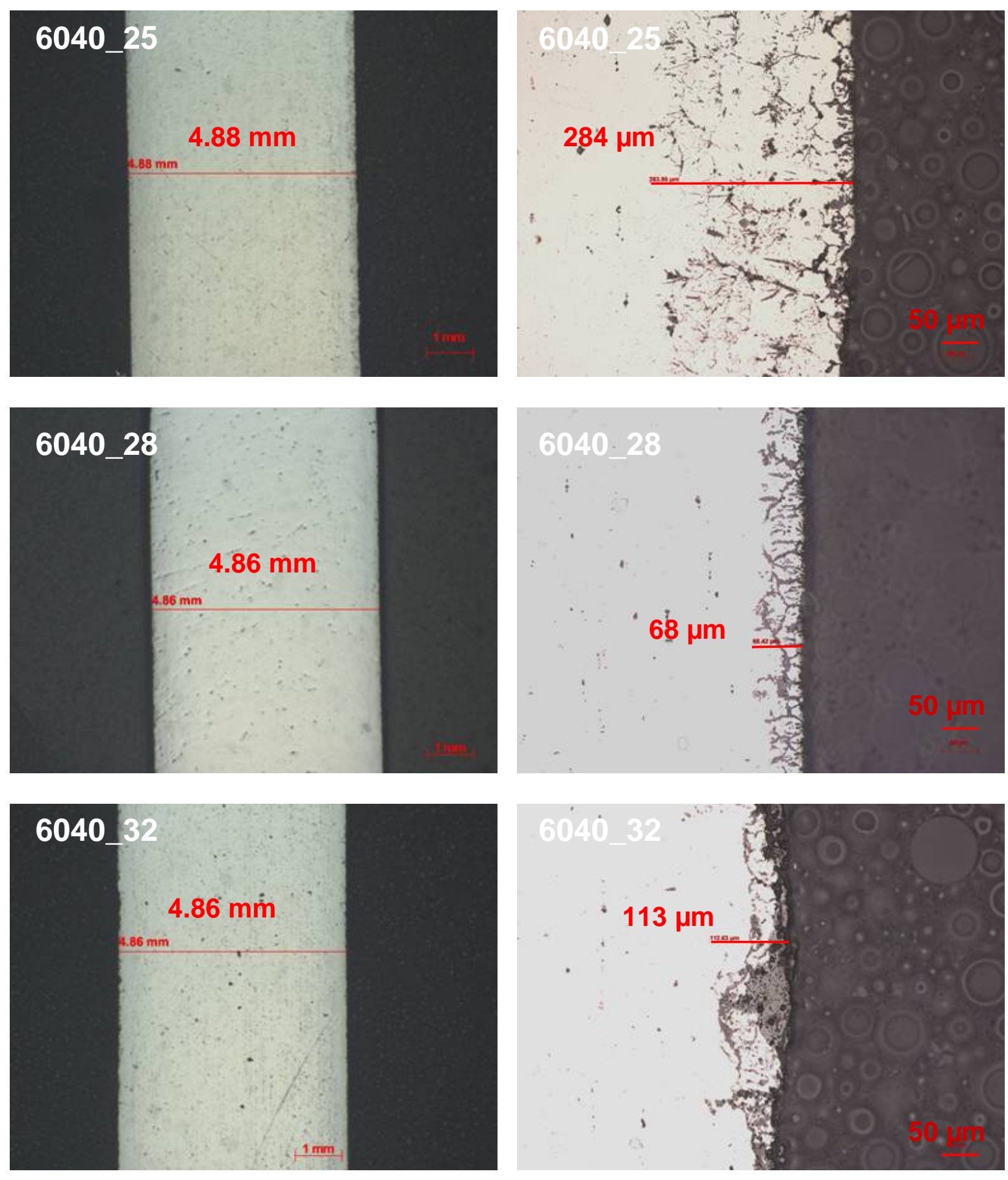

(a)

(b)

Figure 20. Photo micrographs showing the 60:40 series coupons in as-polished condition. (a) entire cross-section at 12.5 times magnification and (b) maximum depth of internal attack at 200 times magnification. 

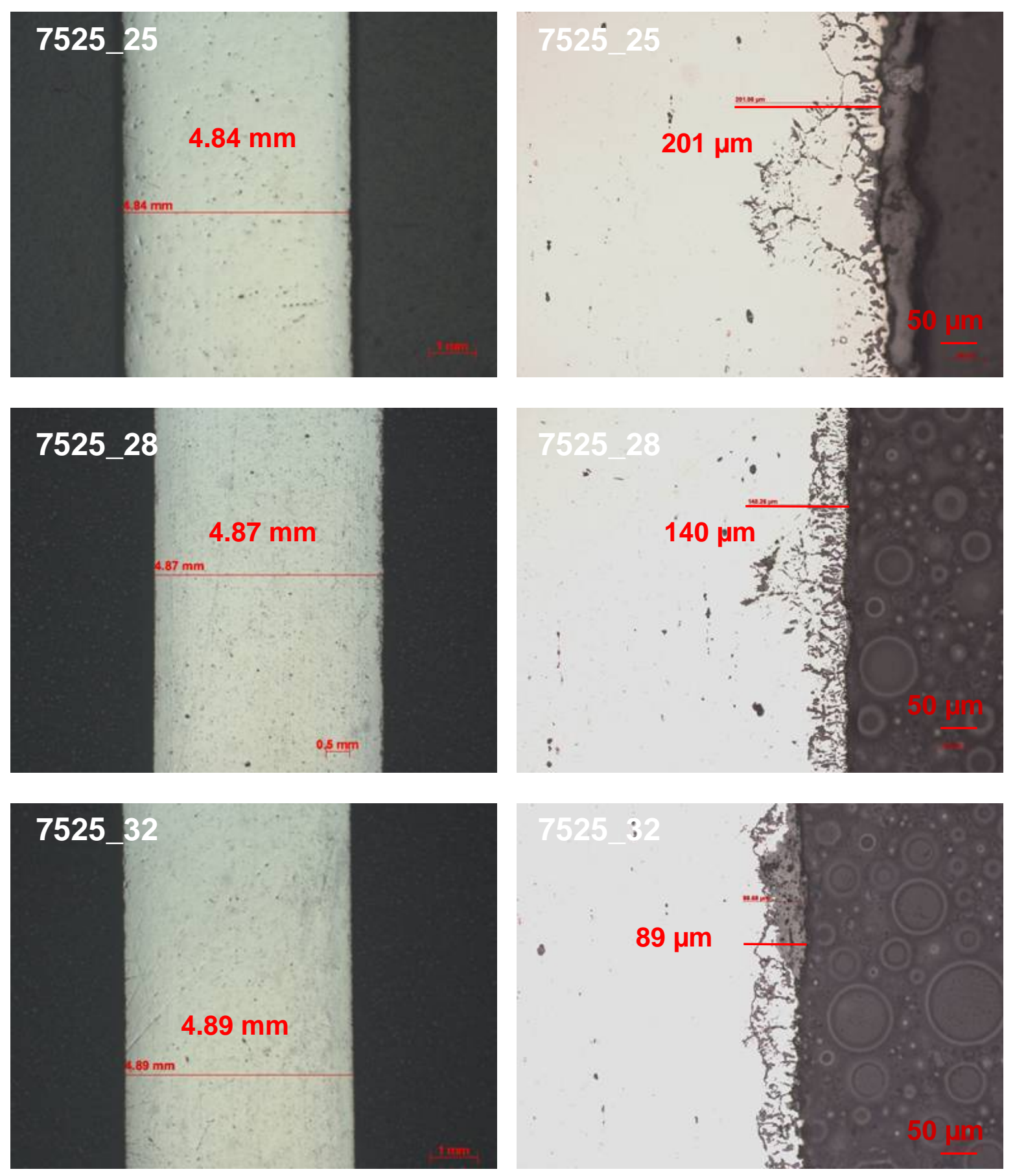

(a)

(b)

Figure 21. Photo micrographs showing the 75:25 series coupons in as-polished condition. (a) entire cross-section at 12.5 times magnification and (b) maximum depth of internal attack at 200 times magnification. 
A continuous oxide layer was only observed on the UK-75:25-25 coupon. The oxide layer had some porosity and was non-uniform in thickness. Although the layer was intact on this coupon, it experienced the highest corrosion rate. In any case the oxide was not effective in protecting the coupon from oxidation and/or corrosion. With respect to the other coupons, the lack of a surface oxide layer does not necessarily mean that it did not exist while the coupon was exposed to the molten glass. After the coupons are removed from the molten glass and they begin to cool, the oxide and glass are subjected to thermal stresses due to thermal expansion coefficient mismatches. The oxide and/or glass may delaminate at either the metal/oxide interface or at the oxide/glass interface. Also the oxide and/or glass may separate due to mechanical stresses that are induced during the cutting, grinding and polishing processes.

\section{Summary}

Sellafield Ltd (United Kingdom) requested technical support from the SRNL to characterize a series of uranium-bearing, mixed alkali borosilicate glasses. The specific glasses to be characterized are based on different blends (75:25, 60:40, and 50:50) of Magnox:Butex waste types as well as different incorporation rates (or waste loadings of 25, 28, and 32\%) of each blend. Each of the waste blend ratios was mixed with a base-glass additive composition targeting the three different waste loadings (WL) resulting in nine different glasses. These nine glasses were fabricated and physically characterized for key processing and product performance properties as defined in the WFO agreement. Specific characterization techniques for the nine study glasses included: chemical composition analysis, XRD, SEM-EDS, durability as defined by the PCT, and high temperature viscosity as a function of temperature. In addition, the corrosion of Nicrofer $6025 \mathrm{HT}$ coupons in each glass system was assessed at a temperature of $1150^{\circ} \mathrm{C}$ for approximately 200 hours. The results of this study are highlighted below:

\section{Visual Observations}

Foam formation and crystallization were observed after the initial melts at $1150^{\circ} \mathrm{C}$. Although no formal assessment was performed to isolate the source of foam formation, a review of the glass compositions suggests that thermal reduction of $\mathrm{CeO}_{2}$ is the likely source. The presence of foam was eliminated (or greatly reduced) after a second melt at $1150^{\circ} \mathrm{C}$ although crystallization was still visually apparent.

\section{Compositional Analysis}

Targeted glass compositions were met based on the analytical elemental results.

\section{XRD/ SEM-EDS}

Undissolved $\mathrm{RuO}_{2}$ and spinel were identified in all but one of the as-fabricated UK study glasses. The presence of undissolved $\mathrm{RuO}_{2}$ is not surprising given the limited solubility of this oxide in glass. Spinels are common in HLW glasses enriched in Fe, Ni, and/or Cr and typically increase in volume or mass percent with increased waste loading. The trend of higher WLs increasing the propensity of spinel formation is consistent with DWPF-type glasses especially those that have undergone slow cooling to simulate the cooling profile along the centerline of the canister. The one UK study glass that did not contain spinel, based on XRD analysis, was the UK-60:40-25 glass (the lowest WL in that series). However, SEM-EDS analysis identified a Cr-rich spinel in this sample which suggests that the volume percent must be below the XRD detection limit (approximately 0.5 vol\%). 


\section{PCT}

Based on the 7-day PCT results, the durability of the UK glasses increased as: (a) WL increased (for each Magnox:Butex blend ratio) and (b) the Magnox:Butex blend ratio decreased.

Longer term PCTs were also performed. Using the longer-term NL [B] values, the results suggest that the corrosion rate slows over the 28-day test period indicative of solution saturation. This type of dissolution behavior is consistent with other HLW glasses which generally show corrosion rates increasing while the solution is undersaturated. The corrosion rate typically slow as the solution becomes saturated. If precipitation of secondary phases occurs due to solution saturation, then the corrosion rates can return to the forward rate of reaction.

However, tracking the release of Al show an opposite trend to that of B. Although a formal analysis of these results was not performed, these results may be an indication of the precipitation of $\mathrm{Al}(\mathrm{OH})_{3}$ due to complex solution reactions $\left(\mathrm{Al}(\mathrm{OH})_{3}(\mathrm{ppt})\right.$ versus $\mathrm{Al}(\mathrm{OH})_{4}$ (aqueous)) which are also influenced by solution $\mathrm{pH}$. The release rates of $\mathrm{Fe}, \mathrm{Mg}$, and $\mathrm{U}$ follow a similar trend to that of $\mathrm{Al}$.

\section{High Temperature Viscosity}

High temperature viscosity measurements were performed on five of the nine UK study glasses. Based on the series of glasses targeting 28\% WL (UK-50:50-28, UK-60:40-28, and UK-72:25-28), the general trend in viscosity suggests that as the Magnox:Butex blend ratio increases the viscosity slightly decreases. Although these data suggest that there is a slight shift in the viscosity with the Magnox:Butex blend ratio, the shift should have very little, if any, practical impact on melter processing. With respect to the potential impacts of $\mathrm{Al}_{2} \mathrm{O}_{3}$ content on the resulting viscosity (a concern mentioned in the WFO), there appears to be very little practical impact.

\section{Corrosion}

The following conclusions are based on the test results obtained from the 200 hour static molten glass exposure tests of the Nicrofer $6025 \mathrm{HT}$ coupons in the various UK glass formulations:

No significant localized attack of the coupons was observed.

- Internal attack (IGA and internal voids) ranged from 0.068 to $0.284 \mathrm{~mm}$ (0.003 to 0.011 inches).

- Internal attack of the UK-60:40-25 was greatest

- Material loss was consistent throughout all the glass formulations and the surface was generally planar with the exceptions of the UK-50:50-32, UK60:40-32, and UK-75:25-32 coupons.

- Coupons UK-50:50-32, UK-60:40-32, and UK-75:25-32 contained a nonuniform attack. The pits were broad with depths approaching 50 microns (0.002 in).

Corrosion rates for the various waste formulations ranged from 3.044 to $4.139 \mathrm{~mm} / \mathrm{yr}$ ( 0.120 to $0.163 \mathrm{in} / \mathrm{yr})$

- Calculated corrosion rates are comparable to corrosion rates measured for components from the DWPF Melter. 
Thick, continuous surface oxide layers were not observed on the majority of the coupons.

- The UK-75:25-25 coupon contained the only continuous oxide layer.

The objective of this task was to provide Sellafield Ltd. with the technical data to evaluate the impacts of various Magnox:Butex blend ratios and WLs on key glass properties of interest. Without knowing the UK "acceptability" criteria for critical processing or product performance properties, the authors can not provide guidance as to the acceptability of the UK glass compositions (based on either the Magnox:Butex blend ratio or WL). In fact, some of the properties measured (e.g., PCT) are US HLW glass criteria and may not be applicable to acceptance of UK glasses.

\section{Recommendations}

The following are recommendations based on the results of this work:

- Complete the measurements of viscosity as a function of temperature for the four remaining UK glasses to confirm results generated thus far.

- Given the long term and opposite trends in the $\mathrm{Al}$ and $\mathrm{B}$ leachate concentrations, geochemical modeling could be performed to provide additional insight into possible precipitation reactions occurring as the solutions become saturated.

- Assess the impact of thermal history on durability of the UK study glasses. More specifically, if the thermal profile of the glass is known as it cools in the canister, the UK glasses could be exposed to that profile and the impact on glass durability could be measured.

- With respect to corrosion of the Nicrofer 6025HT corrosion coupons, SRNL recommends to (a) prepare a second sample from the UK-50:50-32 coupon to verify corrosion data and (b) grind further down into the UK-60:40-25 coupon to verify corrosion data. If similar corrosion data are obtained then expose another sample to the UK-60:40-25 glass formulation. 
SRNL-STI-2011-00012

Revision 0

\section{References}

ASTM. 2002. "Standard Test Methods for Determining Chemical Durability of Nuclear Waste Glasses: The Product Consistency Test (PCT)," ASTM C-1285, (2002).

ASTM. 2007. "Standard Practice for Measuring Viscosity of Glass Above the Softening Point," ASTM C-965, (2007).

Borwn, K.G. and R.L. Postles. 1995. SME Acceptability Determination for DWPF Process Control, U.S. Department of Energy Report WSRC-TR-95-00364, Revision 5 (Editor: T.B. Edwards), Westinghouse Savannah River Company, Aiken, South Carolina.

Crum, J.V., R.L. Russell, M.J. Schweiger, D.E. Smith, J.D. Vienna, T.B. Edwards, C.M. Jantzen, D.K. Peeler, R.F. Schumacher and R.J. Workman. "DWPF Startup Frit Viscosity Measurement Round Robin Results," Pacific Northwest National Laboratory, (Unpublished).

Fulcher, G.S. 1925. "Analysis of Recent Measurements of the Viscosity of Glasses," Journal of the American Ceramic Society, 8 [6] 339-355 (1925).

Fulcher, G.S. 1925. "Analysis of Recent Measurements of the Viscosity of Glasses, II," Journal of the American Ceramic Society, 8 [12] 789-794 (1925).

Jantzen, C.M., N.E. Bibler, D.C. Beam, C.L. Crawford and M.A. Pickett. 1993. "Characterization of the Defense Waste Processing Facility (DWPF) Environmental Assessment (EA) Glass Standard Reference Material," U.S. Department of Energy Report WSRC-TR-92-346, Revision 1, Westinghouse Savannah River Company, Aiken, South Carolina.

Jantzen, C.M., J.B. Picket, K.G. Brown, T.B. Edwards and D.C. Beam. 1995. "Process/Product Models for the Defense Waste Processing Facility (DWPF): Part I. Predicting Glass Durability from Composition Using a Thermodynamic Hydration Energy Reaction Model (THERMO)," U.S. Department of Energy Report WSRC-TR-93-672, Revision 1, Westinghouse Savannah River Company, Aiken, South Carolina.

Peeler, D.K. and I.A. Reamer. 2001. "The Use of $\mathrm{Er}_{2} \mathrm{O}_{3}$ as an $\mathrm{Am}_{2} \mathrm{O}_{3}$ and $\mathrm{Cm}_{2} \mathrm{O}_{3}$ Surrogate", U.S. Department of Energy Report WSRC-RP-99-0021, Revision 1, Westinghouse Savannah River Company, Aiken, South Carolina.

Peeler, D.K., T.B. Edwards, R.J. Workman, and I.A. Reamer. 2004. The Impact of Waste Loading on Viscosity in the Frit 418 - SB3 System, U.S. Department of Energy Report WSRCTR-2004-00429, Revision 0, Westinghouse Savannah River Company, Aiken, South Carolina.

Schumacher, R.F. and D.K. Peeler. 1998. "Establishment of Harrop, High-Temperature Viscometer," U.S. Department of Energy Report WSRC-RP-98-00737, Revision 0, Westinghouse Savannah River Company, Aiken, South Carolina.

Schumacher, R.F., R.J. Workman and T.B. Edwards. 2001. "Calibration and Measurement of the Viscosity of DWPF Start-Up Glass," U.S. Department of Energy Report WSRC-RP-2000-00874, Revision 0, Westinghouse Savannah River Company, Aiken, South Carolina. 
Vienna, J.D., D.K. Peeler, J.G. Darab, J.R. Zamecnik, H. Li and J.E. Marra. 1999. "Chemistry of Rare Earth Oxalate Vitrification,” Materials Research Society Symposium Proceedings, 556, 321 (1999).

Peeler, D.K., J.E. Marra, I.A. Reamer, J.D. Vienna and H. Li. 2000. "Development of the Am/Cm Batch Vitrification Process," Environmental Issues and Waste Management Technologies in the Ceramic and Nuclear Industries V, Edited by G. T. Chandler and X. Feng, Ceramic Transactions, Vol.107, American Ceramic Society, Westerville, OH, p. 517 (2000).

WFO. 2010. Work for Others Agreement for the Savannah River National Laboratory to Provide Services to Sellafield Limited, Proposal No. WFO-10-008, US Department of Energy, June 30, 2010 . 
SRNL-STI-2011-00012

Revision 0

\section{Appendix A}

X-Ray Diffraction Patterns 
SRNL-STI-2011-00012

Revision 0

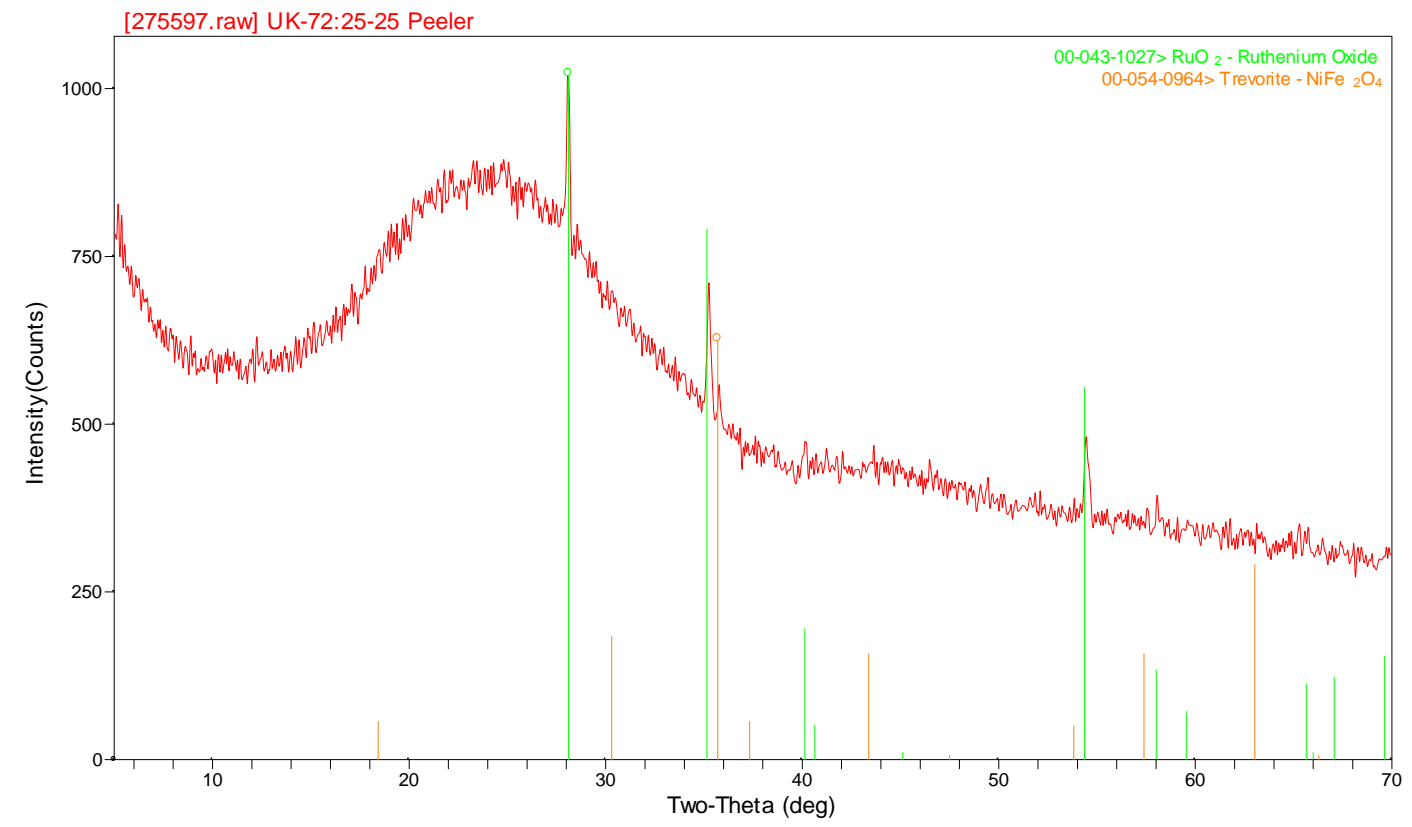

Figure A-1. XRD Result of UK-75:25-25.

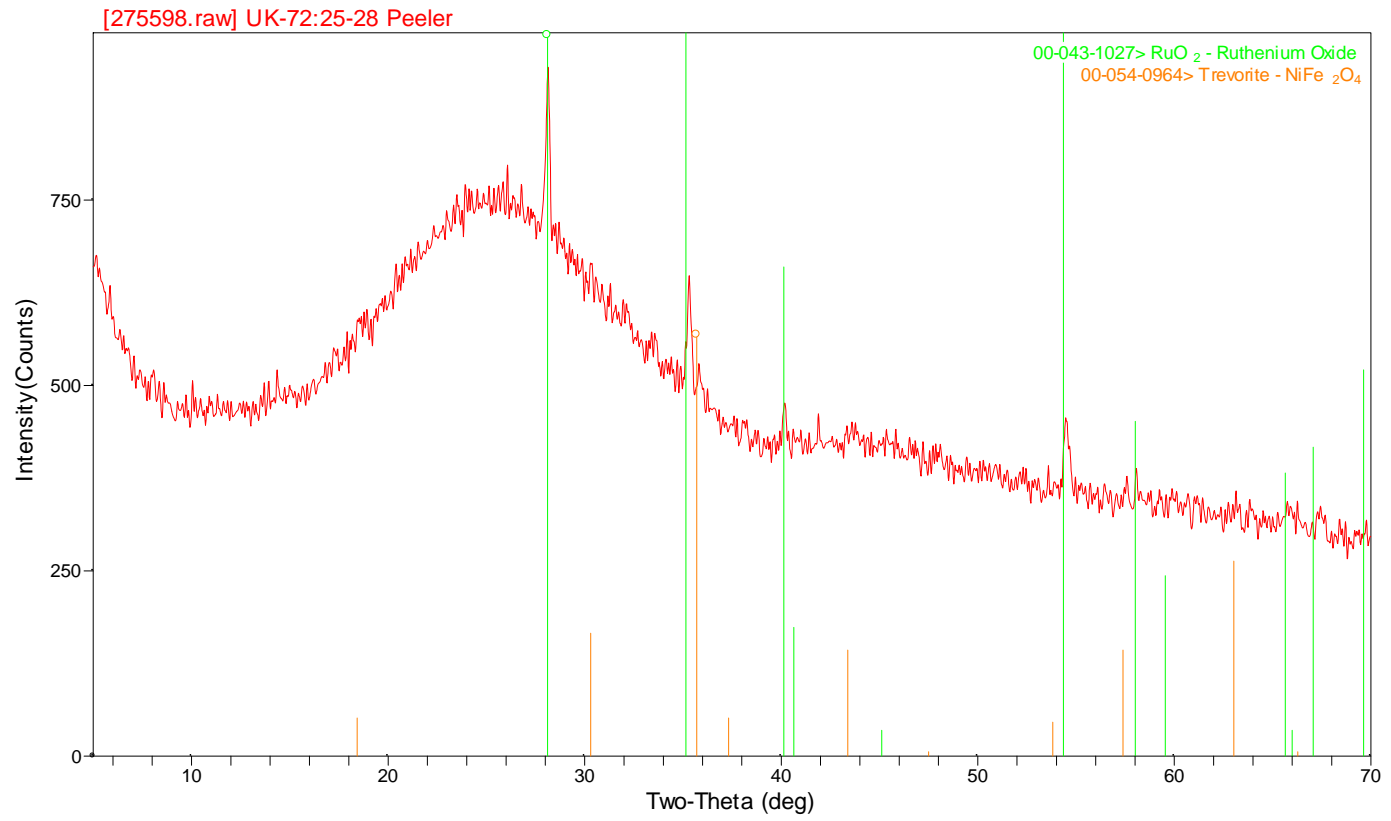

Figure A-2. XRD Result of UK-75:25-28. 
SRNL-STI-2011-00012

Revision 0

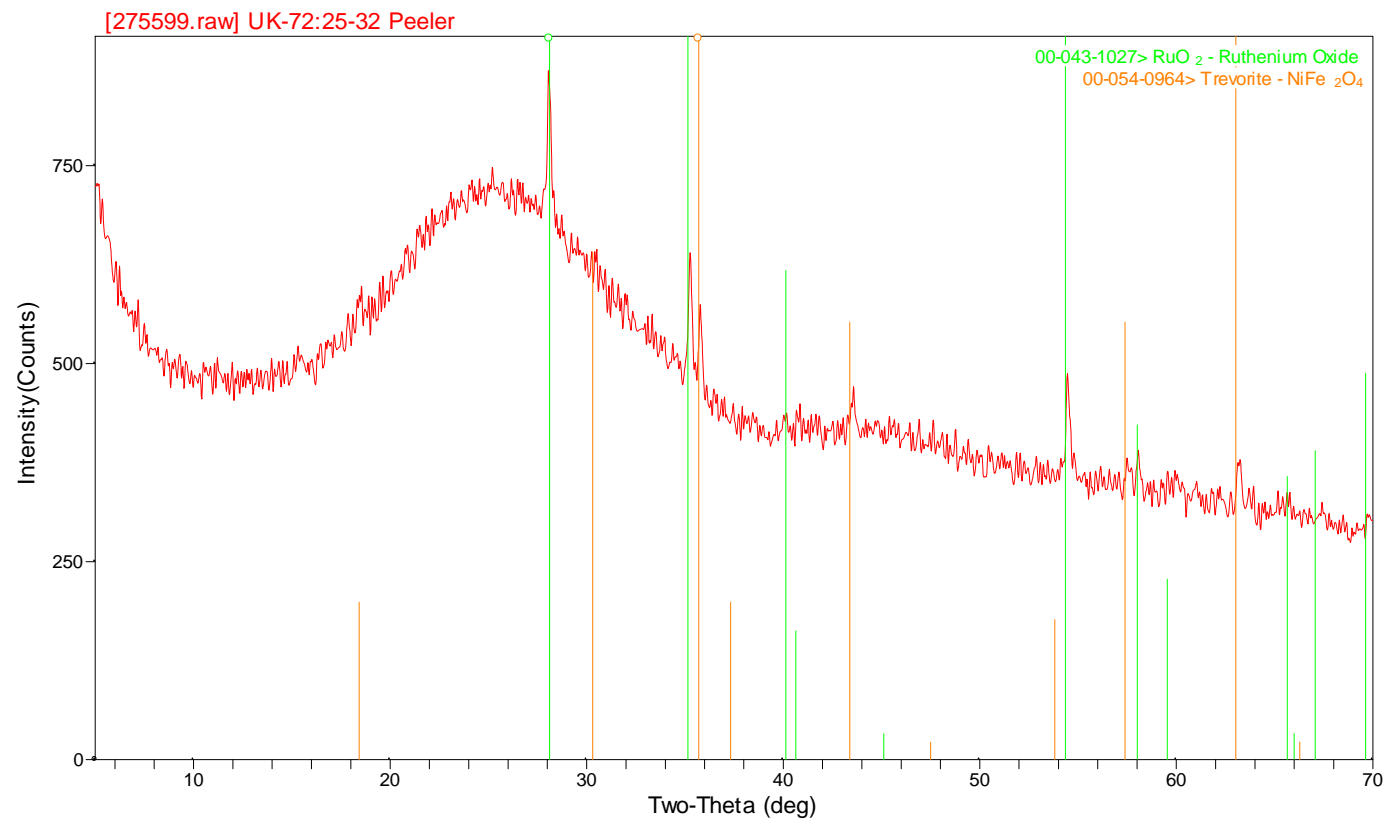

Figure A-3. XRD Result of UK-75:25-32.

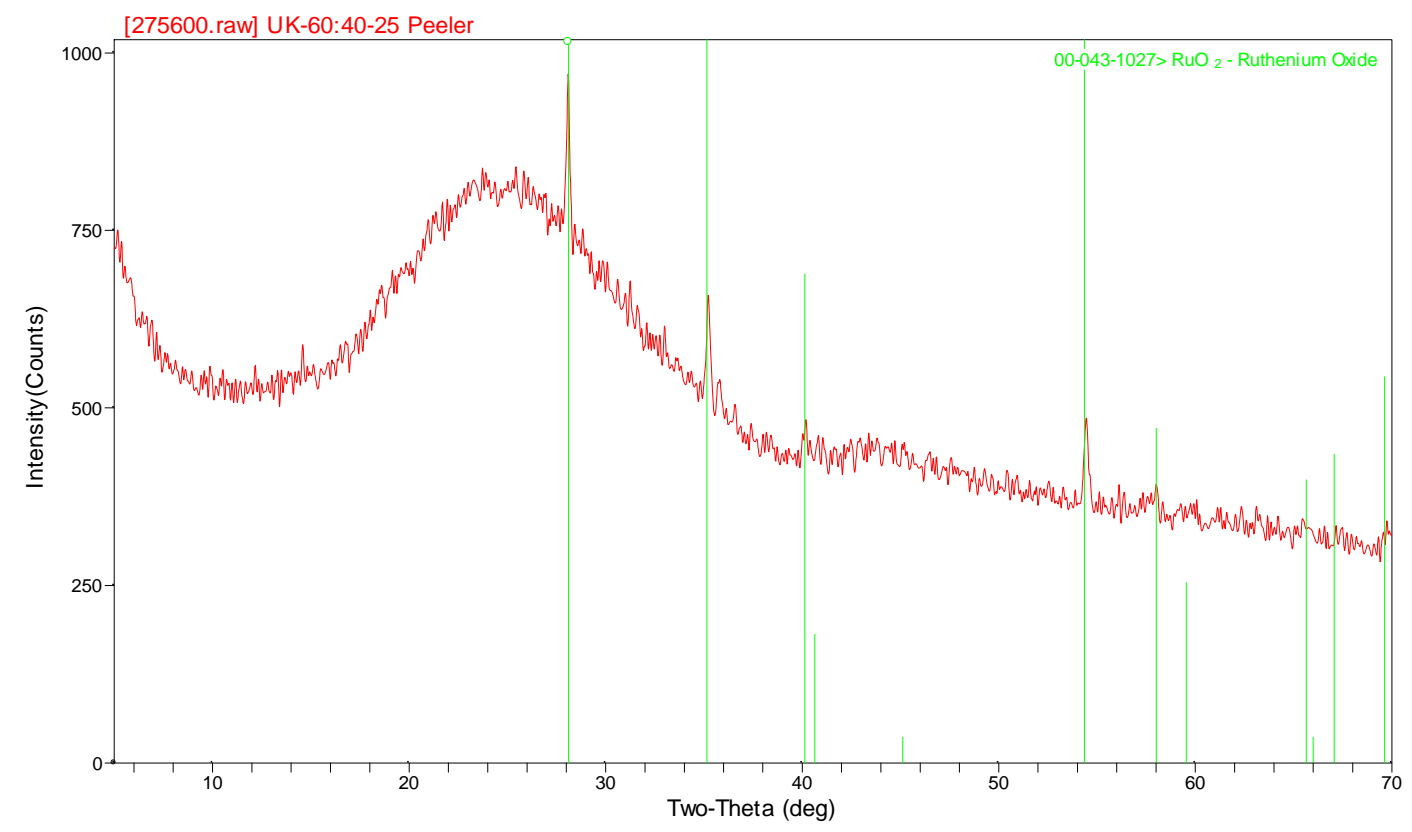

Figure A-4. XRD Result of UK-60:40-25. 


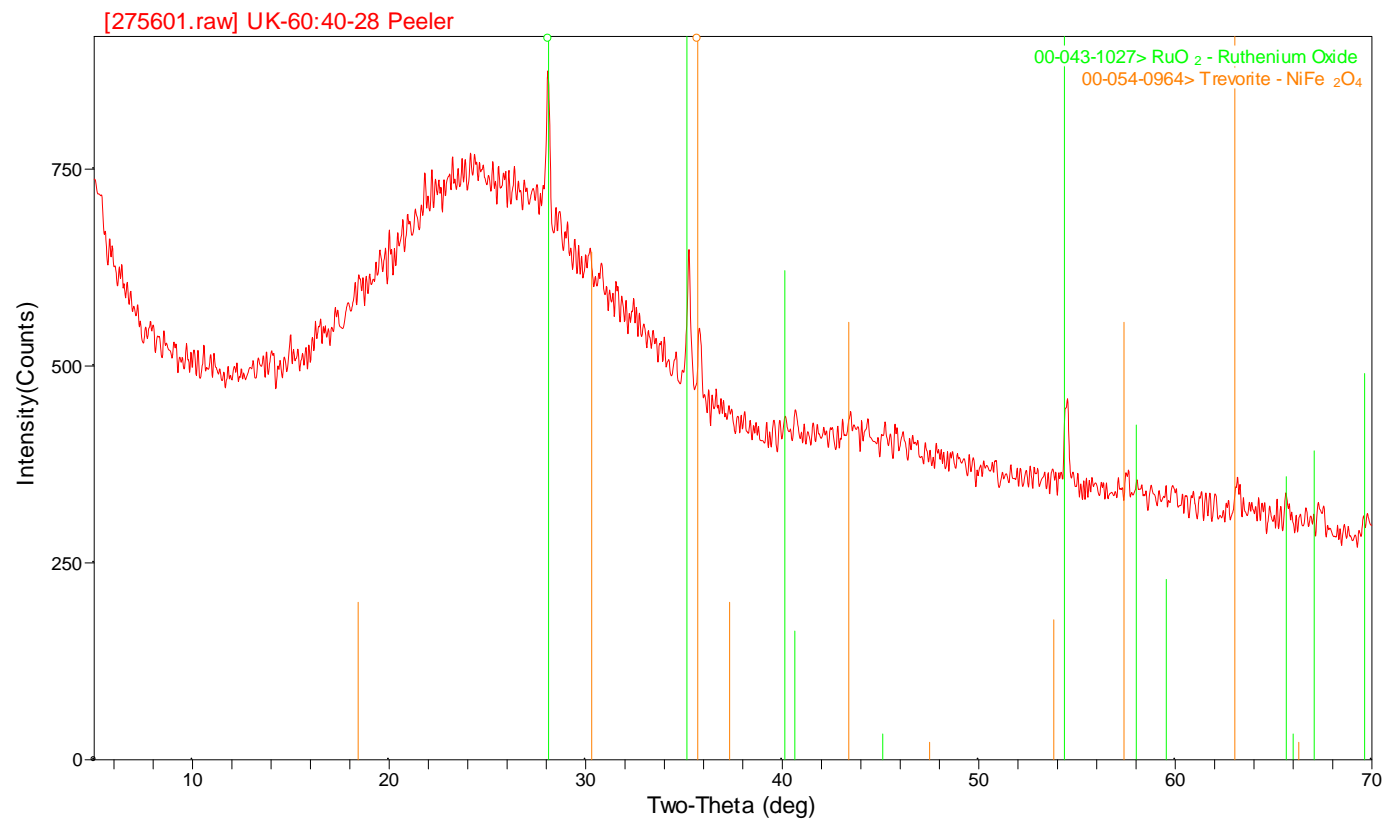

Figure A-5. XRD Result of UK-60:40-28.



Figure A-6. XRD Result of UK-60:40-32. 


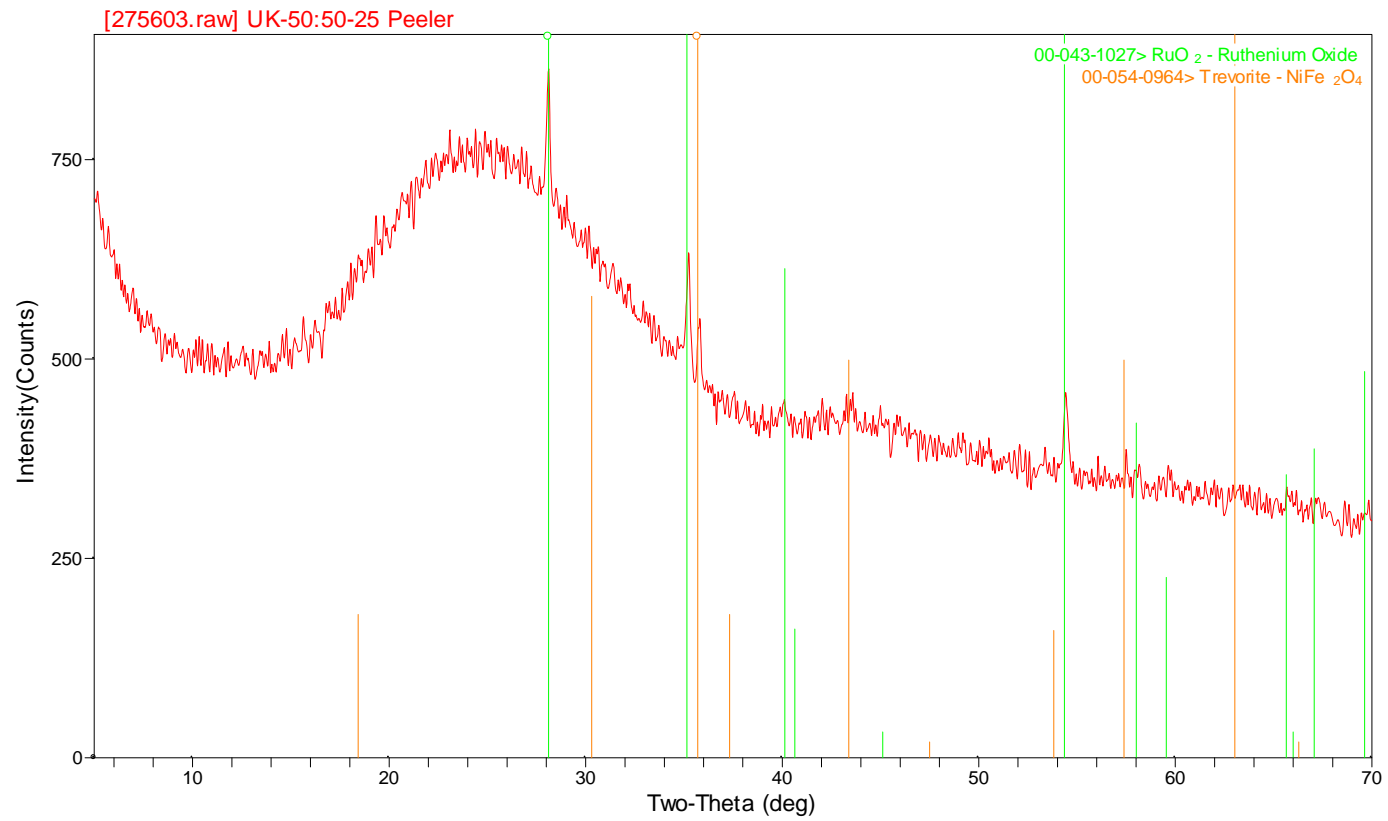

Figure A-7. XRD Result of UK-50:50-25.

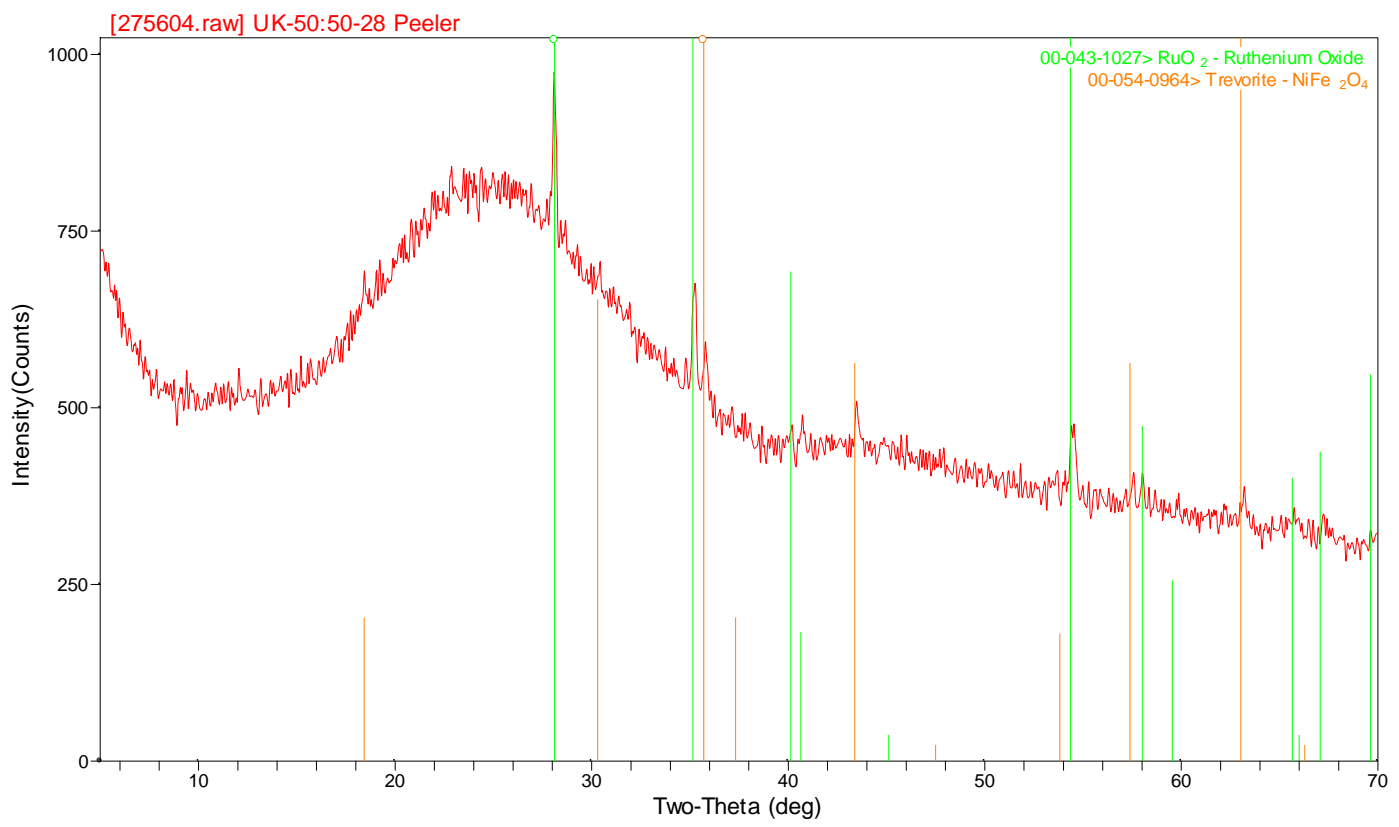

Figure A-8. XRD Result of UK-50:50-28. 
SRNL-STI-2011-00012

Revision 0

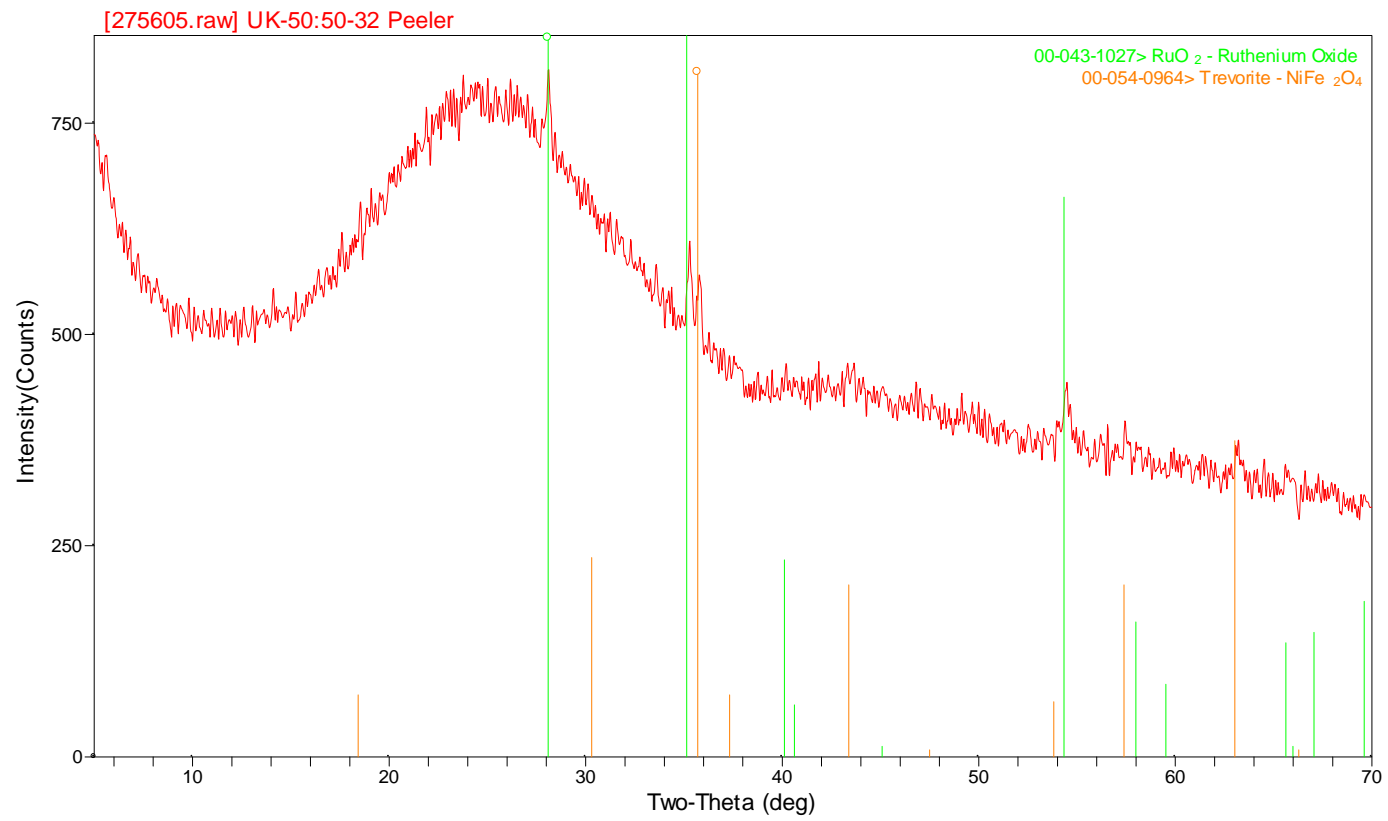

Figure A-9. XRD Result of UK-50:50-32. 
SRNL-STI-2011-00012

Revision 0

\section{Appendix B}

Scanning Electron Microscopy Results 


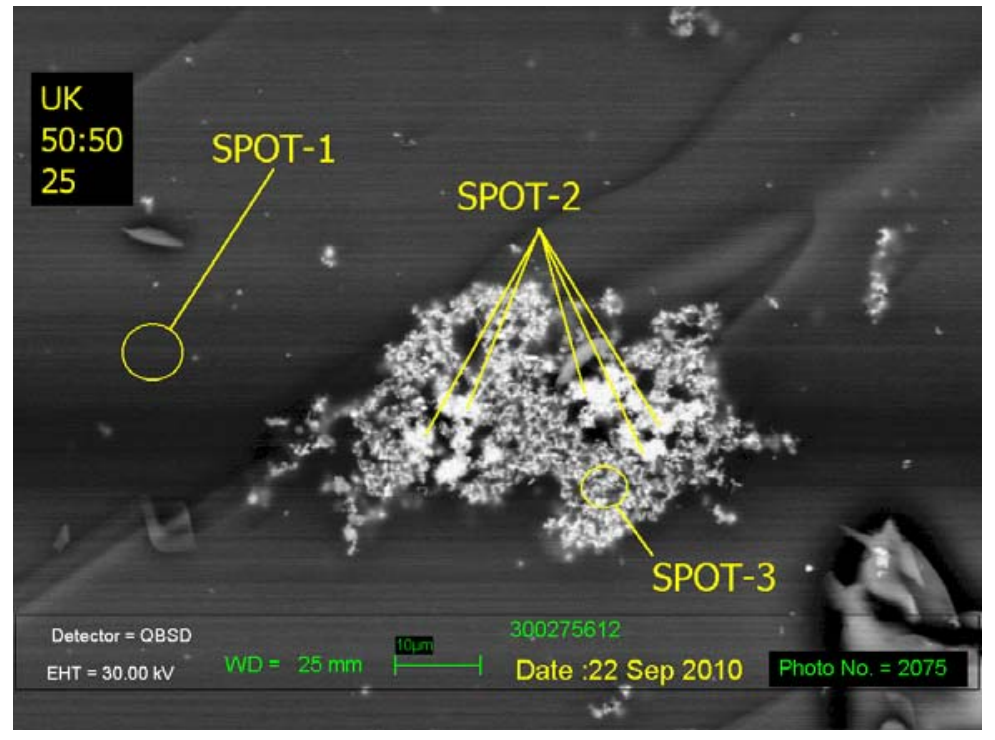

Figure B.1. SEM Micrograph of UK-50:50-25.

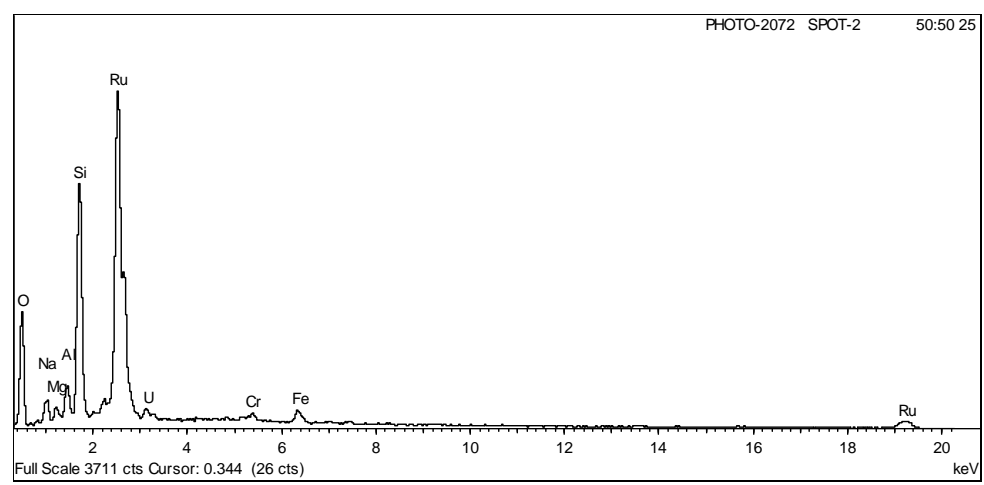

Figure B.2. EDS Analysis of Spot \#2 in Figure B.1. 


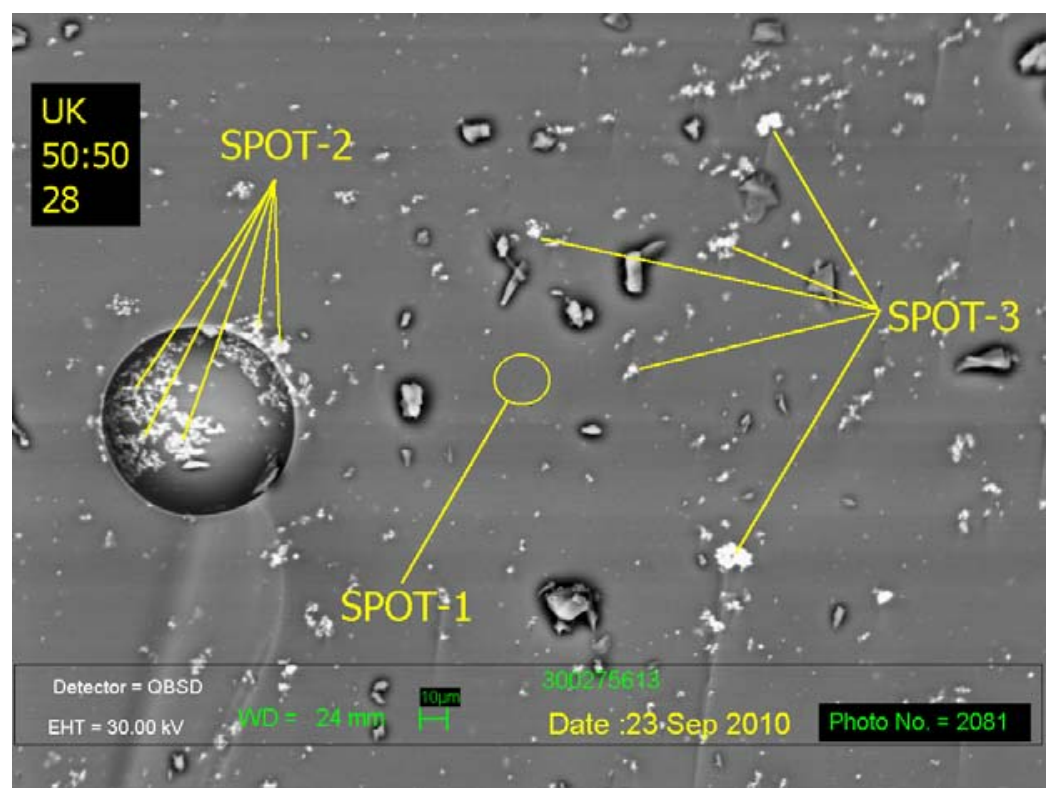

Figure B.3. SEM Micrograph of UK-50:50-28.

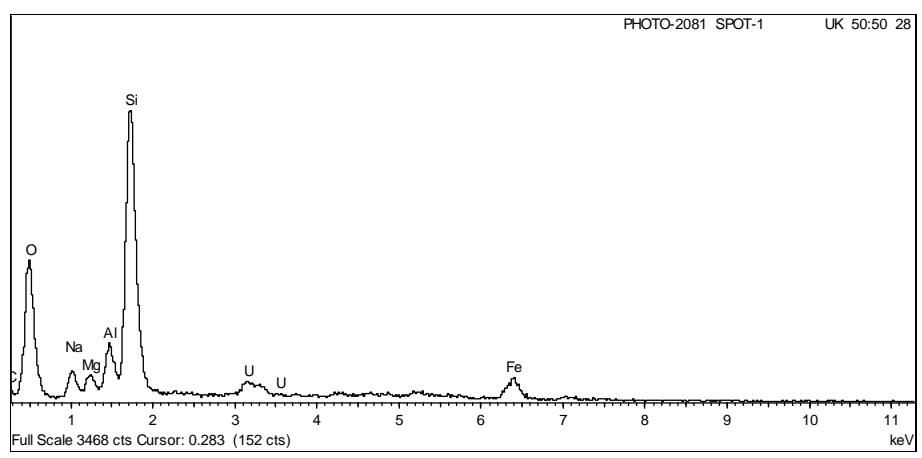

Figure B.4. EDS Analysis of Spot \#1 in Figure B.3.



Figure B.5. EDS Analysis of Spot \#2 in Figure B.3. 
SRNL-STI-2011-00012

Revision 0

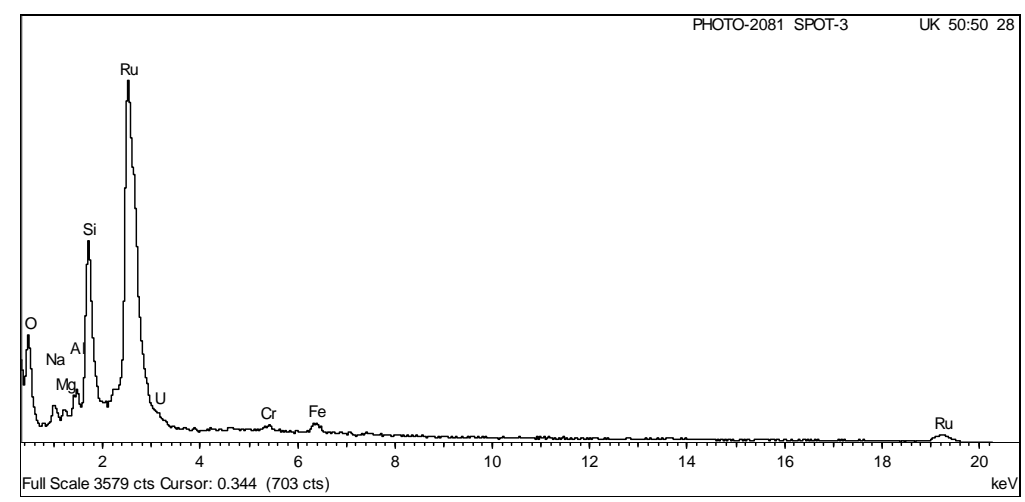

Figure B.6. EDS Analysis of Spot \#3 in Figure B.3.

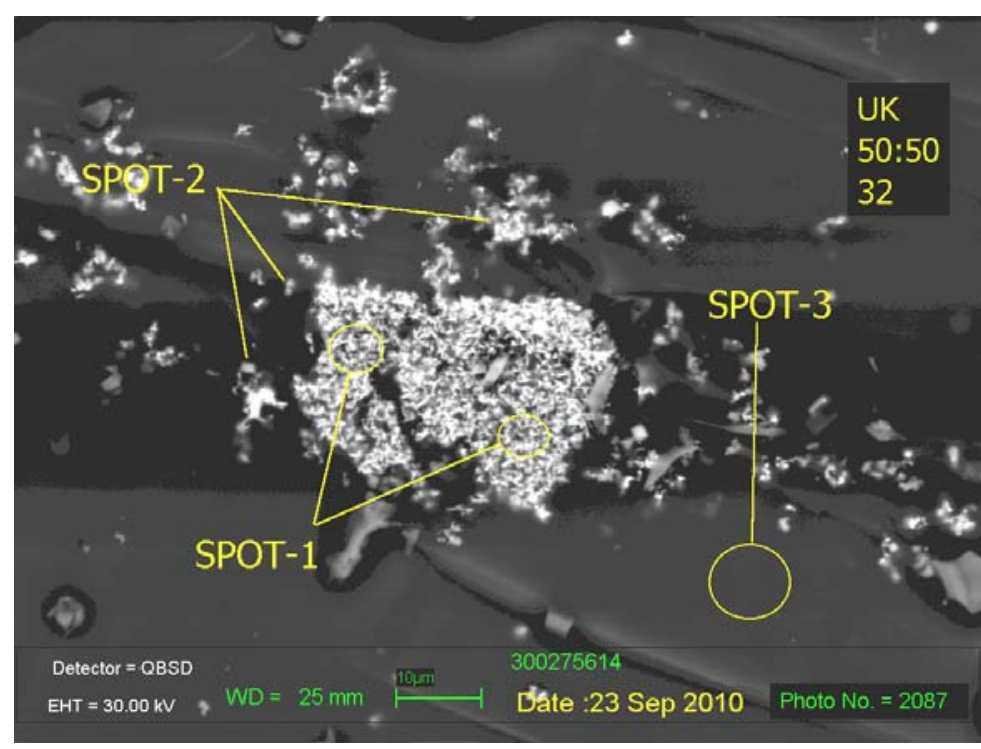

Figure B.7. SEM Micrograph of UK-50:50-32. 
SRNL-STI-2011-00012

Revision 0



Figure B.8. EDS Analysis of Spot \#1 in Figure B.7.

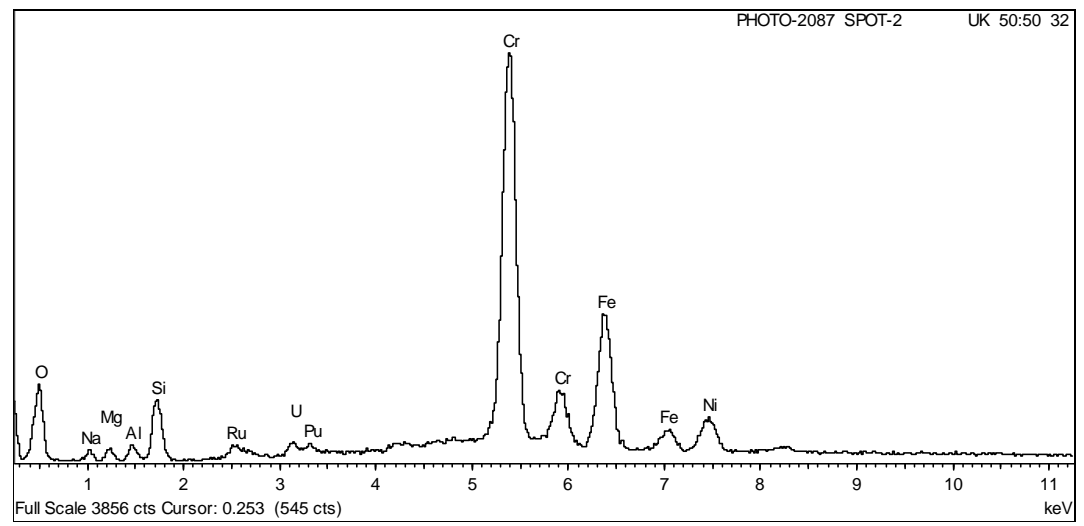

Figure B.9. EDS Analysis of Spot \#2 in Figure B.7.

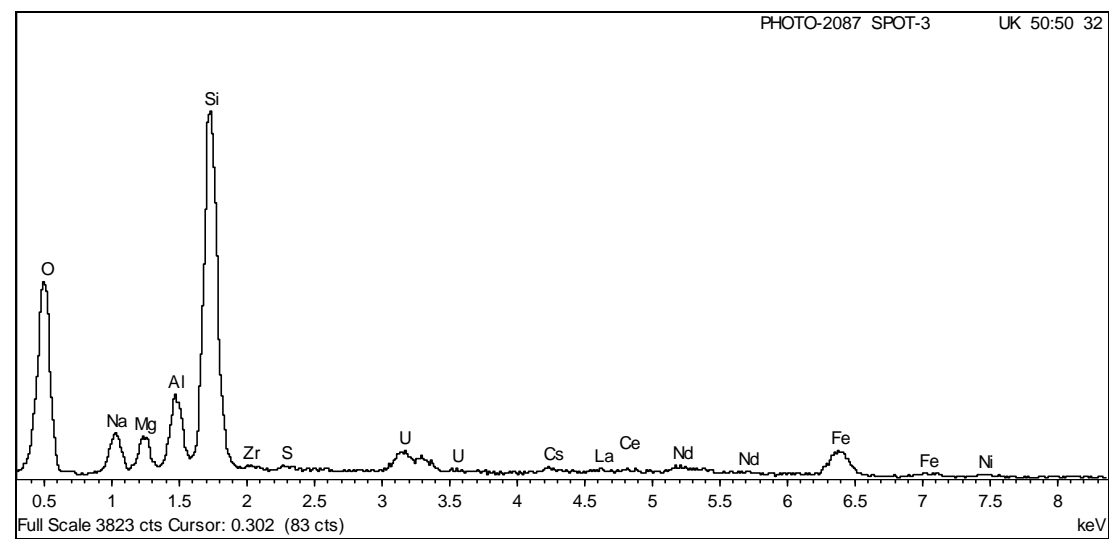

Figure B.10. EDS Analysis of Spot \#3 in Figure B.7. 




Figure B.11. SEM Micrograph of UK-60:40-25.



Figure B.12. EDS Analysis of Spot \#1 in Figure B.11. 
SRNL-STI-2011-00012

Revision 0

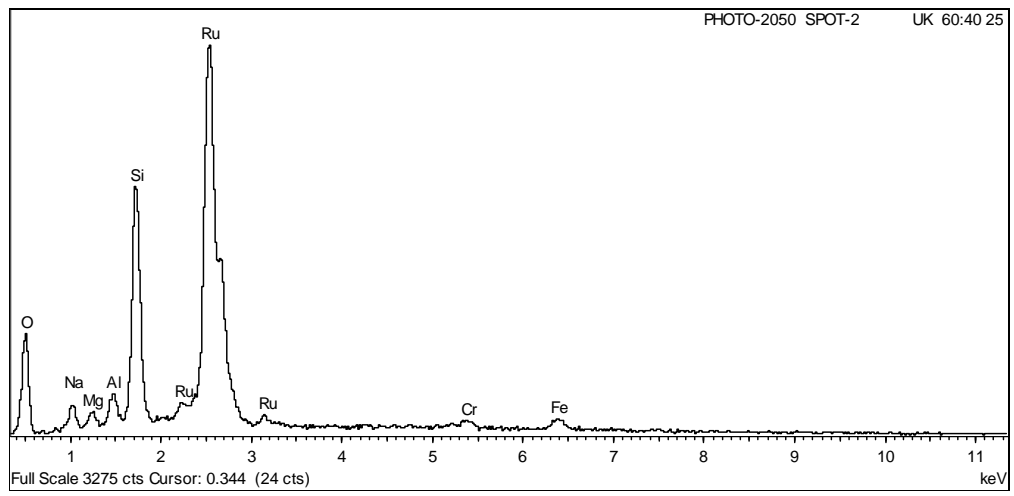

Figure B.13. EDS Analysis of Spot \#2 in Figure B.11.



Figure B.14. EDS Analysis of Spot \#4 in Figure B.11.

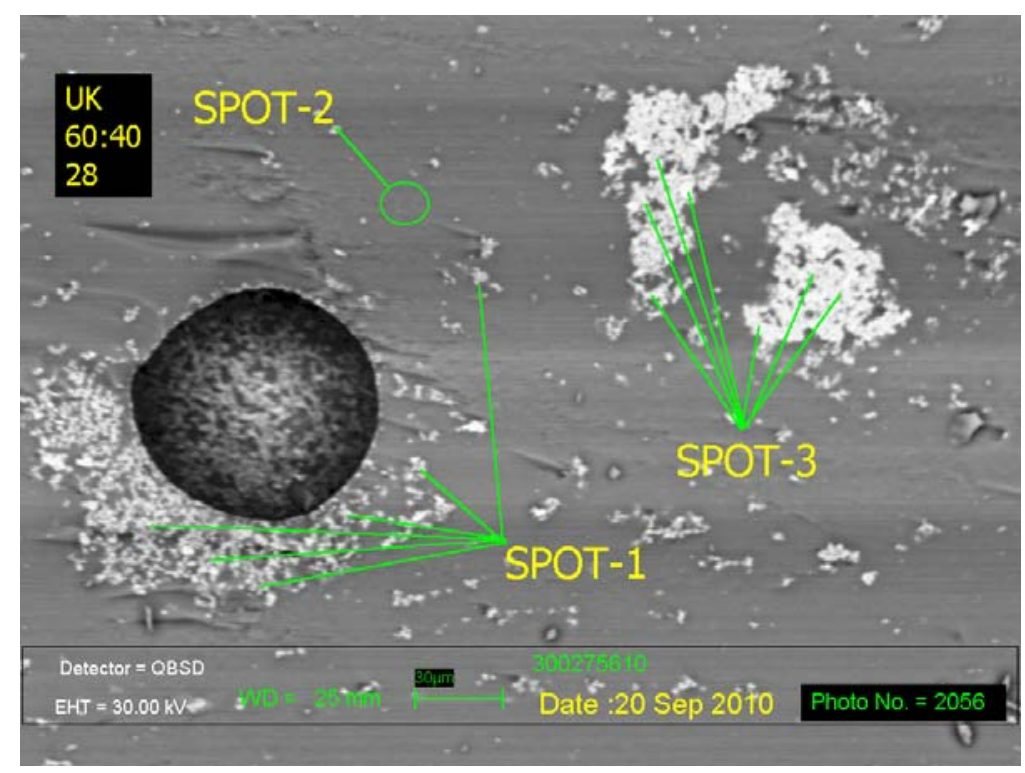

Figure B.15. SEM Micrograph of UK-60:40-28. 
SRNL-STI-2011-00012

Revision 0

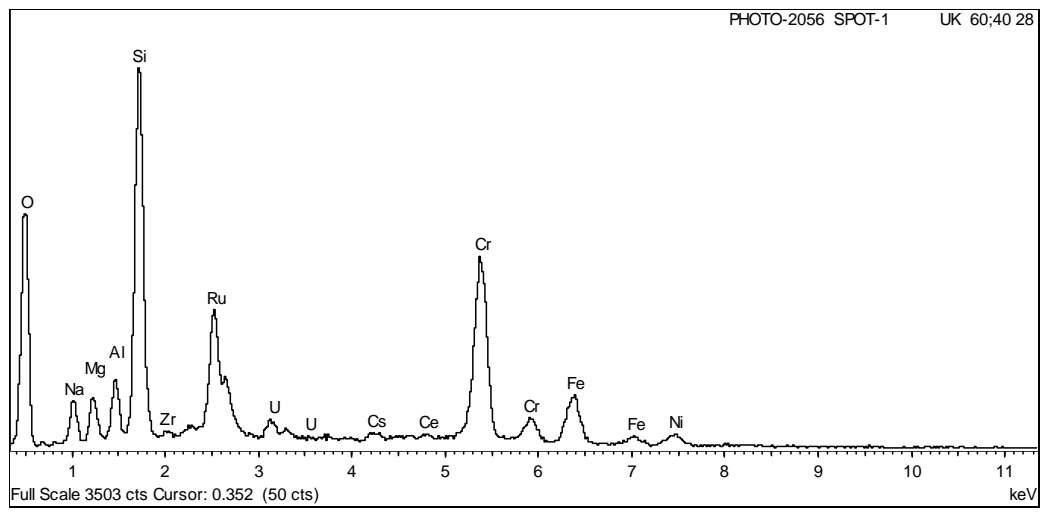

Figure B.16. EDS Analysis of Spot \#1 in Figure B.15.

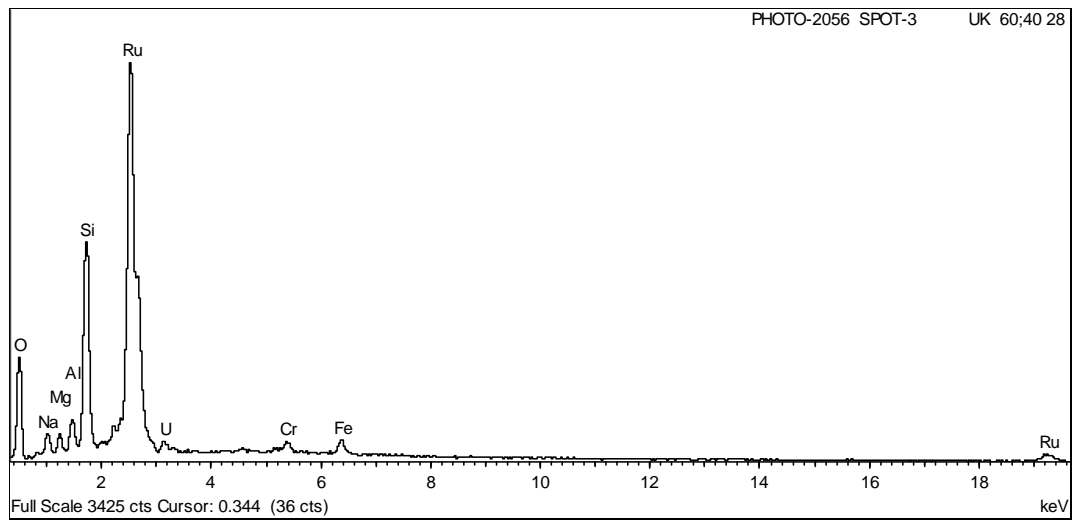

Figure B.17. EDS Analysis of Spot \#3 in Figure B.15.

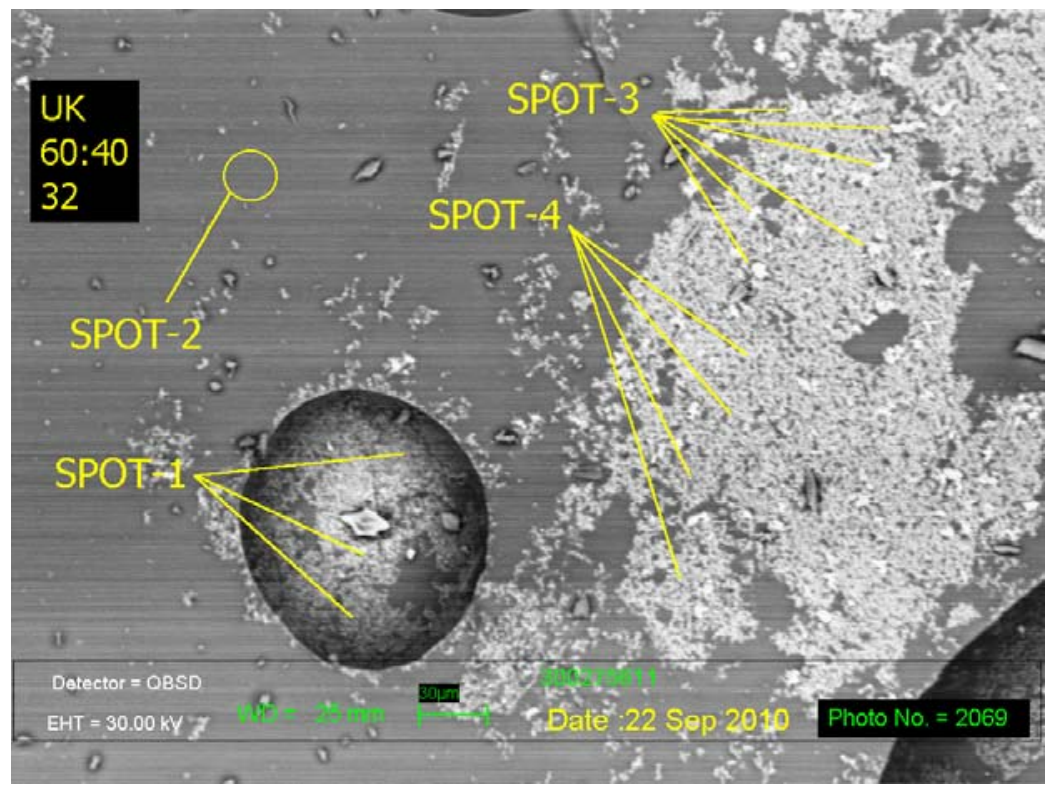

Figure B.18. SEM Micrograph of UK-60:40-32. 


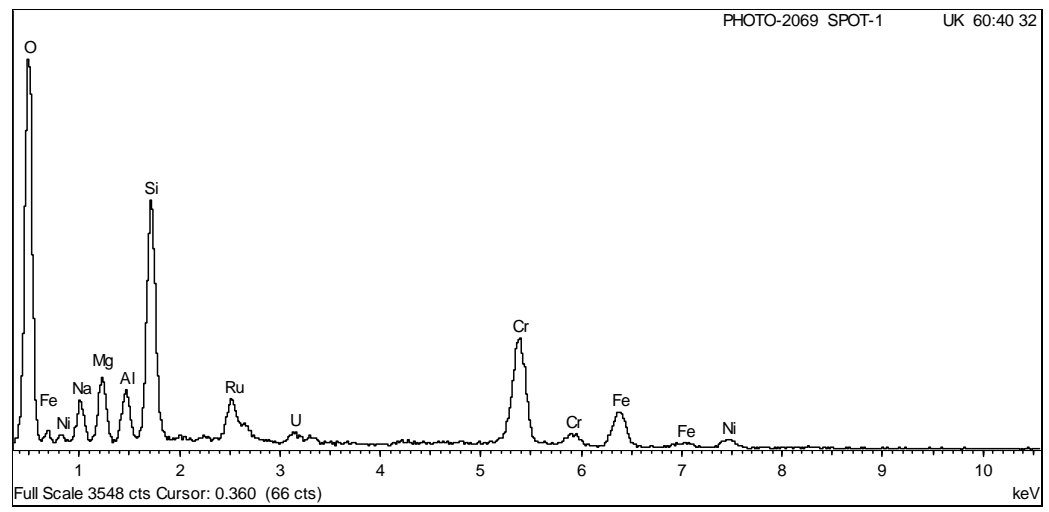

Figure B.19. EDS Analysis of Spot \#1 in Figure B.18.

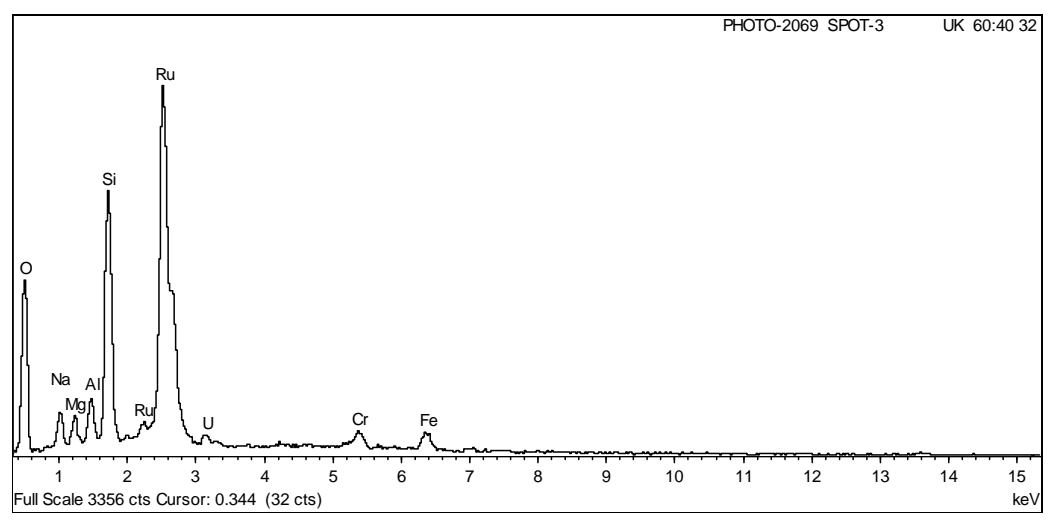

Figure B.20. EDS Analysis of Spot \#3 in Figure B.18.

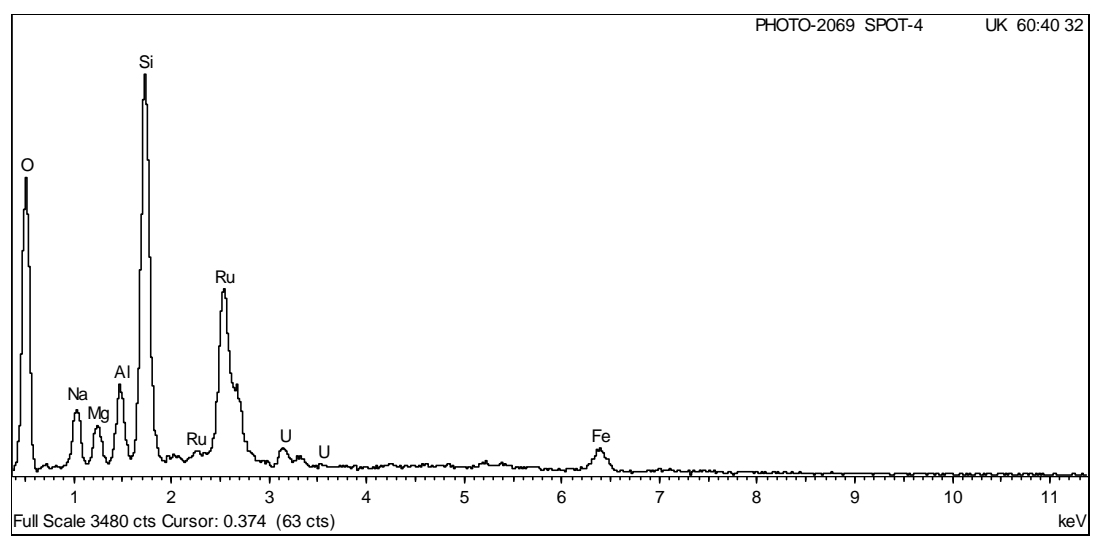

Figure B.21. EDS Analysis of Spot \#4 in Figure B.18. 




Figure B.22. SEM Micrograph of UK-75:25-25.

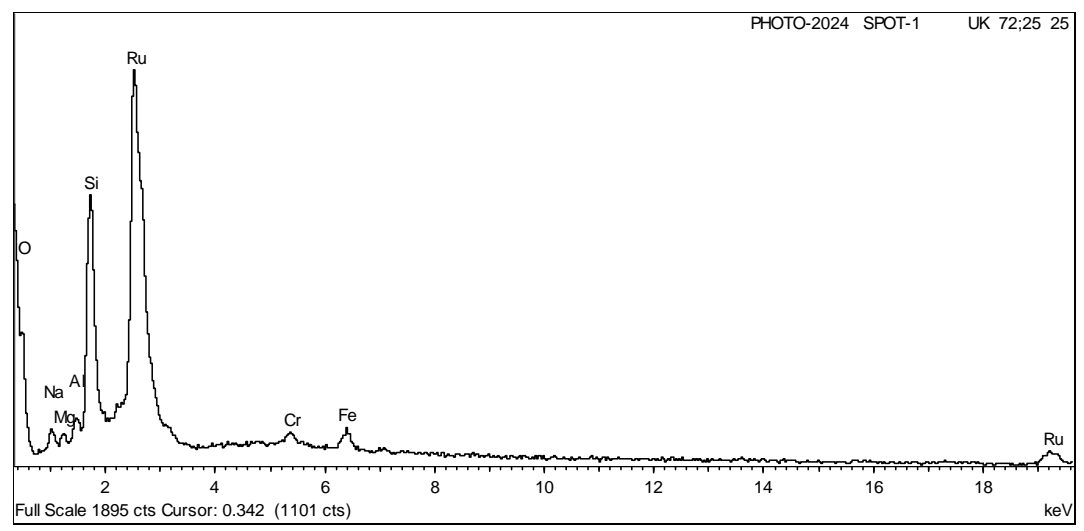

Figure B.23. EDS Analysis of Spot \#1 in Figure B.22. 
SRNL-STI-2011-00012

Revision 0

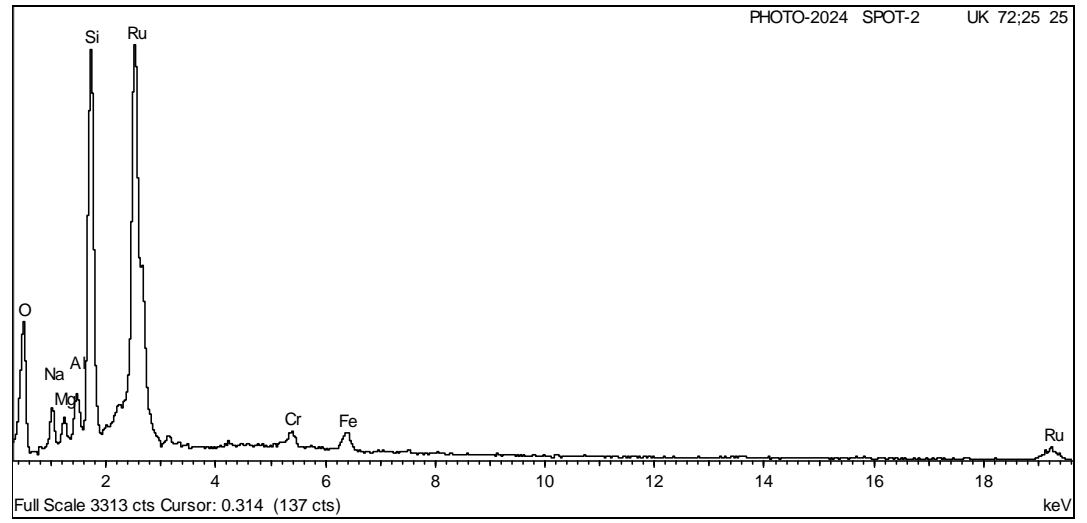

Figure B.24. EDS Analysis of Spot \#2 in Figure B.22.



Figure B.25. EDS Analysis of Spot \#3 in Figure B.22. 


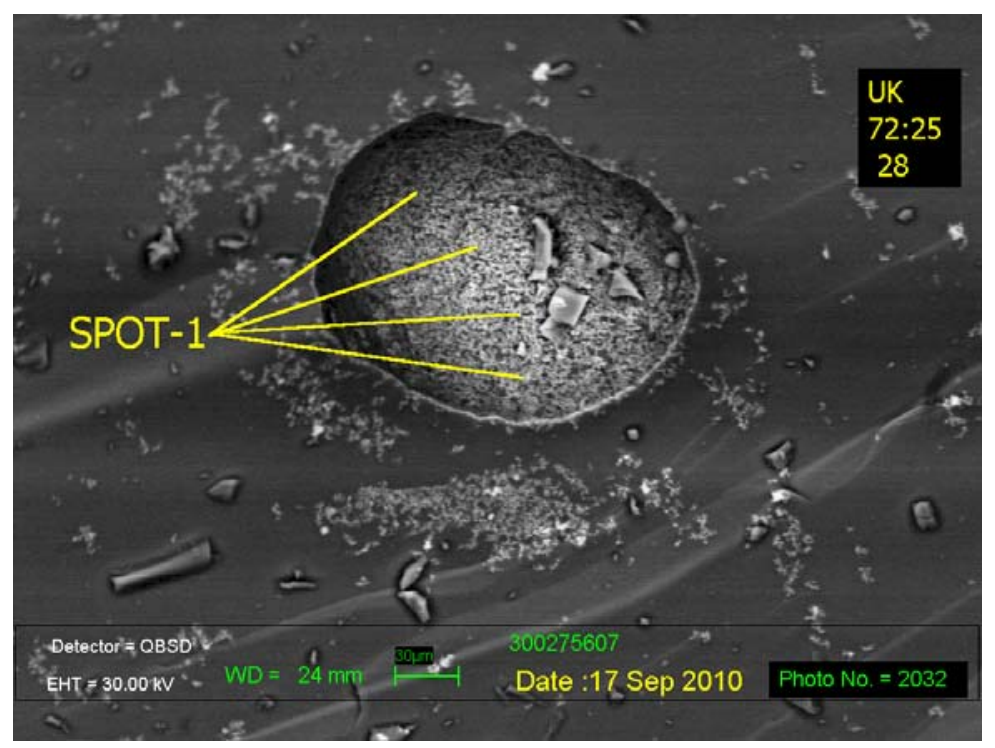

Figure B.26. SEM Micrograph of UK-75:25-28.

(note: glass ID in photo should be UK 75:25-28; not 72:25-28)

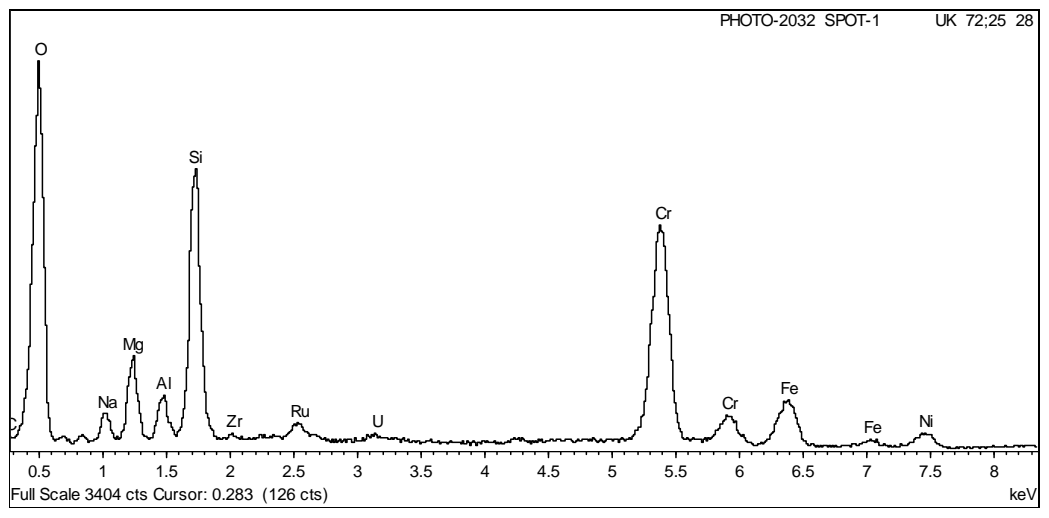

Figure B.27. EDS Analysis of Spot \#1 in Figure B.26. 


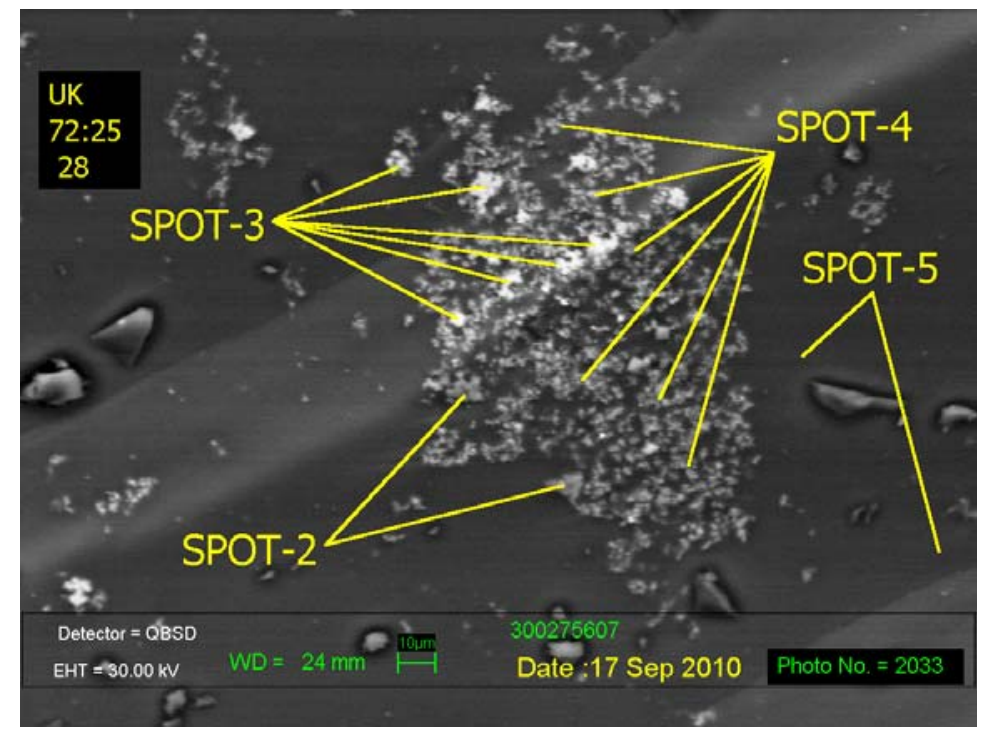

Figure B.28. SEM Micrograph of UK-75:25-28.

(note: glass ID in photo should be UK 75:25-28; not 72:25-28)

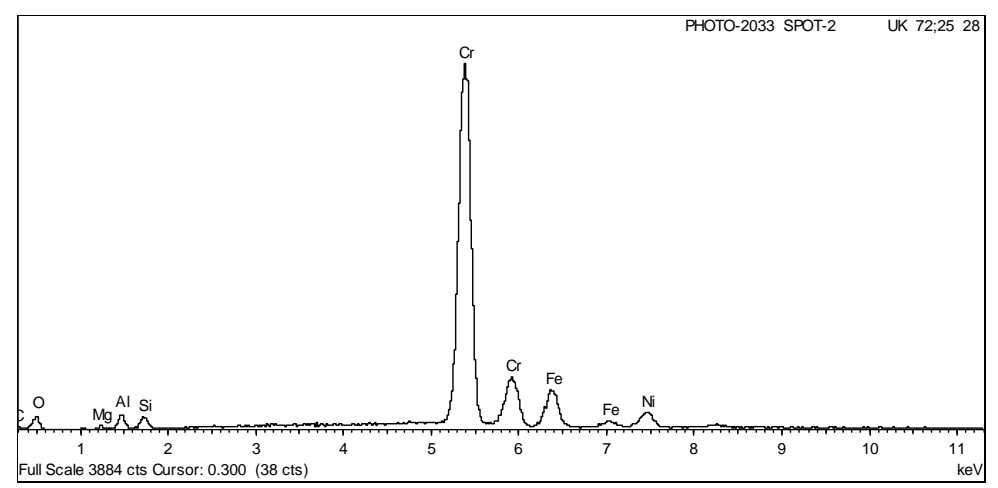

Figure B.29. EDS Analysis of Spot \#2 in Figure B.28.

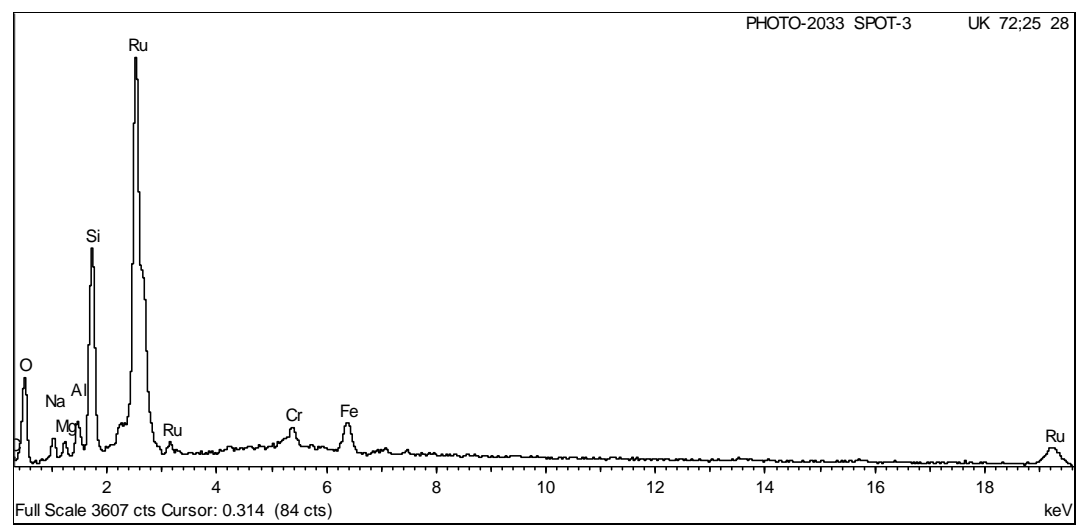

Figure B.30. EDS Analysis of Spot \#3 in Figure B.28. 
SRNL-STI-2011-00012

Revision 0

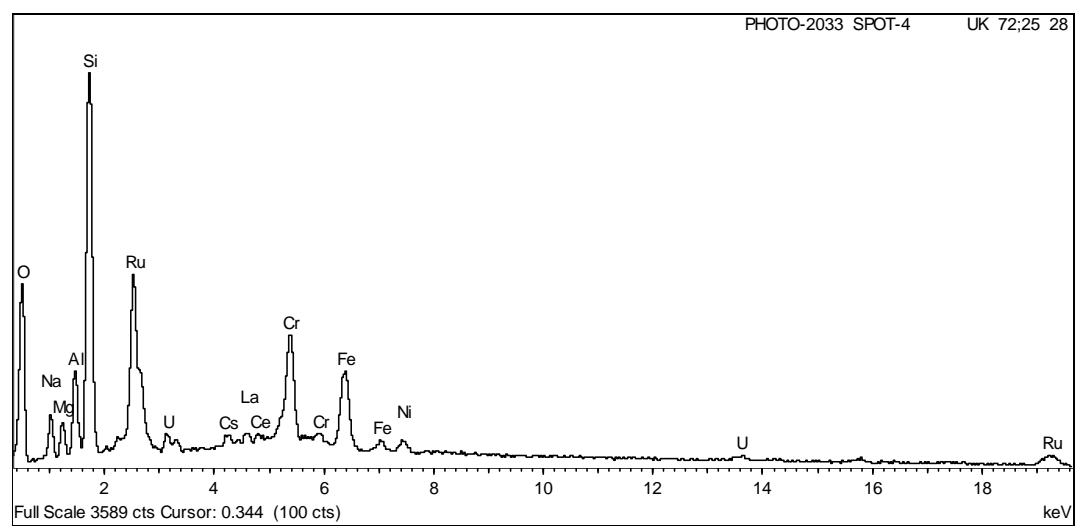

Figure B.31. EDS Analysis of Spot \#4 in Figure B.28.

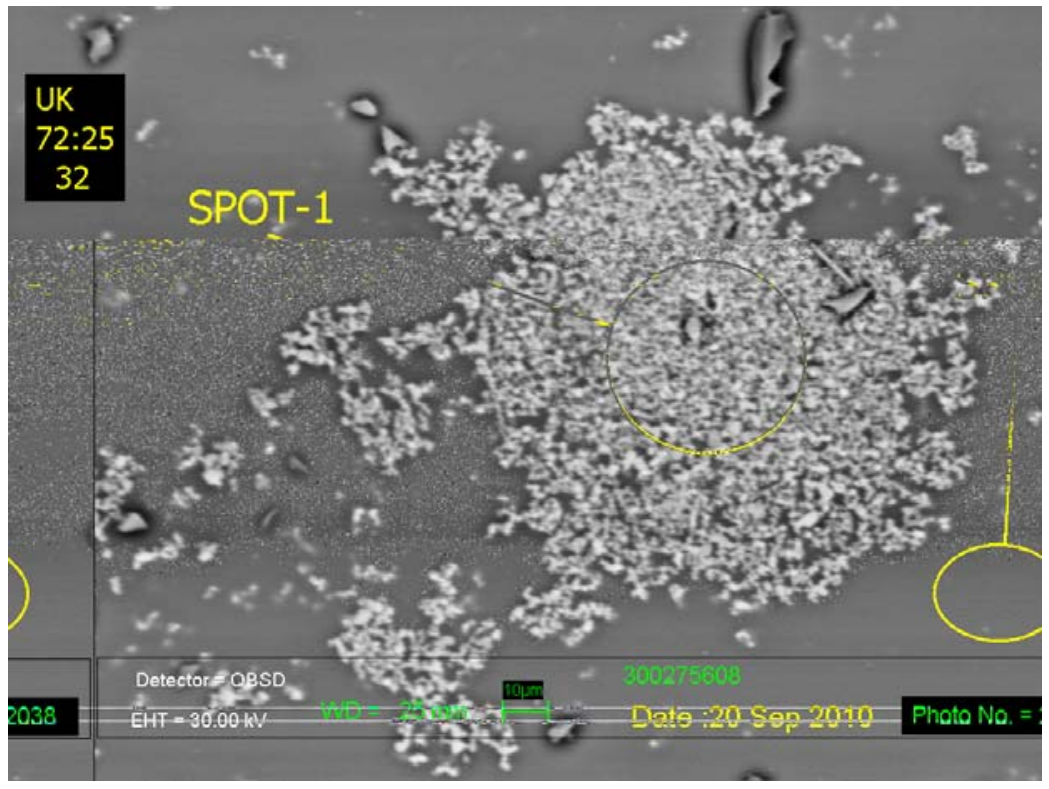

Figure B.32. SEM Micrograph of UK-75:25-32. 
SRNL-STI-2011-00012

Revision 0

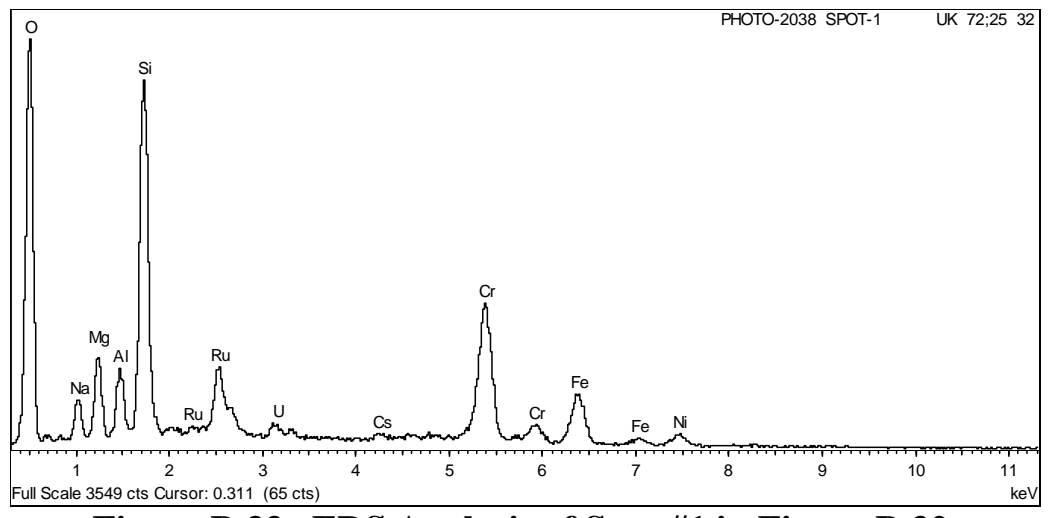

Figure B.33. EDS Analysis of Spot \#1 in Figure B.32.

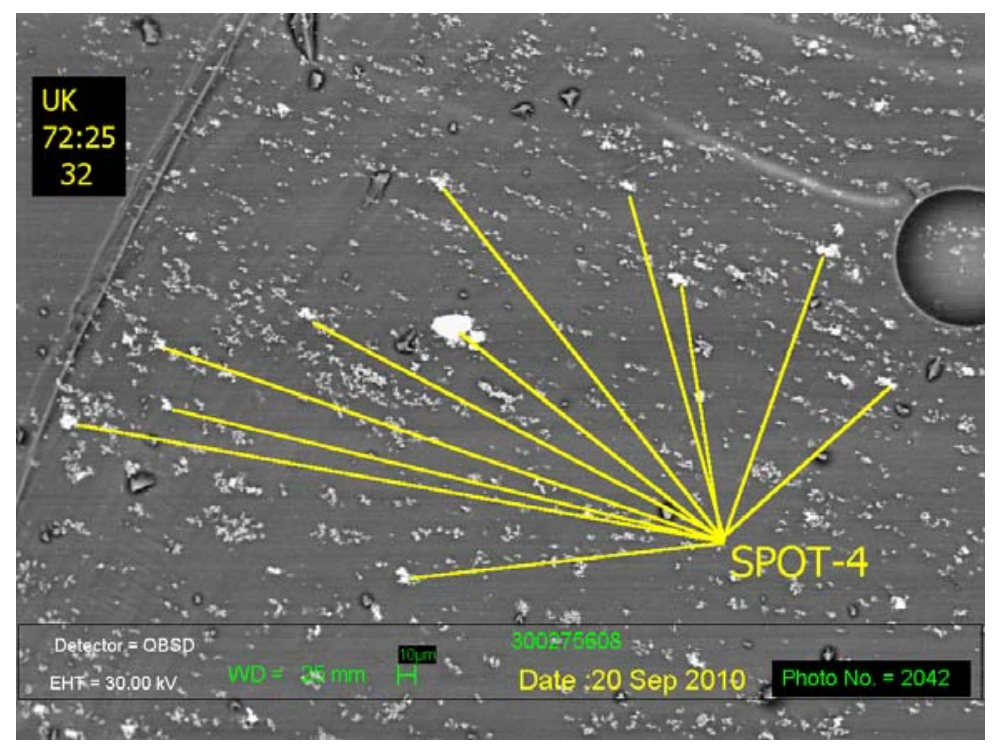

Figure B.34. SEM Micrograph of UK-75:25-32. 
SRNL-STI-2011-00012

Revision 0

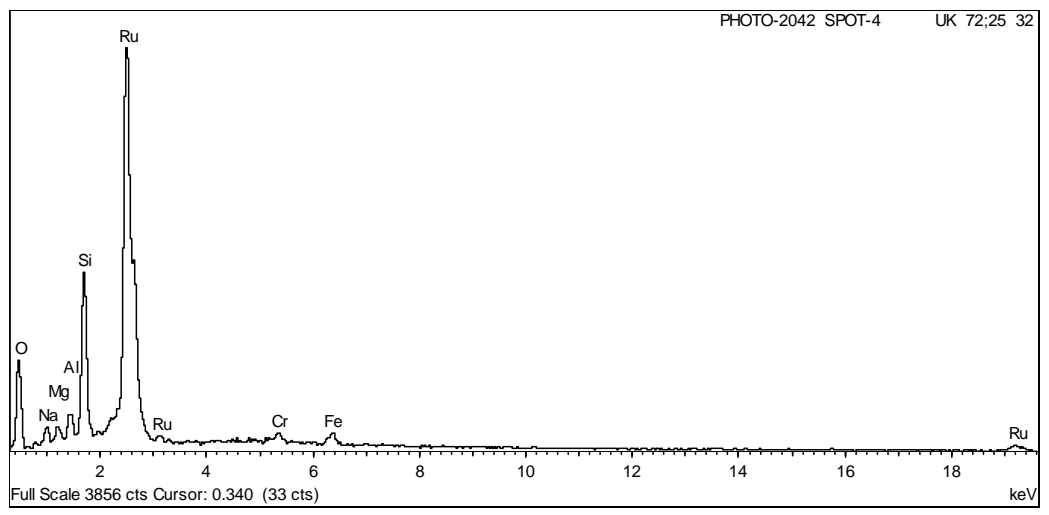

Figure B.35. EDS Analysis of Spot \#4 in Figure B.34.

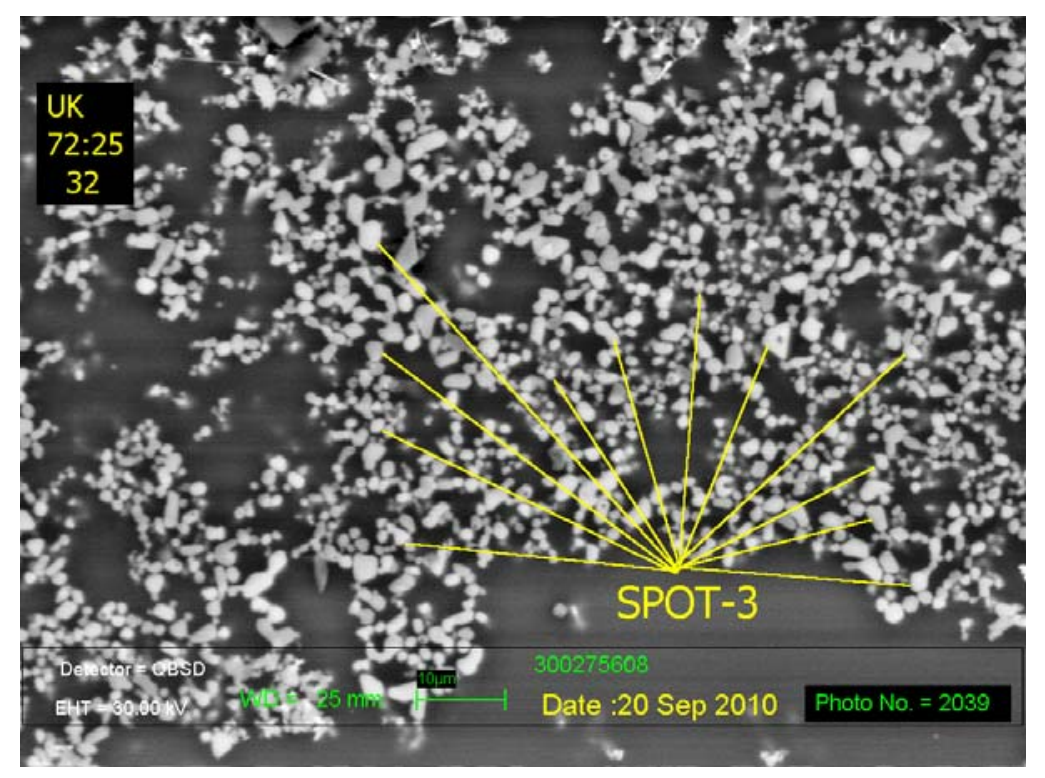

Figure B.36. SEM Micrograph of UK-75:25-32.



Figure B.37. EDS Analysis of Spot \#3 in Figure B.36. 
SRNL-STI-2011-00012

Revision 0

\section{Appendix C}

PCT Results 
Figure C.1 (series). Individual ppm Values for Each Glass as a Function of Time.

(plots provided to show reproducibility of the duplicate measurements for each glass and time period)

\section{Variability Chart for Al (ppm)}

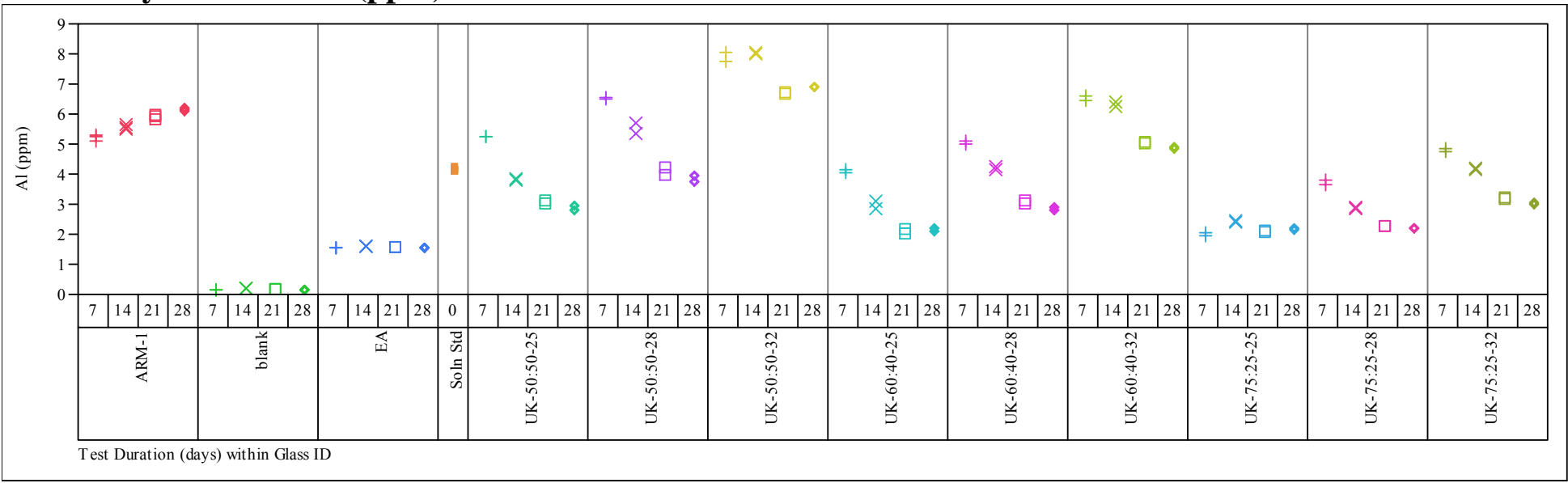

\section{Variability Chart for B (ppm)}

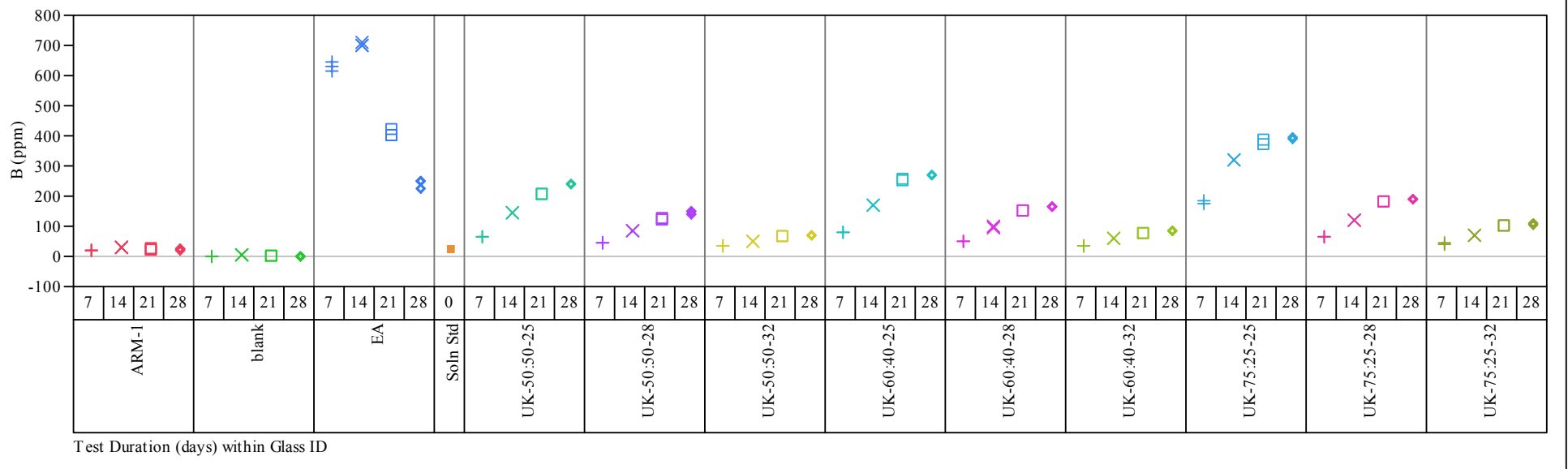


Figure C.1 (series). Individual ppm Values for Each Glass as a Function of Time.

(plots provided to show reproducibility of the duplicate measurements for each glass and time period)

\section{Variability Chart for Fe (ppm)}



\section{Variability Chart for Li (ppm)}

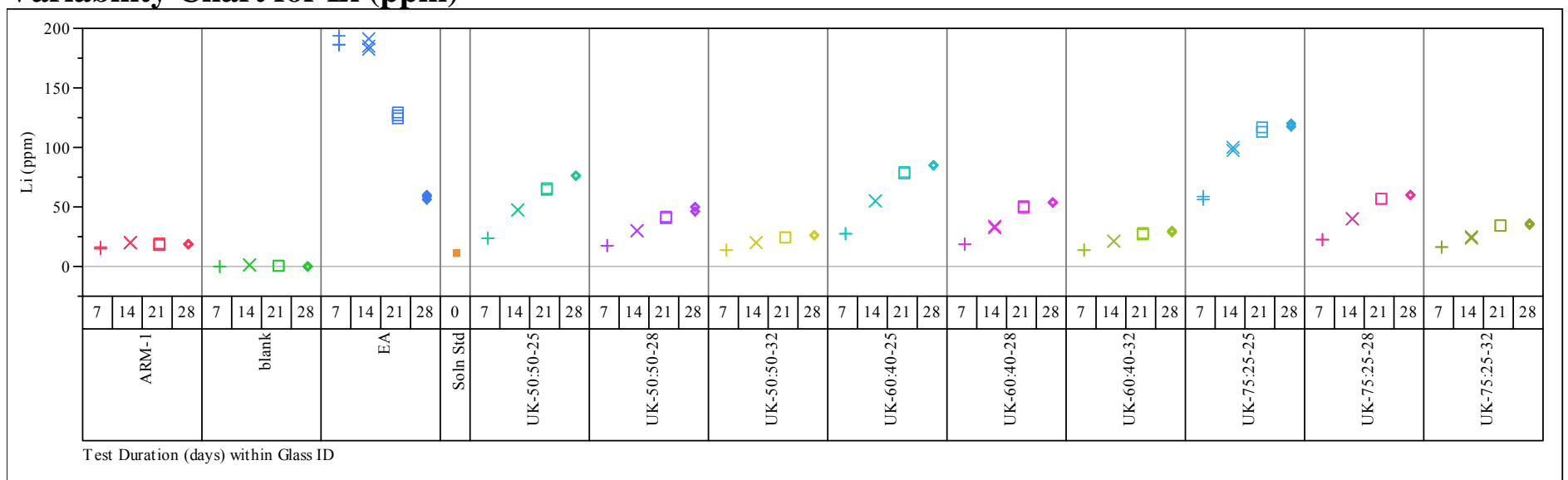


Figure C.1 (series). Individual ppm Values for Each Glass as a Function of Time. (plots provided to show reproducibility of the duplicate measurements for each glass and time period)

\section{Variability Chart for Mg (ppm)}

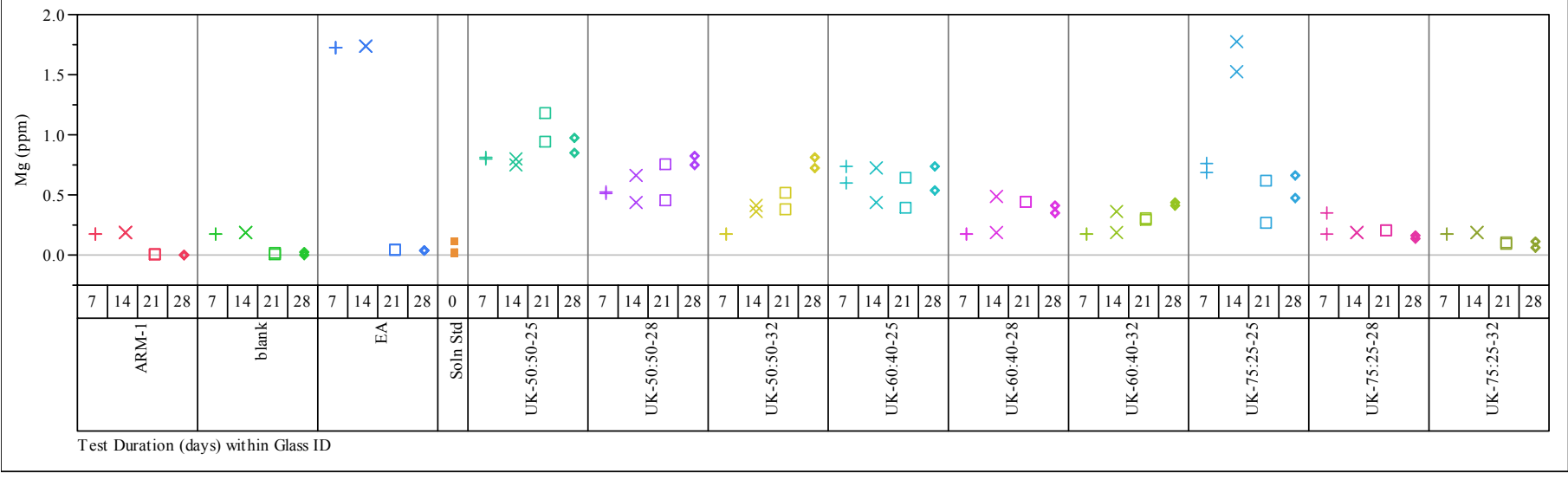

\section{Variability Chart for Mo (ppm)}

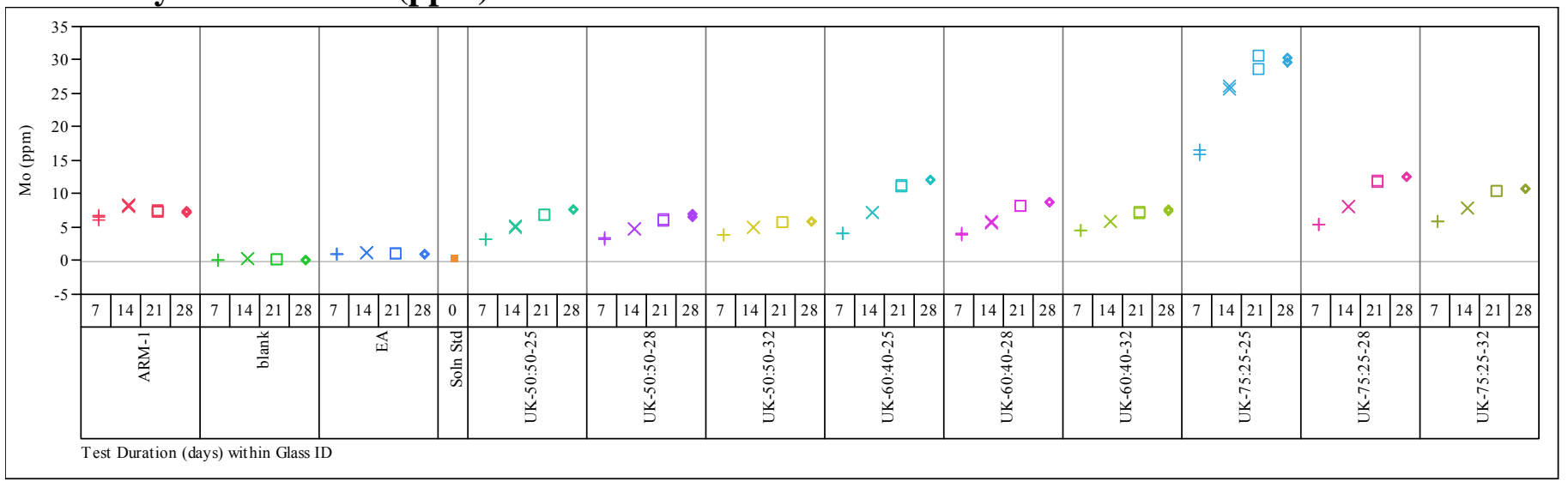


Figure C.1 (series). Individual ppm Values for Each Glass as a Function of Time.

(plots provided to show reproducibility of the duplicate measurements for each glass and time period)

Variability Chart for Na (ppm)

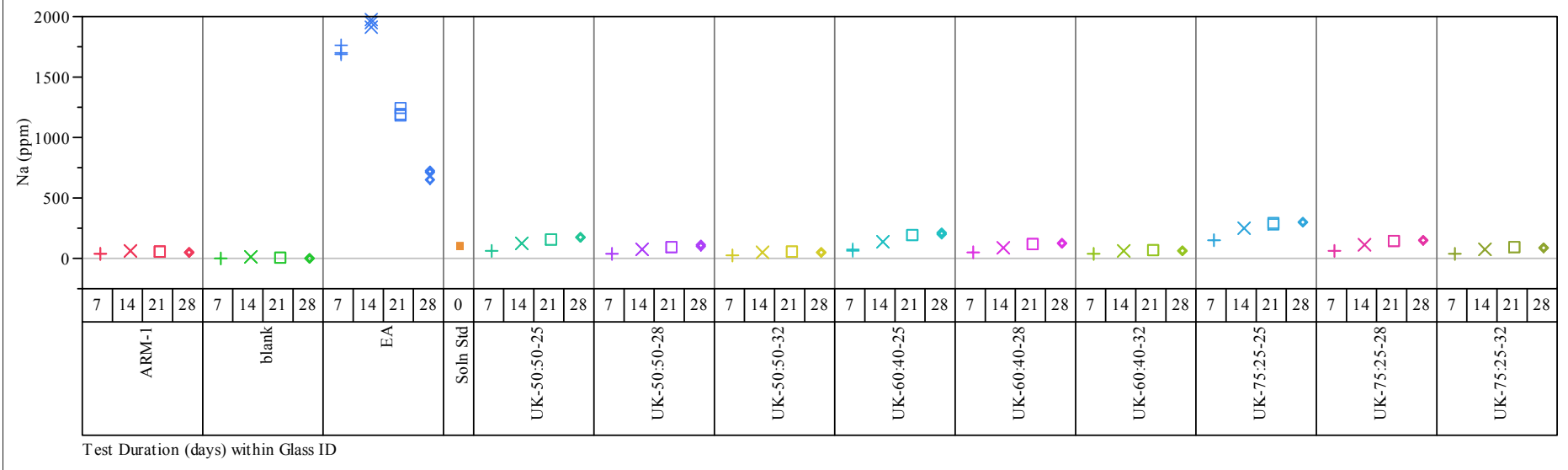

\section{Variability Chart for Si (ppm)}

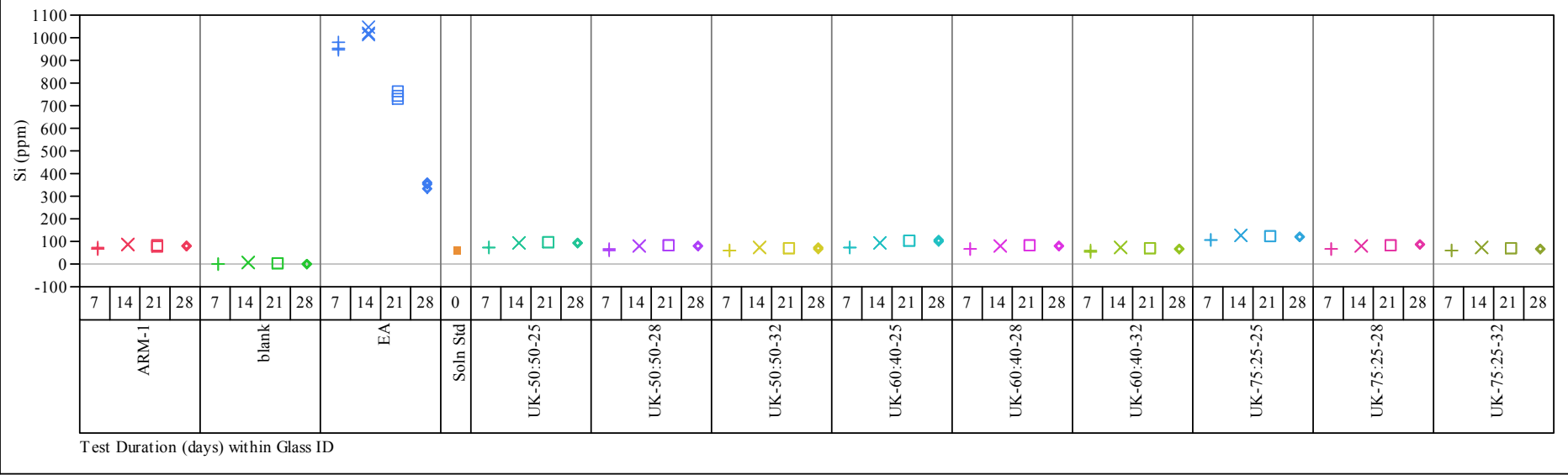


Figure C.1 (series). Individual ppm Values for Each Glass as a Function of Time.

(plots provided to show reproducibility of the duplicate measurements for each glass and time period)

\section{Variability Chart for $\mathbf{U}$ (ppm)}

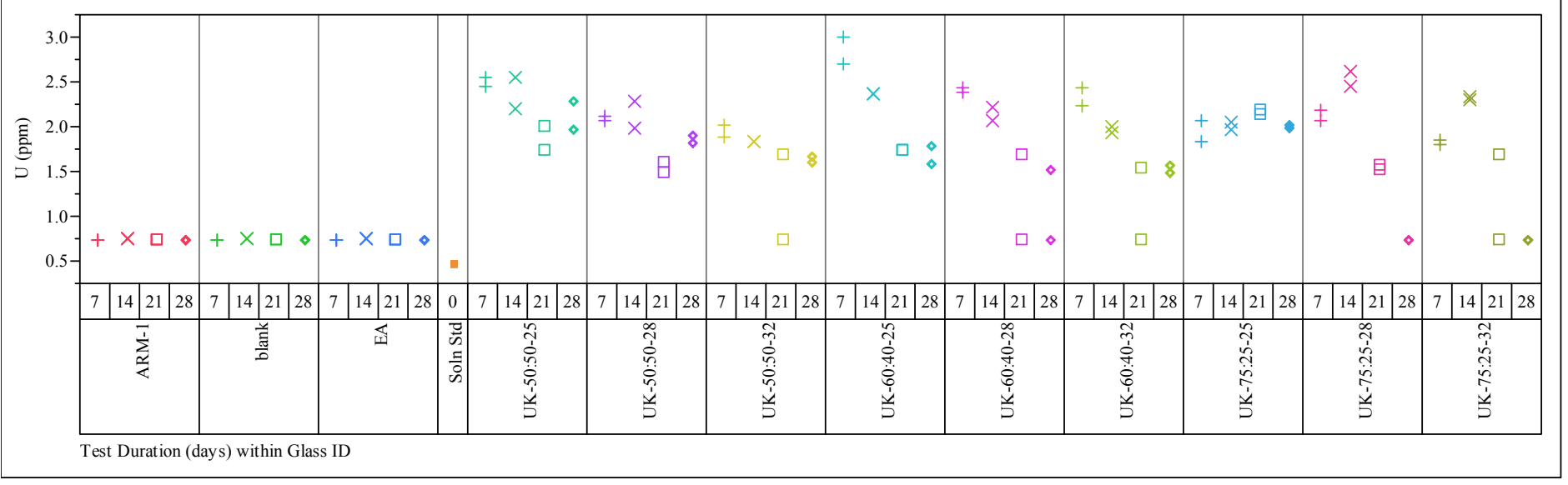


Figure C.2 (series). Individual ppm Values for Each UK Study Glass as a Function of Time (without the EA Glass or other reference glasses to expand y-axis scale).

\section{Variability Chart for Al (ppm)}

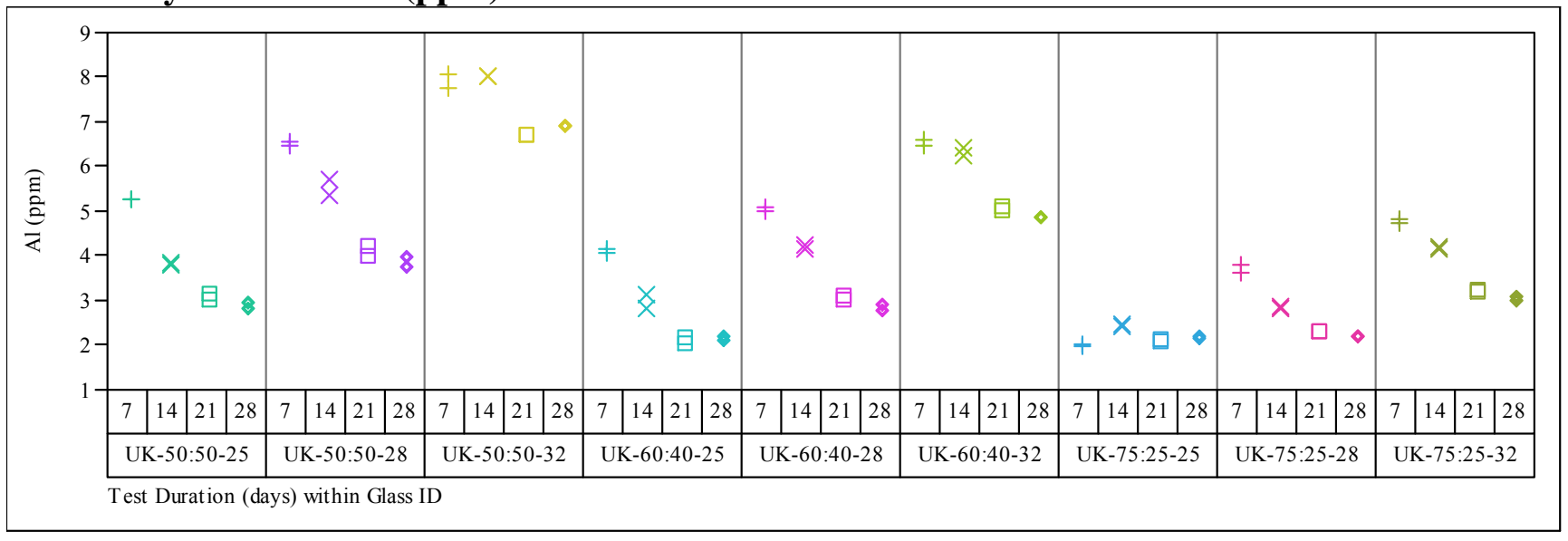

\section{Variability Chart for B (ppm)}

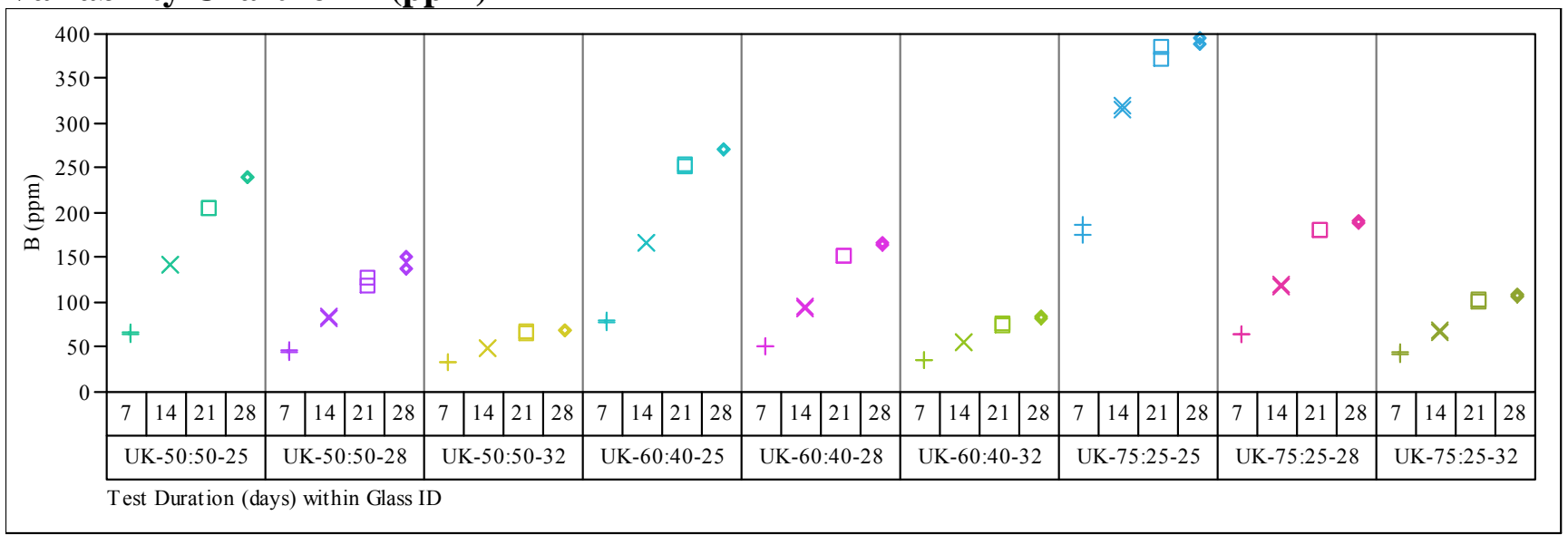


Figure C.2 (series). Individual ppm Values for Each UK Study Glass as a Function of Time (without the EA Glass or other reference glasses to expand y-axis scale).

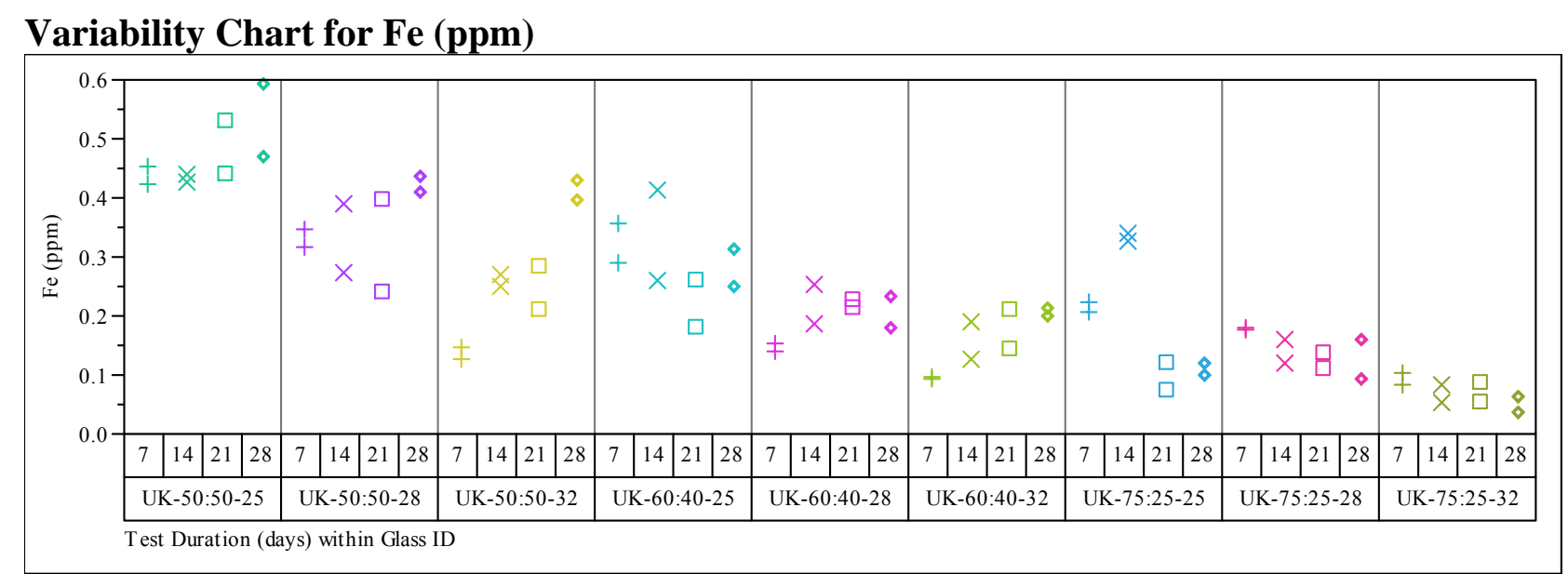

\section{Variability Chart for Li (ppm)}

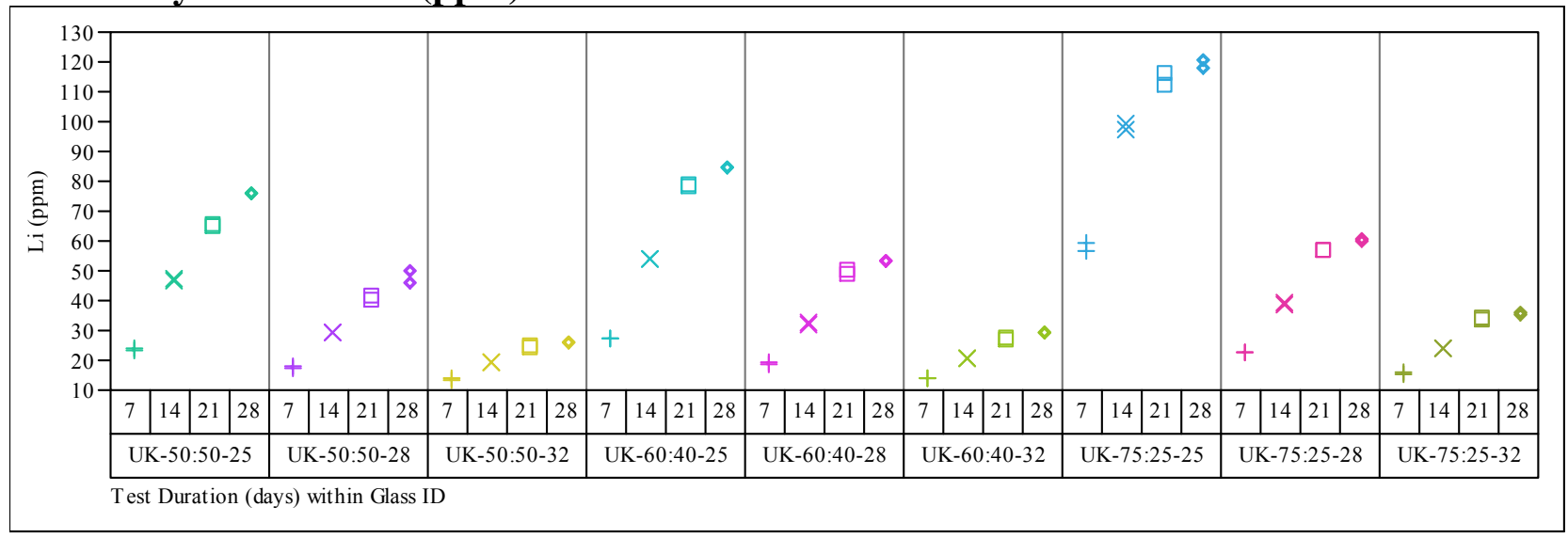


Figure C.2 (series). Individual ppm Values for Each UK Study Glass as a Function of Time (without the EA Glass or other reference glasses to expand y-axis scale).

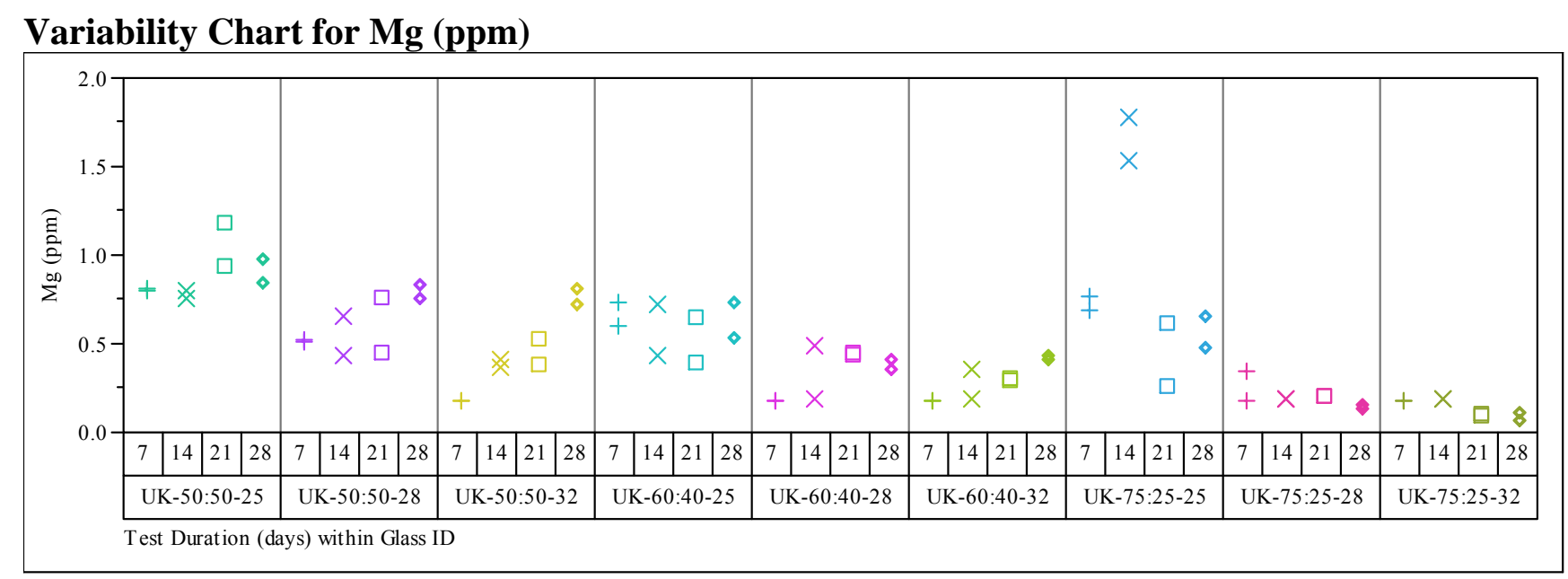

\section{Variability Chart for Mo (ppm)}

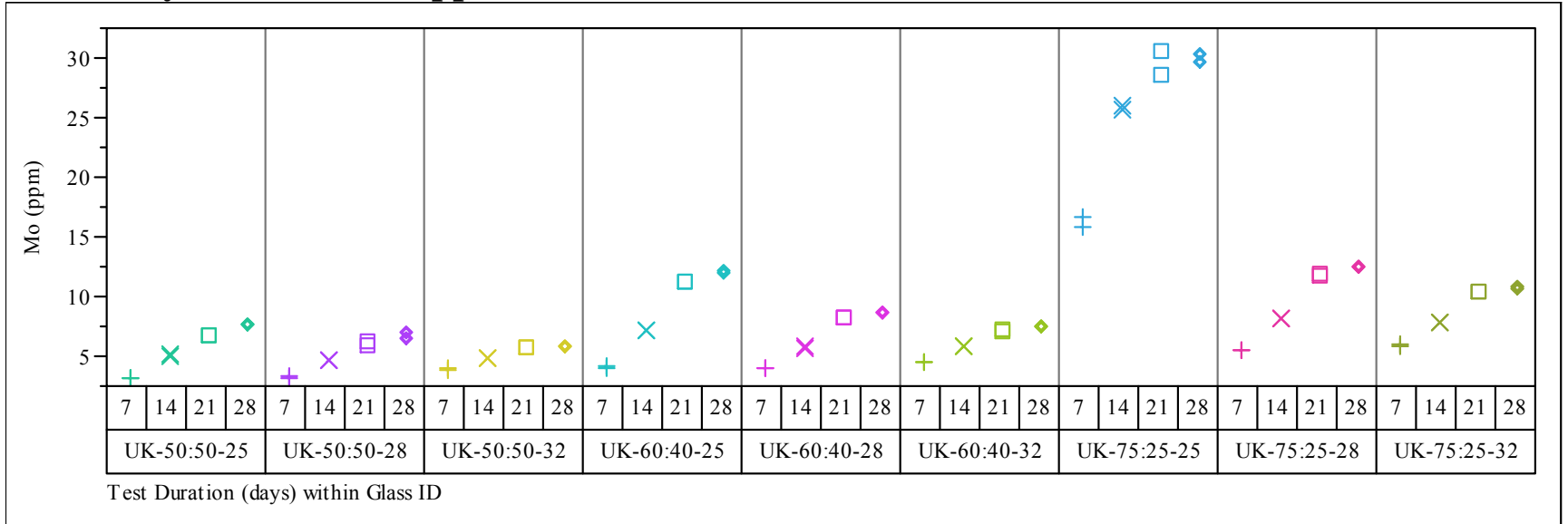


Figure C.2 (series). Individual ppm Values for Each UK Study Glass as a Function of Time (without the EA Glass or other reference glasses to expand y-axis scale).

\section{Variability Chart for Na (ppm)}

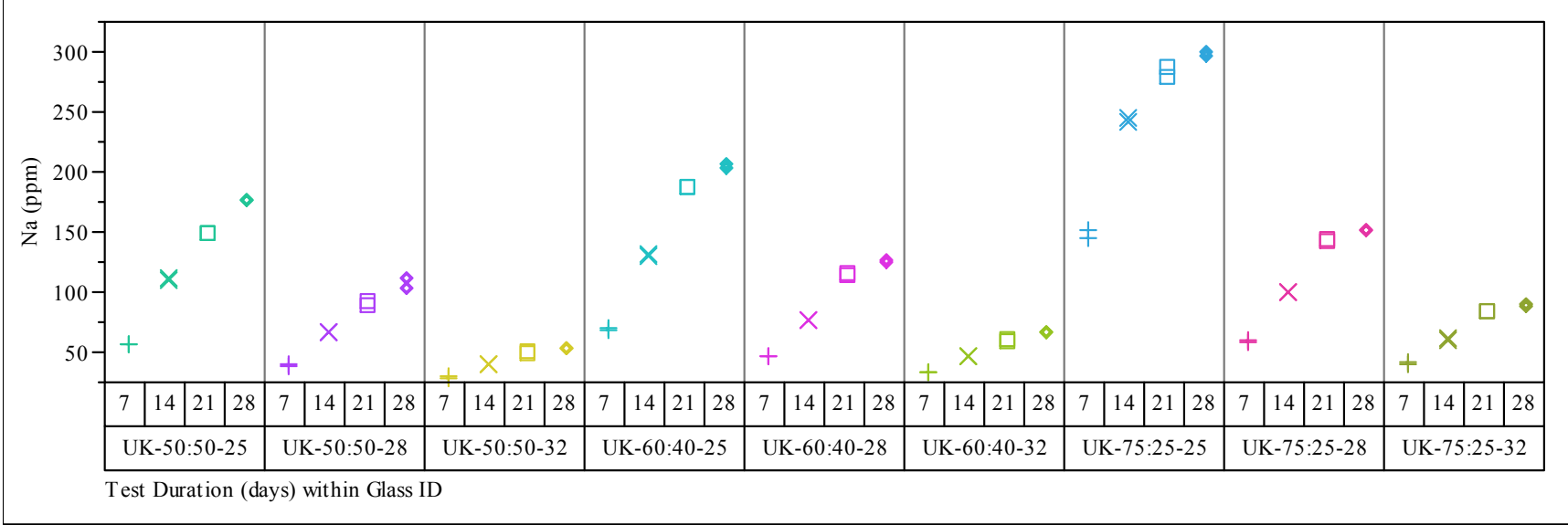

\section{Variability Chart for Si (ppm)}

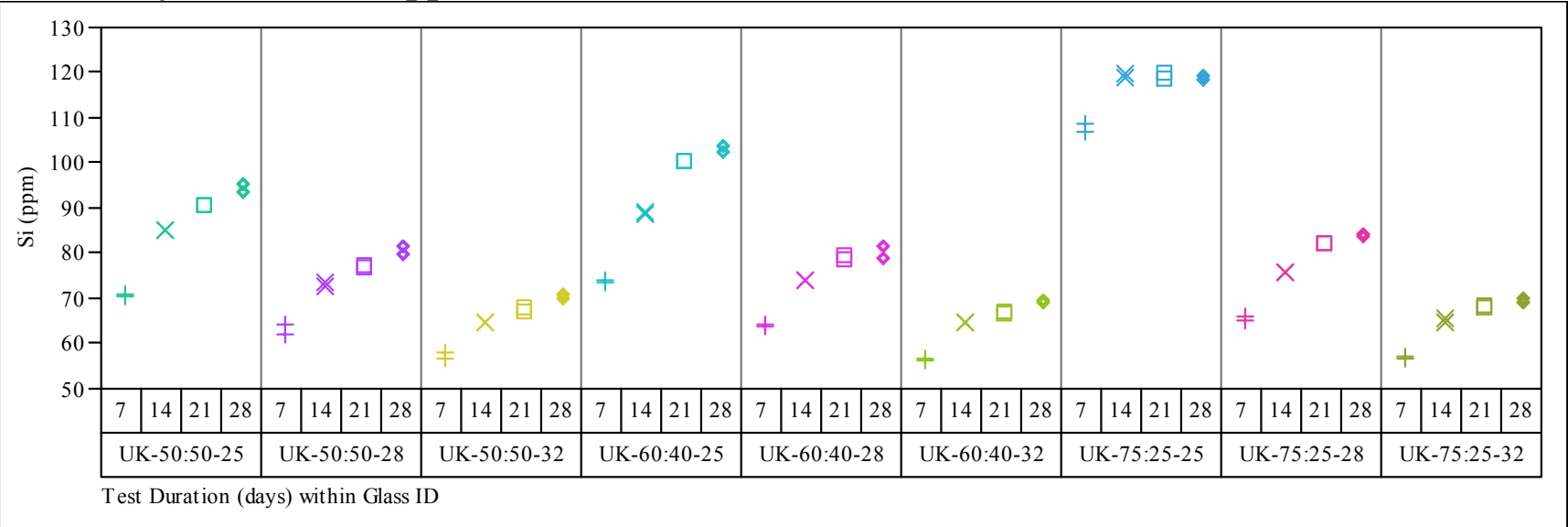


Figure C.2 (series). Individual ppm Values for Each UK Study Glass as a Function of Time (without the EA Glass or other reference glasses to expand y-axis scale).

\section{Variability Chart for U (ppm)}

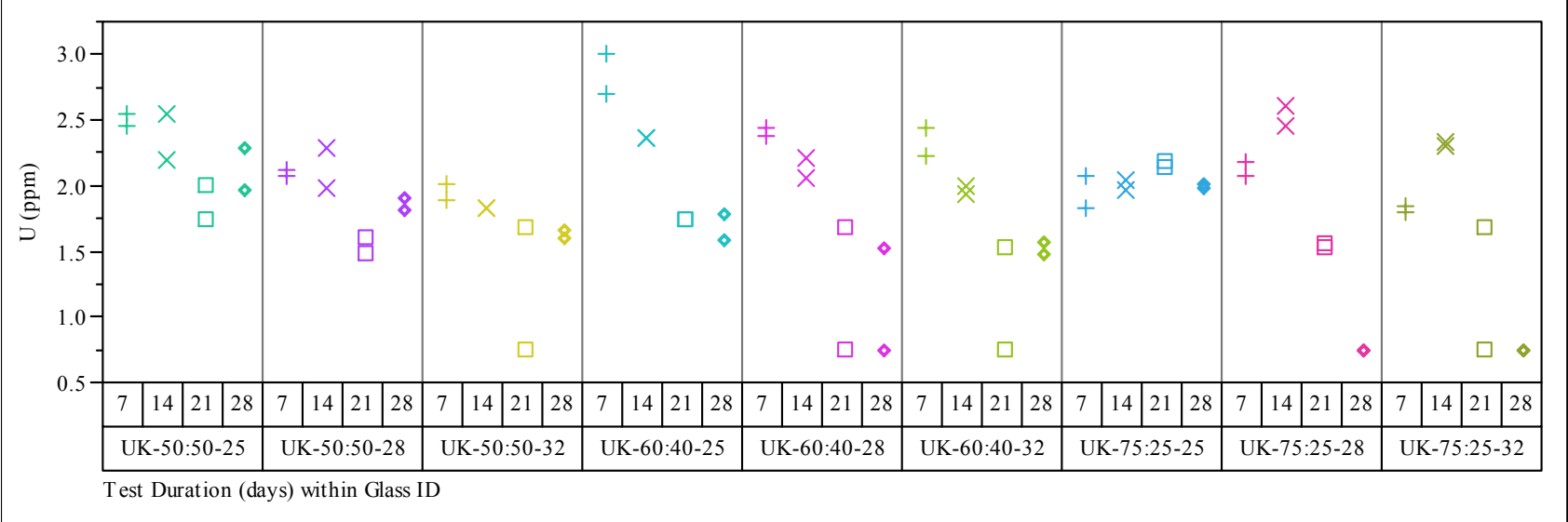


Figure C.3 (series). Variability Charts for log Normalized Elemental Releases Each Glass as a Function of Time. (without EA or other reference glasses shown to expand y-axis)

\section{Variability Chart for $\log \mathrm{NL}[\mathrm{Al}(\mathrm{g} / \mathrm{L})]$}

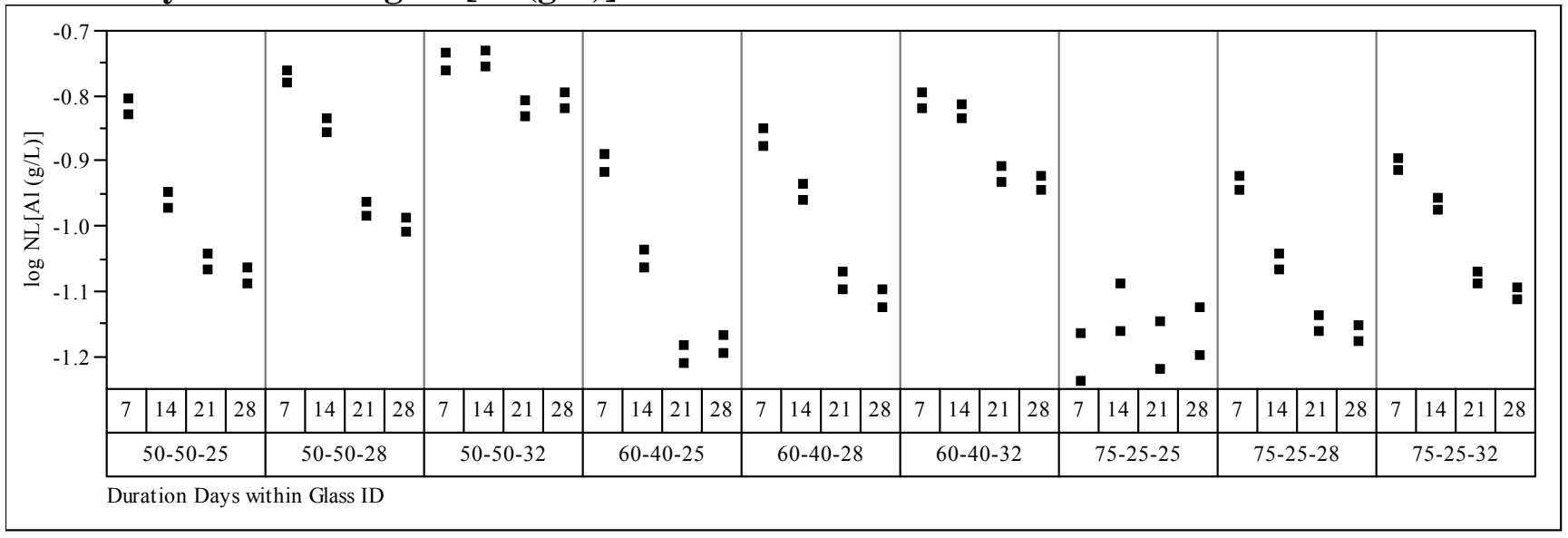

\section{Variability Chart for $\log$ NL[B (g/L)]}

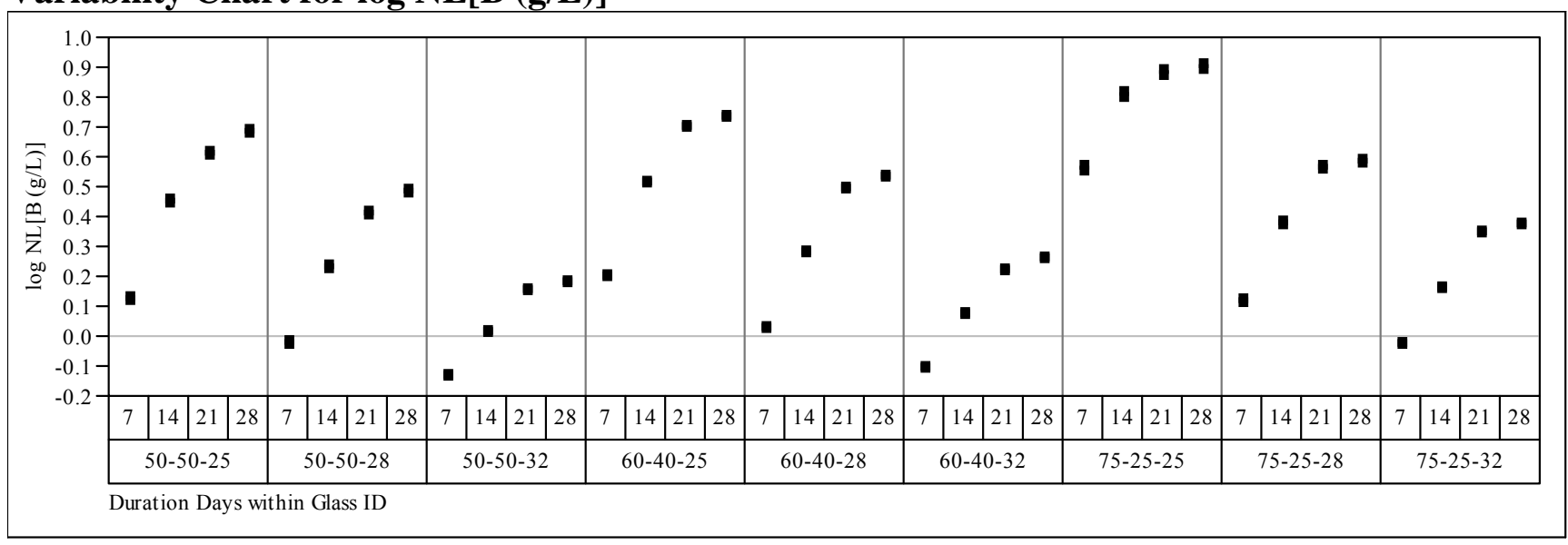


Figure C.3 (series). Variability Charts for log Normalized Elemental Releases Each Glass as a Function of Time. (without EA or other reference glasses shown to expand y-axis)

Variability Chart for $\log$ NL[Fe (g/L)]

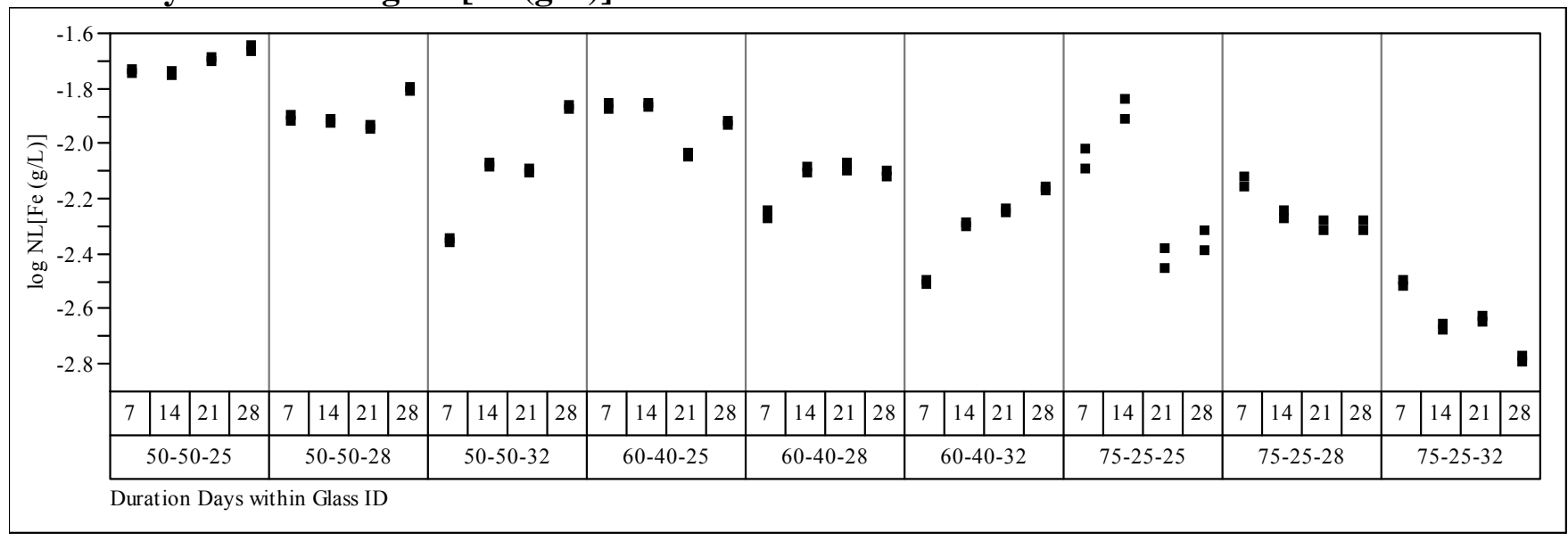

\section{Variability Chart for log NL[Li(g/L)]}

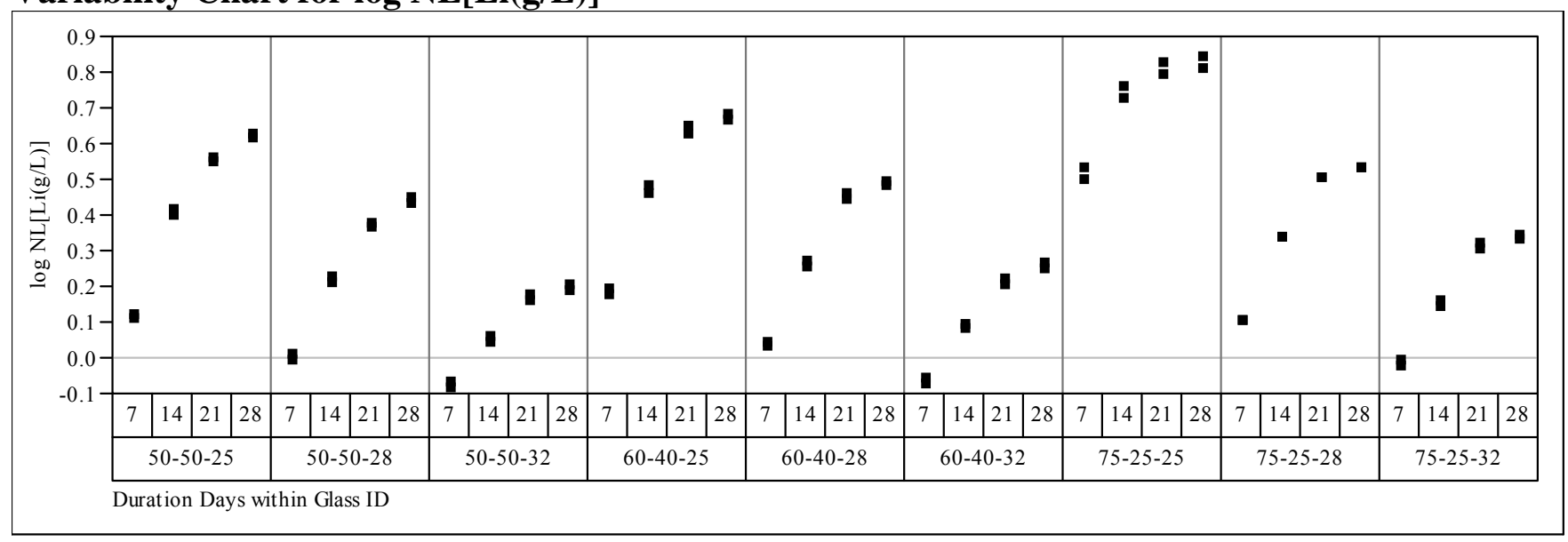


Figure C.3 (series). Variability Charts for log Normalized Elemental Releases Each Glass as a Function of Time. (without EA or other reference glasses shown to expand y-axis)

\section{Variability Chart for $\log \mathrm{NL}[\mathrm{Mg}(\mathrm{g} / \mathrm{L})]$}

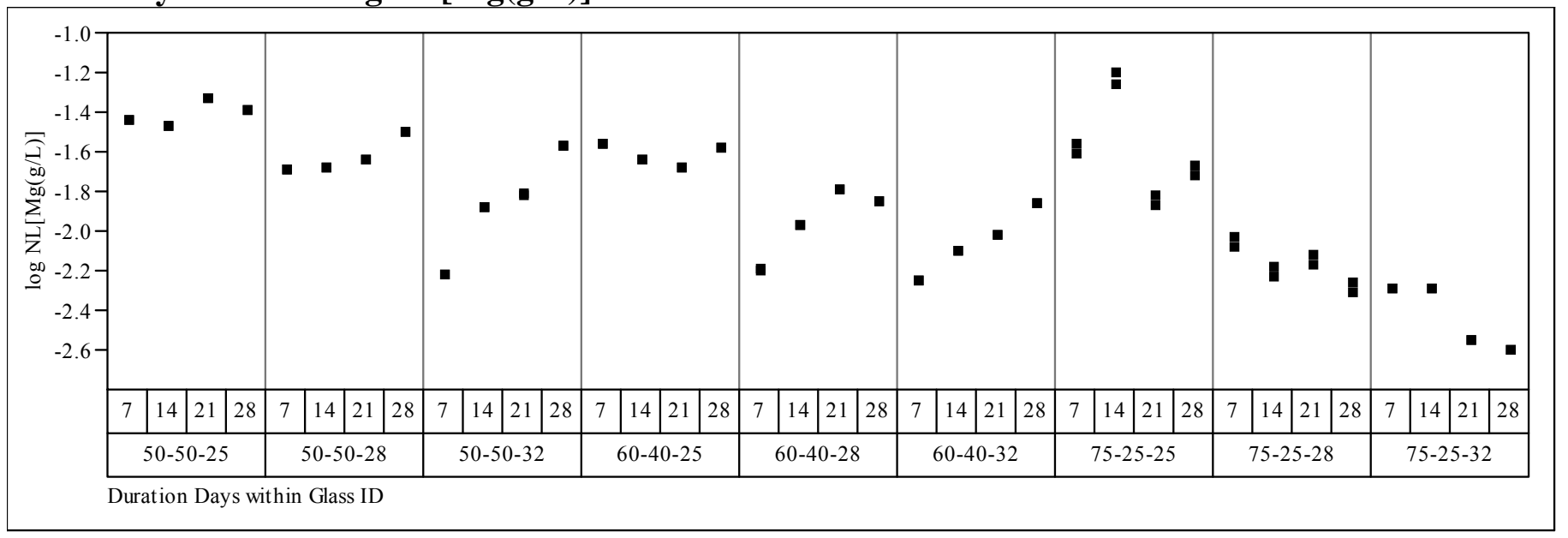


Figure C.3 (series). Variability Charts for log Normalized Elemental Releases Each Glass as a Function of Time. (without EA or other reference glasses shown to expand y-axis)

\section{Variability Chart for $\log \mathrm{NL}[\mathrm{Mo}(\mathrm{g} / \mathrm{L})]$}

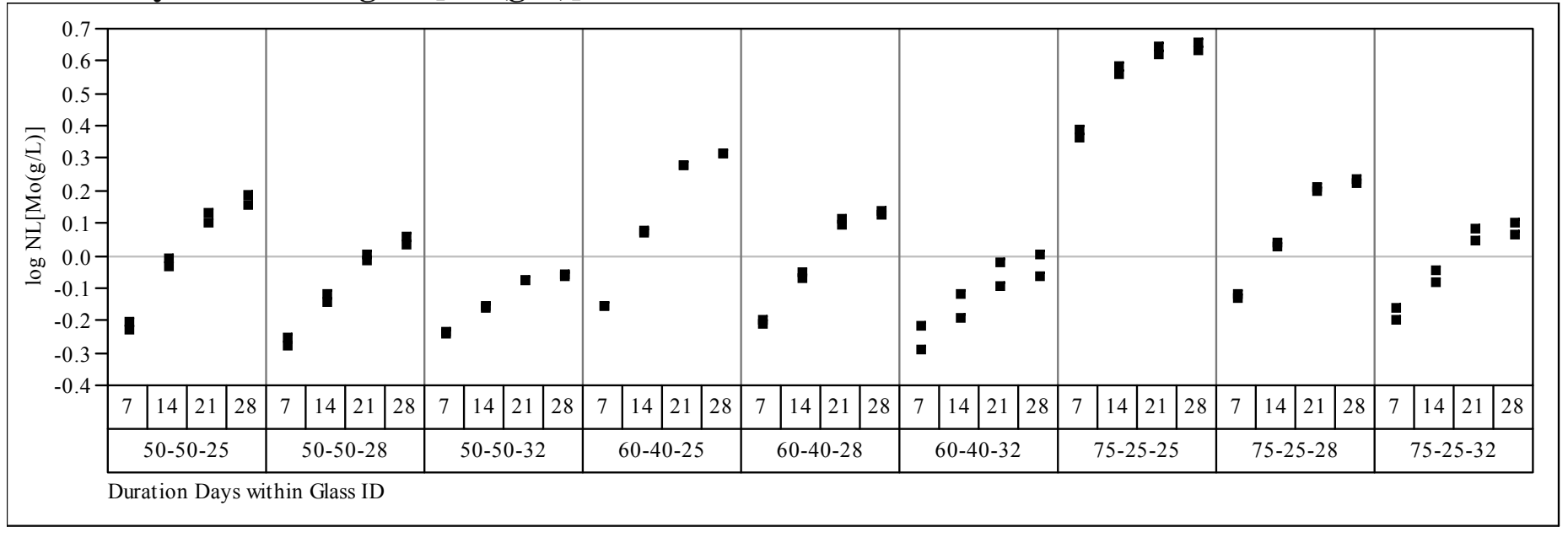


Figure C.3 (series). Variability Charts for log Normalized Elemental Releases Each Glass as a Function of Time. (without EA or other reference glasses shown to expand y-axis)



\section{Variability Chart for log NL[Si (g/L)]}

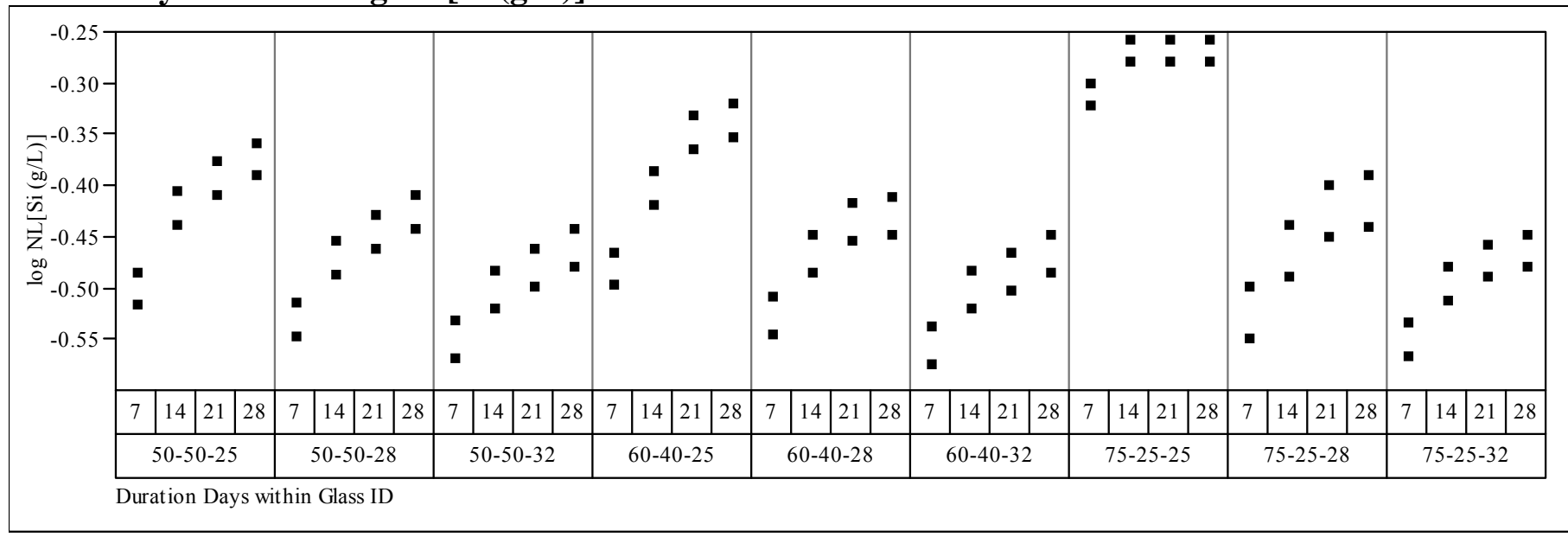


Figure C.3 (series). Variability Charts for log Normalized Elemental Releases Each Glass as a Function of Time. (without EA or other reference glasses shown to expand y-axis)

\section{Variability Chart for $\log$ NL[U (g/L)]}

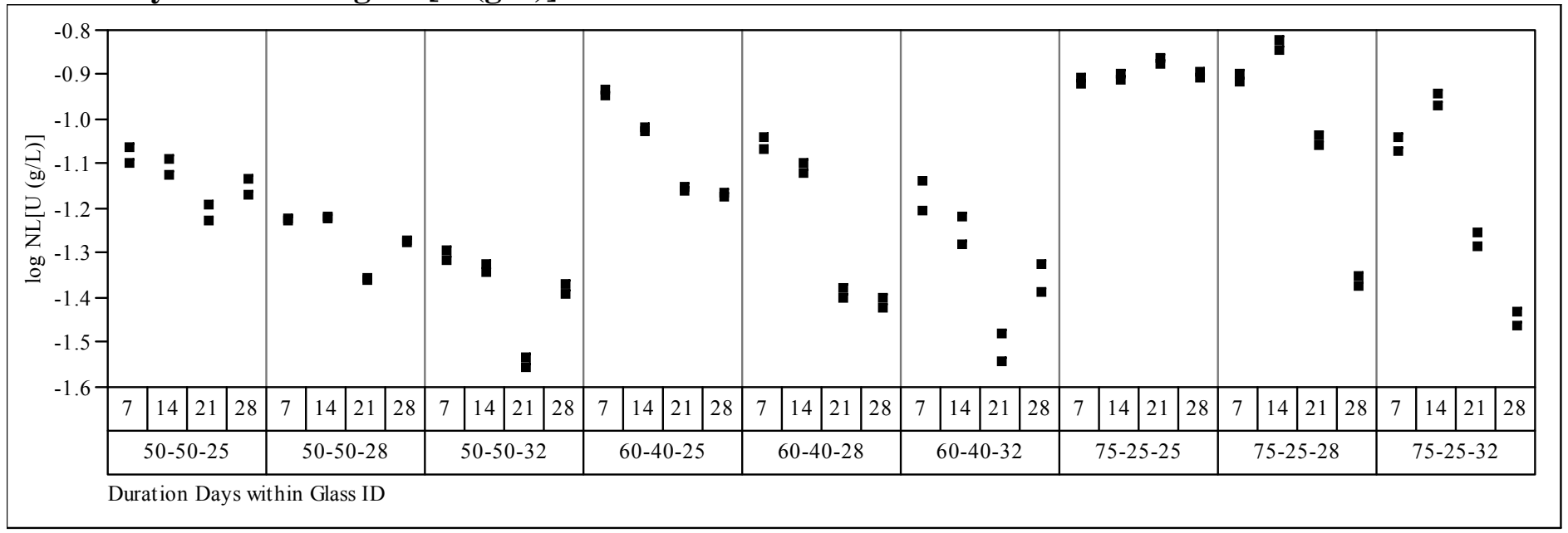


SRNL-STI-2011-00012

Revision 0

\section{Appendix D}

Viscosity Data 
Table D.1. High Temperature Viscosity Data

\begin{tabular}{|c|c|c|c|c|c|c|}
\hline Glass ID & $\begin{array}{l}\text { Temp } \\
\left({ }^{\circ} \mathrm{C}\right)\end{array}$ & $\begin{array}{c}\begin{array}{c}\text { Viscosity } \\
\text { (poise) }\end{array} \\
\end{array}$ & $\begin{array}{l}\text { In (n; } \\
\text { poise) }\end{array}$ & $\begin{array}{l}\text { In (n; } \\
\text { VTF) }\end{array}$ & $\begin{array}{c}\begin{array}{c}\text { Viscosity (Poise) } \\
\text { from Fit }\end{array} \\
\end{array}$ & $\begin{array}{c}\text { Fitted } \\
\ln (\mathbf{n} ; \text { VTF })\end{array}$ \\
\hline UK 50-50-25 & 1150.2 & 51.66 & 3.94 & 2.39 & 54.67 & 4.00 \\
\hline UK 50-50-25 & 1210.5 & 33.54 & 3.51 & 2.04 & 34.51 & 3.54 \\
\hline UK 50-50-25 & 1266.0 & 24.27 & 3.19 & 1.75 & 23.95 & 3.18 \\
\hline UK 50-50-25 & 1152.5 & 55.42 & 4.01 & 2.38 & 53.63 & 3.98 \\
\hline UK 50-50-25 & 1094.7 & 90.34 & 4.50 & 2.75 & 89.74 & 4.50 \\
\hline UK 50-50-25 & 1047.5 & 145.8 & 4.98 & 3.09 & 146.48 & 4.99 \\
\hline UK 50-50-25 & 1151.5 & 56.12 & 4.03 & 2.38 & 54.07 & 3.99 \\
\hline UK 50-50-25 & 1150.0 & . & . & 2.39 & 54.74 & 4.00 \\
\hline UK 50-50-28 & 1152.5 & 50.11 & 3.91 & 2.38 & 51.44 & 3.94 \\
\hline UK 50-50-28 & 1205.8 & 32.96 & 3.50 & 2.07 & 34.05 & 3.53 \\
\hline UK 50-50-28 & 1257.3 & 24.46 & 3.20 & 1.80 & 24.07 & 3.18 \\
\hline UK 50-50-28 & 1153.0 & 52.49 & 3.96 & 2.37 & 51.22 & 3.94 \\
\hline UK 50-50-28 & 1101.5 & 82.14 & 4.41 & 2.71 & 81.24 & 4.40 \\
\hline UK 50-50-28 & 1048.5 & 140.87 & 4.95 & 3.09 & 141.71 & 4.95 \\
\hline UK 50-50-28 & 1152.5 & 52.11 & 3.95 & 2.38 & 51.44 & 3.94 \\
\hline UK 50-50-28 & 1150.0 & . & . & 2.39 & 52.52 & 3.96 \\
\hline UK 50-50-32 & 1152.7 & 56.54 & 4.03 & 2.38 & 57.05 & 4.04 \\
\hline UK 50-50-32 & 1203.8 & 37.55 & 3.63 & 2.08 & 37.91 & 3.64 \\
\hline UK 50-50-32 & 1255.5 & 26.46 & 3.28 & 1.80 & 26.35 & 3.27 \\
\hline UK 50-50-32 & 1153.0 & 57.85 & 4.06 & 2.37 & 56.89 & 4.04 \\
\hline UK 50-50-32 & 1101.5 & 91.15 & 4.51 & 2.71 & 91.09 & 4.51 \\
\hline UK 50-50-32 & 1049.8 & 157.17 & 5.06 & 3.08 & 157.32 & 5.06 \\
\hline UK 50-50-32 & 1152.3 & 57.11 & 4.04 & 2.38 & 57.22 & 4.05 \\
\hline UK 50-50-32 & 1150.0 & . & . & 2.39 & 58.37 & 4.07 \\
\hline UK 75-25-28 & 1150.5 & 47.04 & 3.85 & 3.88 & 48.53 & 3.88 \\
\hline UK 75-25-28 & 1202.5 & 31.4 & 3.45 & 3.47 & 32.28 & 3.47 \\
\hline UK 75-25-28 & 1253.2 & 23.14 & 3.14 & 3.12 & 22.74 & 3.12 \\
\hline UK 75-25-28 & 1151.5 & 49.04 & 3.89 & 3.87 & 48.12 & 3.87 \\
\hline UK 75-25-28 & 1099.5 & 79.04 & 4.37 & 4.34 & 76.62 & 4.34 \\
\hline UK 75-25-28 & 1048.5 & 128.08 & 4.85 & 4.86 & 129.67 & 4.86 \\
\hline UK 75-25-28 & 1150.5 & 48.71 & 3.89 & 3.88 & 48.53 & 3.88 \\
\hline UK 75-25-28 & 1150.0 & . & . & 3.89 & 48.73 & 3.89 \\
\hline UK 60-40-28 & 1151.5 & 48.19 & 3.88 & 3.90 & 49.63 & 3.90 \\
\hline UK 60-40-28 & 1202.8 & 32.57 & 3.48 & 3.49 & 32.89 & 3.49 \\
\hline UK 60-40-28 & 1254.0 & 22.9 & 3.13 & 3.13 & 22.81 & 3.13 \\
\hline UK 60-40-28 & 1152.5 & 50.21 & 3.92 & 3.90 & 49.21 & 3.90 \\
\hline UK 60-40-28 & 1100.5 & 78.56 & 4.36 & 4.37 & 78.69 & 4.37 \\
\hline UK 60-40-28 & 1049.3 & 133.07 & 4.89 & 4.89 & 133.10 & 4.89 \\
\hline UK 60-40-28 & 1151.5 & 50.5 & 3.92 & 3.90 & 49.63 & 3.90 \\
\hline UK 60-40-28 & 1150.0 & . & . & 3.92 & 50.27 & 3.92 \\
\hline
\end{tabular}


SRNL-STI-2011-00012

Revision 0

\section{Distribution:}

S.L. Marra, 773-A

C.C. Herman, 999-W

C.M. Gregory, 773-A

T.M. Adams, 773-A

J.W. Amoroso, 999-W

A.L. Billings, 999-W

Sellafield

C. Steele

N. Gribble

M. Harrison

A. Riley

T.B. Edwards, 999-W

R. Short

K.M. Fox, 999-W

F.R. Johnson, 999-W

D.K. Peeler, 999-W 